\title{
University of Oslo
}

Predictors and change in dietary behaviours among young men; an intervention in the military

Solveig Uglem 
(C) Solveig Uglem, 2012

Series of dissertations submitted to the Faculty of Medicine, University of Oslo No. 1377

ISBN 978-82-8264-456-3

All rights reserved. No part of this publication may be reproduced or transmitted, in any form or by any means, without permission.

Cover: Inger Sandved Anfinsen.

Printed in Norway: AIT Oslo AS.

Produced in co-operation with Akademika publishing. The thesis is produced by Unipub merely in connection with the thesis defence. Kindly direct all inquiries regarding the thesis to the copyright holder or the unit which grants the doctorate. 


\section{Contents}

Acknowledgements $\quad 4$

Summary 6

List of Papers $\quad 10$

Abbreviations $\quad 11$

1. Introduction 12

$\begin{array}{ll}1.1 \text { Young men as a target group } & 12\end{array}$

1.2 Vegetables, fruits and whole grains in a health perspective 13

1.3 Biomarkers - folate and homocysteine 15

1.4 Recommendations and dietary intake of vegetables, fruit and $\quad 16$ whole grain cereals in Norway

1.5 Socio economic status in relation to intake of vegetables, $\quad 18$ fruit and whole grain cereals

1.6 Food patterns 18

1.7 Weight and health perceptions $\quad 19$

1.8 Prediction of vegetable intake 20

1.9 Intervention studies promoting vegetables, fruit and 24 whole grain cereals

2. Aims and objectives 28

3. Methods 30

3.1 Design 30

3.2 Participants 30

3.3 Intervention strategies 33

3.4 Research instruments $\quad 34$

3.4.1 Food diary $\quad 35$

3.4.2 Attitudinal questionnaire 37

3.4.3 Pre-testing of the questionnaires 39

3.4.4 Clinical questionnaire 39

3.4.5 Anthropometric measures 39

3.5 Blood samples $\quad 39$

3.6 Statistical analyses 40 
Paper III

Paper IV

Paper V

\section{Discussion}

5.1 Methodological considerations

5.1.1 The military as research setting 48

5.1.2 Generalisability 49

5.1.3 Selection errors 49

5.1.4 Attrition 51

5.1.5 Statistical power $\quad 52$

5.1.6 Validation of the diary and the questionnaire 53

5.1.7 Information errors 54

5.1.8 Seasonal variations 56

5.1.9 Measuring attitudes and perceptions of vegetables 57

5.1.10 Blood samples 57

5.2 Discussion of main findings $\quad 58$

5.2.1 Baseline eating habits of vegetables, fruits and whole 58 grain cereals

5.2.2 Factors associated with the intake of vegetables and 58 other foods

5.2.3 Eating patterns and weight and health perceptions 63

5.2.4 Effects of the intervention 65

6 Concluding remarks and implications for further research 68

7 References $\quad 72$

Paper I - V

Appendices 


\section{Acknowledgements}

In conversation with my father, 14 years old: "The problem is not to write a doctoral thesis, but to find a topic to write about".

I have changed my mind several times during the last eight years.......

The work presented in this thesis was supported by grants from the Norwegian Research Council.

A special thank to my supervisor Margareta Wandel for grateful and patient guiding during the whole process and for sharing with me of your great experience. Thank you for always believing that I was able to finish. You made me feel that all good ideas and solutions were mine, even though I know this is not true. Further, my co-supervisor Wenche Frølich, I want to thank you for giving me the opportunity to take part in this project, for all the work with planning and organizing the project, and for valuable feedback on my papers.

Tonje Holte Stea, thank you for always being there, professionally and personally. Thank you for supporting me while I didn't want to finish this thesis and most importantly; while I really wanted to. Thanks for sharing your experience with me. Marte Karoline Råberg Kjøllesdal, you always delivers quick and precise, and your help with data-processing and statistical analyses have been invaluable.

I want to thank the personnel at Værnes Military Training Centre and The Norwegian Army, Bardufoss for helping us organizing the data collections. A special thank also to the kitchen personnel for sharing the recipes and for the cooperation in the intervention period. 
Colleagues in room 3100 and those, who often visited us; thank you for fruitful discussions, several cups of coffee, and for a "fellow feeling" I never find somewhere else. My frustrations never seemed so big after sharing them with you.

Thanks to Grilstad for giving me the opportunity to finish this thesis, by giving me some weeks leave to work with it on full time. Thanks to my colleagues for motivational smiles and comments.

I could not have finished this process without patient, love and care from my family and friends. Thanks to my father for being the first one to inspire me to write a doctoral thesis. Mom, thank you for love and care in the three most intensive years. Arne, you deserve a special thanks for always supporting and encouraging me. Thank you for carrying questionnaires in your old, white Mercedes and for calling my thesis a "craft certificate", giving me this mischievous smile. Thanks to my daughter Ella, you're simply the best!

Trondheim, January 2012.

Solveig Uglem 


\section{Summary}

Young men are difficult to reach with conventional nutrition information and they have a low intake of vegetables and fruits and whole grain cereals. The low intake of these foods gives rise to concern about their future health. Few intervention studies have focused on improving young men's consumption of vegetables, fruits and whole grain cereals and few studies have explored important correlates of young men's intake of vegetables.

This study is a part of a larger project with the aim to improve the diet among young men in the military by offering a combination of nutritional information and increased availability of vegetables, fruits and whole grain cereals. The present thesis presents the results from a sub study of the larger project. Since the knowledge base on dietary perceptions and behaviour in the target group is weak, the objectives were to first explore factors that may influence young men's food intake, and then to investigate changes in intake of selected foods and nutrients as well as reflected changes in a biomarker after a dietary intervention. The focus was directed to the foods that were targeted in the intervention: vegetables, fruits and whole grain cereals, with special emphasis on vegetables. The biomarker was plasma homocysteine.

The study included male recruits at Værnes Military Training Centre in the intervention group; 578 recruits at baseline and 376 at follow up. The control group consisted of 105 male recruits at The Norwegian Army, Bardufoss. The dietary intervention programme was a combination of nutritional information and increased availability of vegetables, fruits and whole grain cereals and lasted for five months. 
The results from the baseline showed that the recruits in the intervention group had an average intake of vegetables of $244 \mathrm{~g} / \mathrm{day}$, of which $43 \%$ was potatoes. There was a large variation in the intake of vegetables among the recruits in spite of the fact that the recruits ate most of their meals in the military mess hall. Only $6 \%$ of the recruits reached an intake of $450 \mathrm{~g}$ of vegetables daily, which was recommended at the time of the study. The most important sources of vegetables were the hot composite dishes served for lunch and dinner. Optimistic bias of own vegetable intake was observed, since nearly one-third of the recruits perceived their intake as sufficient. The recruits reported high preferences for vegetables: $78 \%$ reported a liking for raw vegetables, and $58 \%$ for cooked vegetables.

The recruit's intake of vegetables at baseline was positively associated with number of hot meals eaten in the military mess hall, a high intake of vegetables when still living at home, their parent's socio economic status and high scores on taste preferences for cooked vegetables. Weight beliefs (desire for slenderness) were also positively associated, while social influence and smoking habits were negatively associated with the recruit's intake of vegetables. These correlates explained $32 \%$ of the variance in the recruit's vegetable intake.

Three different food intake patterns were discerned in a principal component analysis, based on the intake data collected among the recruits in the intervention group at baseline. These were called: 1) plant foods, 2) fast food/soft drinks and 3) milk/cereals, explaining $42 \%$ of the variance in the intake. The desire for slenderness was positively related to level of physical activity but not to the food intake patterns. However, BMI was related to food intake pattern; those who scored high on the plant food pattern were less likely to have a high BMI. 
After the intervention, a significant change in intake was observed for the food items which were in focus in the intervention. The recruits in the intervention group increased their consumption of vegetables with $55 \%$, whole grain bread with $29 \%$ and fruits with $12 \%$. The increases in the intervention group were significantly different from the control group for all these food items. The increased intakes were reflected in increased intake of folate and dietary fibre. Concomitantly, a reduction in plasma total homocysteine (p-tHcy) was observed. The reduction in p-tHcy was significantly related to an increased intake of folate from whole grain bread but not to that from vegetables, fruits and juice. Furthermore, the percentage of recruits who had three out of four correct answers on the nutritional knowledge score increased from $5 \%$ to $25 \%$ during the intervention. The recruits with increased knowledge scores had increased their vegetable intake more than the others.

In conclusion, behavioural factors were most important in explaining the recruit's intake of vegetables. The dietary intervention with both increased availability and easily understood nutritional messages, turned out to be effective in increasing the intake of vegetables, fruits and bread among young male recruits. This was reflected in increased intake of both dietary fibre and folate and a reduction in plasma homocysteine. This study has contributed to information on important correlates of vegetable intake and effective strategies for increasing the consumption of healthy food items among young men. 


\section{List of papers}

Paper I

Preferences and perceptions of personal vegetable consumption: A study among young men in the Norwegian National Guard.

Uglem S, Frølich W, Stea TH, Wandel, M.

International Journal of Food Science and Nutrition. 2008; 59 (4): 279-290

Paper II

Correlates of vegetable consumption among young men in the Norwegian National Guard.

Uglem S, Frølich W, Stea TH, Wandel, M.

Appetite. 2007; 48 (1): 46-53.

Paper III

Body weight, weight perceptions and food intake patterns. A cross-sectional study among male recruits in the Norwegian National Guard.

Uglem S, Stea TH, Frølich W, Wandel, M.

BMC Public Health. 2011; 11: 343

Paper IV

A nutrition intervention focusing on vegetables, fruit and bread among young men

Uglem S, Stea TH, Kjøllesdal MK, Frølich W, Wandel, M.

Submitted

Paper V

Association between folate intake from different food sources in Norway and homocysteine status in a dietary intervention among young male adults.

Stea TH, Uglem S, Wandel, M, Mansoor MA, Frølich W.

British Journal of Nutrition, 2009; 102 (6): 899-906. 


\section{Abbreviations}

BMI: Body Mass Index

ASE-model: Attitude - Social environment - Self Efficacy - model

p-tHcy: Total homocysteine in plasma 


\section{Introduction}

\subsection{Young men as a target group}

Young men are difficult to reach with conventional nutritional information $(1,2)$. Few studies have focused on predictors of young men's dietary behaviours, and few interventions have been designed to directly target young men. Furthermore, young men are among the groups with the lowest intake of vegetables and fruits in Norway (3). Their intake of cereals is relatively high, but a low intake of whole grain cereals is resulting in a low intake of dietary fibre (3).

Studies have shown that dietary behaviours adopted early in life may track into adulthood $(4,5)$. This is of concern since dietary patterns formed in youth may have implications for future health. However, in certain parts of the life cycle strong forces may change dietary behaviour. When moving away from home in early adulthood, is a time when changes in food behaviour are likely to occur. Young adults are in transition from parental supervision to development of their own food patterns. Interventions promoting healthy dietary habits in this period of life may assist them in preventing overweight and diet-related diseases later in life.

Because of the compulsory military service practiced in Norway, a military camp is a unique setting to reach young men of different socio economic, cultural and geographical backgrounds. Furthermore, they mainly eat their foods in a military mess hall which gives a unique opportunity to intervene through collaboration with the kitchen personnel to increase the availability of vegetables and whole grain cereals. 


\subsection{Vegetables, fruits and whole grain cereals in a health perspective}

Plant-based foods, such as vegetables, fruit/berries and whole grain cereals are given increased attention as important ingredients in a healthy diet since they may protect against obesity and related chronic diseases, such as cardiovascular disease, diabetes and some types of cancers (6-14). The protective effect has been ascribed to a number of components in these foods. They are the main contributors to the dietary intake of vitamins, minerals and other bioactive compounds which may have protective effects against chronic disease $(9,12,15,16)$. They are also the source of dietary fibre (17). Furthermore, vegetables, fruits and whole grain cereals may replace more energy dense foods in the diet (18).

Obesity has become a major health concern worldwide, with unbalanced diet and lack of physical activity as the main determinants. In many populations, those of lower socioeconomic standing are hardest hit by overweight and obesity (19-23). This is also the case in Norway $(4,24)$. A high intake of vegetables, fruits and whole grain products has been related to weight loss and weight maintenance $(25,26)$. These foods are therefore regarded as healthy dietary choices to prevent overweight and obesity.

Cardiovascular diseases comprise the largest group of chronic diseases in Norway both with regard to incidence, prevalence and as causes of death (17). There is convincing evidence that a diet rich in vegetables, fruit and berries reduces the risk of cardiovascular disease $(7,17,27)$. This applies both for coronary heart disease, high blood pressure and stroke (7). There is also increasing evidence that a diet rich in dietary fibre, especially that from whole grain, reduces the risk of coronary heart disease $(7,28)$. 
Diabetes type 2 is rapidly increasing worldwide. In all societies, overweight and obesity is associated with an increased risk of type 2 diabetes, especially when the excess adiposity is centrally distributed (7). Moderate weight reduction, regular physical activity, and a diet rich in whole grain and reduced intake of energy and fat may reduce the risk of type 2 diabetes $(29,30)$

With regard to cancer, the latest report from the World Cancer Research Fund and American Institute for Cancer Research (31) on colorectal cancer, states a protective role of dietary fibre when the intake of all foods containing dietary fibre are included. Furthermore, the report shows that overweight and obesity increases the risk of certain types of cancer, such as those of oesophagus, pancreas, breast (postmenopausal), and colorectal cancer (31). Physical activity reduces the risk. There is also evidence that vegetables, fruit and berries reduce the risk of certain cancers, such as those in the oral cavity, pharynx, oesophagus and stomach cancer (6).

In a newly published study, which was based on 560000 US subjects followed for 9 years, the risk of death (from all causes) was reduced by $22 \%$ for those with a high intake of dietary fibre, compared to those with a low intake (28). The risk of death from cardiovascular disease, infectious and respiratory diseases was reduced by $30-60 \%$ for the high fibre subjects. The relationships were shown to be related to dietary fibre from whole grain cereals and not to fibre from other sources, like legumes, vegetables and fruits.

Even though there is a need for more knowledge to understand the exact role of single food items and food components in the development of chronic diseases, the evidence of a 
protective role for a diet rich in vegetables, fruit and whole grain, in addition to increased physical activity and smoking cessation, is considered sufficient for preventive actions $(7,17)$.

\subsection{Biomarkers - folate and homocysteine}

Dietary assessment methods, which rely on subjects recording their own food intake, are subject to many sources of error. These include among others, information errors because of misunderstanding, inability or lack of motivation to report certain food items, social desirably bias, and over - or underreporting. These may result in large errors in the estimation of intake. In recent years, biomarkers have attracted increased attention because of its objective and reliable assessment which potentially may reflect dietary intake.

Vegetables, fruits and whole grain cereals are important dietary sources of folate (32). A low dietary intake is considered to be the most important cause of poor folate status (33). Serum or erythrocytfolate have shown low specificity and sensitivity as markers of folate status. Therefore, other markers of folate status have been proposed. Such a marker is plasma total homocystein (p-tHcy) (34), since increased intake of folate has been shown to reduce plasma homocysteine (35). The intake of vitamin B12, B6 and B2 has also shown associations with homocysteine concentrations, but to a lesser extent $(36,37)$.

Elevated concentrations of homocysteine have been associated with increased risk of cardiovascular disease (34). However, it is still debated whether homocysteine is a marker or a cause of the diseases. Nevertheless, homocysteine has been suggested as a marker of generally poor nutritional status and thereby of increased risk of cardiovascular disease (38). Elevated concentrations of plasma homocysteine may also be a result of genetic factors that impair the ability to metabolize folate (39), but this is not further investigated in this thesis. 


\subsection{Recommendations and dietary intake of vegetables, fruits and whole grain cereals in}

\section{Norway}

Many countries, including Norway, have made recommendations for a healthy diet, including recommendations for vegetables, fruits and whole grain cereals. The recommendations for vegetables and fruits are in some countries manifested as "5-a-day". The Norwegian Directorate of Health recommends a daily intake of $250 \mathrm{~g}$ vegetables and $250 \mathrm{~g}$ fruits, fruit juice and berries (17). These new dietary recommendations from 2011 do not include potatoes, but fruit juice is included with a limitation of one glass/day (17). In the former recommendations, which were current at the time of the intervention, three $150 \mathrm{~g}$ servings of vegetables and two $150 \mathrm{~g}$ servings of fruits, giving a total amount of 750 gram per day were recommended. Potatoes and fruit juice were included in those recommendations (33).

The intake of vegetables, fruits and berries in the Norwegian population has increased the last centuries, but it is still lower than the official recommendations (40). The latest report from 2010 estimates the intake per capita to be about 320 g/day. Studies have shown that young men tend to have the lowest intake $(3,41-44)$. In a national study from 1997, the intake among men aged 16 to 29 was $234 \mathrm{~g} / 10 \mathrm{MJ}$ including potatoes (3). A north-south difference in vegetable consumption in Europe has been observed with a high intake in southern countries and a low intake in northern countries (45-48). For example, only 5\% of Swedish men reached the Swedish recommendations of 500 gram/day (49).

The Norwegian Directorate of Health recommends a daily intake of four servings of cereals, of which 70 - 90 gram should be whole grain (17). Three slices of bread with whole-grain flour and a large serving of whole-grain pasta are given as examples to achieve the recommendation. The intake of cereals in the Norwegian population has increased during the 
last 30 years (40). The intake of whole grain cereals is about $50 \mathrm{~g} /$ day, which is lower than the recommendations of 70 - $90 \mathrm{~g} / \mathrm{day}(17)$.

Bread often contains malted flour which gives a dark colour. This often leads to a misunderstanding that dark bread contains a high amount of whole grain. A four-point scale indicating the amount of whole grains related to the total amount of flour in the bread was introduced in 2007 to help Norwegian consumers to choose bread (Figure 1).

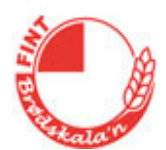

0-25\% whole grains

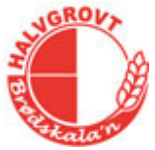

$25-50 \%$ whole grains $\quad 50-75 \%$ whole grains
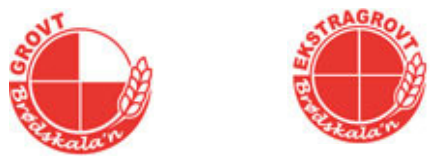

$75-100 \%$ whole grains

Figure 1: A four-point scale indicating amount of whole grain of the total flour in the bread. (50)

In a report from 2008, based on data from Norwegian consumers, $45 \%$ reported that they used the symbols to choose bread (51). However, the report showed that women and highly educated people more often used the symbols. Problems in choosing bread with a high content of whole grain may still exist since the bread often is coloured brown or added different seeds to make it look like whole grain bread. Furthermore, young people often eat breakfast at cafeterias and snack bars (51) where only certain types of bread are available and the whole grain content usually is unknown to the consumer. 


\subsection{Socio economic status in relation to intake of vegetables, fruits and whole grain cereals}

Education, occupation and income are the most commonly used variables to measure socio economic status in epidemiological studies. These indicators are related, but reflect different aspects of the association between socioeconomic status and health $(2,53)$. Education represents an individual's knowledge-related assets, and may be a strong predictor of occupation and income. Income reflects material circumstances. Occupation is a predictor of social relations and different privileges and facilities (54).

Most studies report that higher social status, measured with one or more of these indicators, is associated with a healthier diet (53-58). The consistency in the results across several studies, different age-groups and the use of different variables to measure socio economic status reflects the strength of these findings (54). Of concern to health authorities, are the results of prospective studies showing that the gap in consumption of healthy food items between different socioeconomic groups is not decreasing $(54,55,59)$.

Norwegian studies have also shown a positive relationship between socio economic status and intake of fruit and vegetables $(3,60)$. Among men, both education and occupational level were positively associated with a higher intake of vegetables and fruits (3). A higher intake of dietary fibre was also observed in $\mathrm{g} / 10 \mathrm{MJ}$ among subjects in the high educational and occupational groups (3).

\subsection{Food patterns}

In addition to analysis of single food items, food patterns may give important and useful information about people's diet. Food habits are complex and the ability to study the whole 
diet and not only single food items is useful. Factor analysis is a method to explore food patterns, since in a factor analysis foods are separated into groups based on correlations between intake data of different foods (61). Studies that have used factor analysis often derive a healthy food pattern or "prudent" pattern, high in plant-based foods and fish $(62,63)$. Further, a pattern high in refined grain, sweets, French fries and processed meats, named "Western" pattern, is often observed $(62,63)$.

The patterns emerging from factor analysis can be used to explore the relation with other health related behaviours and attitudes. The comparison of food patterns derived by factor analysis with other health related behaviours have shown that a healthy diet often is part of a generally healthy lifestyle (61). For example, the majority of those in the "healthy diet pattern" were not smoking (61). Furthermore, the prudent diet has been positively associated with socio-economic status and regular physical activity (63). In a Norwegian study, the prudent food pattern was positively associated with education and occupation (professionals, higher administrators) among men, and work control among women (64). Furthermore, the dietary patterns were associated with both BMI and waist/hip ratio (64).

The food patterns emerging from factor analysis can also be followed from childhood to adulthood (65). In a Finnish study, a high proportion of those who where in the upper quintiles of the eating patterns derived in childhood, persisted in the same quintiles in adulthood (65).

\subsection{Weight and health perceptions}

Few studies have investigated young men's perceptions of weight. Most of such studies relates to women. However, in recent years an increased concern about weight and body 
image is observed also among men $(66,67)$. In a review, Cohane and Pope (67) observed that the ideal body image among boys varied; some boys had a thin ideal while others had a heavier one. Studies have shown that among Australian male adults aged 13 to 18 years; nearly $15 \%$ perceived they were too thin, nearly $18 \%$ perceived they were too fat, while $66 \%$ perceived they were about right. (68). Furthermore, among university students in Europe, $17 \%$ of men were trying to loose weight (66).

Body image and weight beliefs may influence eating behaviours and other health related attitudes and behaviours. Some studies have shown unhealthy eating behaviours among young males who wanted to gain weight (69). Eating more food and performing less exercise, as well as eating more fatty, fried and junk food were identified as the most important weight gain behaviours among male adolescents aged 13 to 18 years in Australia (69). These practices were chosen instead of eating more healthful foods in combination with exercise in order to gain weight and get a more "heavy look". However, among adolescent boys the most reported weight gain behaviours was exercise (42\%) followed by dieting (12\%) (69).

A better understanding of young men's weight perceptions and the impact on diet and weight is important to better address messages about healthy eating practices in this group, both for gaining weight and loosing weight.

\subsection{Prediction of vegetable intake}

Food choices are the result of a complex interplay between several factors. Both personal and environmental factors influence dietary habits. Personal factors include among others psychosocial, socio economic and demographic factors. Environmental factors include availability, encouragement or social norm, food distribution and media. 
A number of social cognitive theories and models of health behaviour have been developed in order to understand and predict dietary behaviour. The various theories and models overlap considerably. In The Theory of Reasoned Action, behavior is determined by the intention to perform the behavior in question, which again is determined by attitude and subjective norm (70). In the Theory of Planned Behavior, perceived behavioral control is included since several behaviors are not under volitional control (71). In other theories, such as the Social Cognitive Theory, environmental factors are included in addition to personal factors (72). Several researchers have also modified these models. One example is the ASE-model $(73,74)$. The ASE-model (Attitudes, Social influence and Self-Efficacy) has incorporated several predictors of dietary behavior (Figure 2). According to this theory, a person's intention to perform a behavior is predicted by attitude, social influences and the ability to perform the behavior. Barriers and self-efficacy further influence the intention to perform the behavior. The intention to perform the behavior may be good, but the barriers may seem too high or the practical skills are not present.

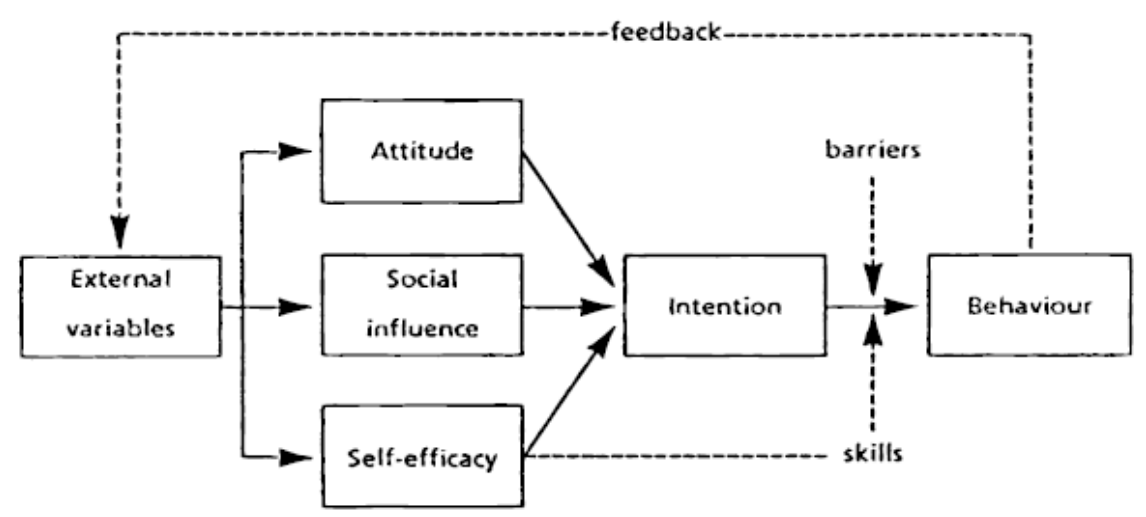

Figure 2: ASE-model (75) 
Studies have shown an inconsistent association between nutritional knowledge and fruit and vegetable intake (76). The knowledge of why and how to eat a healthy diet is important, but researchers have debated whether or not knowledge alone is enough for people to increase their intake. Nutritional courses focusing on increased knowledge to encourage dietary change have shown efficacy in increasing knowledge, but not necessarily changes in dietary intake among college students (77). However, some studies have shown that awareness of the recommendations is associated with the intake of fruit and vegetables $(76,78,79)$, and that knowledge is a good predictor of intake (80-82). In a recent study, the students increased their intake of fruit and vegetables after class-based nutrition courses (77).

A substantial amount of research has examined how food preferences influence consumption (82-88). For example, in the enKid study among children and young people aged 2-24 years old, disliking was associated with low consumption of vegetables or fruit (85). Bitter taste has been reported as a sensory determinant for disliking vegetables $(89,90)$ and might be a barrier to adopt a diet rich in vegetables.

Attitudes have been identified as a predictor of fruit and vegetable intake $(42,74,80,81)$ or the intention to consume fruits and vegetables which in turn predicts intake (91). However, in focus group interviews, young adult men reported disbeliefs in the benefits of consuming fruits and vegetables (92). Self-efficacy or perceived behavioural control have also shown associations with high intake of fruits and vegetables $(76,80,93)$. Among college students, self-efficacy was shown as a predictor of intake among women, but not men (94).

Connor and Armitage (95) have proposed that past behaviour may predict future behaviour. Therefore, habit has been included as a variable in models explaining dietary behaviour 
$(4,96)$. Oulette and Wood (97) showed that past behaviour was predictive of future behaviour independent of intentions, attitudes, norms and perceived behavioural control. Two Norwegian studies have also showed tracking of eating habits from childhood to adulthood $(4,98)$. Lien et al (98) showed that those who reported the most frequent consumption of fruits and vegetables at age 14 still reported the most frequent consumption at age 21 , even though their consumption of fruits and vegetables decreased.

Several environmental factors influence the intake of fruits and vegetables. Availability has been associated with fruit and vegetable intake in some studies (99-102) and a study among children showed that availability was one of the strongest correlates (99). The availability of fruits and vegetables at lunch and dinner seems to be important for the overall intake: in a review of psychosocial correlates of dietary intake, adults reported consuming most fruits, juice and vegetables at dinner (1.5 servings/day) and lunch (1.4 serving/day) (81).

Social environmental influences or encouragements can be pointed out as factors influencing dietary intake and were among the most important predictors in a recent review (80). The influence of the household-keeper was pointed out in focus group interviews as an important determinant of both the partners' and children's vegetable intake (103). Furthermore, a study among college students showed that social support from family, friends and co-workers had an impact on dietary changes towards a more healthy diet (104).

Factors related to time and convenience may also predict the intake of healthy food (93). The amount of healthy food choices, including fruits and vegetables, in vending machines, fastfood restaurants and petrol stations have increased in recent years, but still these places are mostly offering high-fat, energy-dense food. Factors within the larger society which may 
affect the intake of fruits and vegetables include food and nutrition policy, food production and distribution, price and quality, as well as the media.

\subsection{Intervention studies promoting vegetables, fruits and whole grain cereals}

Various methods have been used for stimulating changes in dietary habits. Some of these have been based on the theoretical models described earlier in this chapter. Interventions focusing on environmental and multiple strategies to achieve changes in dietary intake, have received increased attention in recent research. Limited research exists on intervention studies promoting higher intakes of fruits and vegetables among young men and even less research exist in promoting whole grain cereals (105). Most interventions targeting young adult's dietary habits have been conducted in university settings and most of the studies include more women than men $(106,107)$

Mostly, self-reported intake is used as outcome measures in intervention studies and epidemiologic studies. Measurements of changes in micro- and macro nutrients and biomarkers reflecting a change in intake have attained increased attention in recent years, but are more expensive and time-demanding. The association between food intake and biomarkers has been shown in other studies $(18,108-111)$, such as the relationship between vegetable and fruit intake and plasma folate (112) and vitamin C and carotenes (18). Studies in North European countries $(35,36)$ and at New Zealand (113) investigating changes in folate and homocysteine status in relation to changes in intake of folate-rich and fortified foods have found an increase in folate concentration. Interventions aimed at reduction in plasma homocysteine concentrations have showed mixed results (35). 
Effective strategies to increase the intake of vegetables and fruits among young adults have included nutrition education programmes; both nutrition classes (77), and internet-based education programs (104). Furthermore, newsletters, reports and magazines with recipes, which were tailored for the target group, were effective among low-income young adults (114). In a study by Ha and co-workers (77) among university students, the participant's nearly doubled their intake of fresh vegetables and total amount of vegetables after participating in a 15 week education programme.

Increased availability has been associated with increased intake of fruits and vegetables in other population groups. Among school-children, increased availability of fruits and vegetables has been shown to be one of the most effective strategies to increase the consumption. In a Norwegian study among $4^{\text {th }}$ graders an intervention effect was shown for the intervention group with paid subscription in the school fruit programme (99). An additional effect was shown for the intervention group when fruits and vegetables were distributed for free.

Several dietary interventions have been conducted at work places $(100,102,115-119)$. In a review by Pomerleau and co-workers (120), eight of eleven worksite interventions showed positive effects. Increased availability $(102,121)$, environmental changes in combination with individual behavioural changes (119), and price reduction (121) have shown to be effective strategies. As an example of this, the results from a Danish study, including a military base, showed an increase of on average $70 \mathrm{~g}$ per person per day of fruits and vegetables (102).

Few intervention studies have been conducted with the aim to increase the intake of wholegrain cereals. However, among the few studies identified, effective strategies to increase the 
intake of high fibre cereals have been nutrition courses (105), nutrition counselling (122), increased availability and a stimulating eating environment (123). A study conducted among university students showed that the intake of whole grain cereals nearly tripled after nutrition lectures (from 0.37 ounces to 1.16 ounces) (105).

Interventions that are successful in increasing young men's intake of vegetables, fruits and whole grain cereals may improve their health and prevent development of chronic diseases later in life. Food and dietary behaviour is complex and targeting different subgroups with different strategies may be effective. Interventions to target young people seem to be more effective when they include multiple intervention components. The focus on nutritional education and increased availability has shown promising results in other studies (123-125). 


\section{Aims and objectives}

This study is one of two parts of a larger project with the aim to improve the diet among young men in the military by offering a combination of nutritional information and increased availability of vegetables, fruit and whole grain cereals. Since the knowledge base for this target group is weak, the project was designed to first explore factors which may influence young men's food intake, and then to investigate the possibility for change in diet and risk factors for cardiovascular disease after a 5-months dietary intervention. The present thesis is based on data from the dietary part of the larger project, including both the factors associated with food intake and changes in intake of selected foods and nutrients as well as reflected changes in plasma homocysteine. The focus is directed to the foods that were targeted in the intervention: vegetables, fruits and whole grain cereals, with a special emphasis on vegetables. The other part of the large project was performed by another $\mathrm{PhD}$ student who was responsible for the work to increase the availability of the targeted foods in the military mess, and for collection of blood samples to study the changes in risk factors for cardiovascular disease (126).

This thesis consists of five papers with the following aims and objectives:

- To investigate vegetable intake, preferences and perceptions of own vegetable intake among the male recruits when entering the military service. Second, to study the characteristics between high and low vegetable consumers in terms of vegetable selection, perception of own intake and need to increase vegetable intake (paper I)

- To explore to what degree intake of vegetables is predicted by behavioural, personal and socio environmental factors among young men when entering military service. Further, to 
investigate the most important single correlates of vegetable consumption among the recruits (paper II)

- To study body weight, weight perceptions and food intake patterns among male recruits. Further to study the relation between intake of some healthy and unhealthy food items at home and in the military (paper III).

- To evaluate if a combination of nutritional information and increased availability is an effective strategy to increase the intake of vegetables, whole grain cereals and fruits among young men (paper IV).

- To evaluate changes in estimated nutrient intake (folate and dietary fibres) and biomarker (plasma homocysteine) after the five months dietary intervention (paper V) 


\section{Methods}

\subsection{Design}

The study was conducted in two military camps in Norway. Data on food intake and psychosocial variables were collected with the help of a diary and two questionnaires, and blood samples were drawn from male recruits in Værnes Military Training Centre (intervention group) and Bardufoss Military Training Centre (control group).The criteria for choosing the two different military camps were that they had similar distribution of young men concerning social classes. The young men were represented from different parts of the country and the level of physical activity in the two camps was similar (127). A five-month dietary intervention was delivered to the recruits in the intervention group. Blood samples and data on dietary intake, with focus on vegetables, fruits and whole grain bread and other cereals were collected before the onset of the intervention (baseline) and after the five-month intervention period (follow up). In addition, predictors of vegetable intake, socio economic status, smoking habits, body weight and height and physical activity were collected.

The same intervention was performed with two enrolments at Vaernes Military Training Centre; the first from January 2004 to May 2004 and the second from July 2004 to November 2004. For the control group, at Bardufoss Military Training Center, the same data were collected at baseline in September 2005 and at follow-up in February 2006.

\subsection{Participants}

Figure 3 gives an overview of the participants in this study. A total of 739 recruits were asked to participate in the intervention group and 237 in the control group. Only recruits following ordinary military service in the two military camps were asked to participate, and soldiers on 
special training for leaderships in the army were not included. A few of those who were asked to participate refused, while others dropped out of military service. Some were excluded from the analyses due to incomplete data sets.

Included in the analyses for paper I, II and III, are 578 recruits that participated in the baseline study in the intervention group. Participation in the entire study (baseline and follow up) was 376 recruits in the intervention group and 105 recruits in the control group. These are included in the evaluation of the five-month dietary intervention (paper IV). In the study where food intake was related to changes in folate and homocysteine, 416 recruits were included in the intervention group and 105 in the control group (paper V). The most common reason for the recruits not completing the entire study was exclusion from the military due to health problems. Recruits that did not complete the food diary on at least three days were excluded from the analysis. 


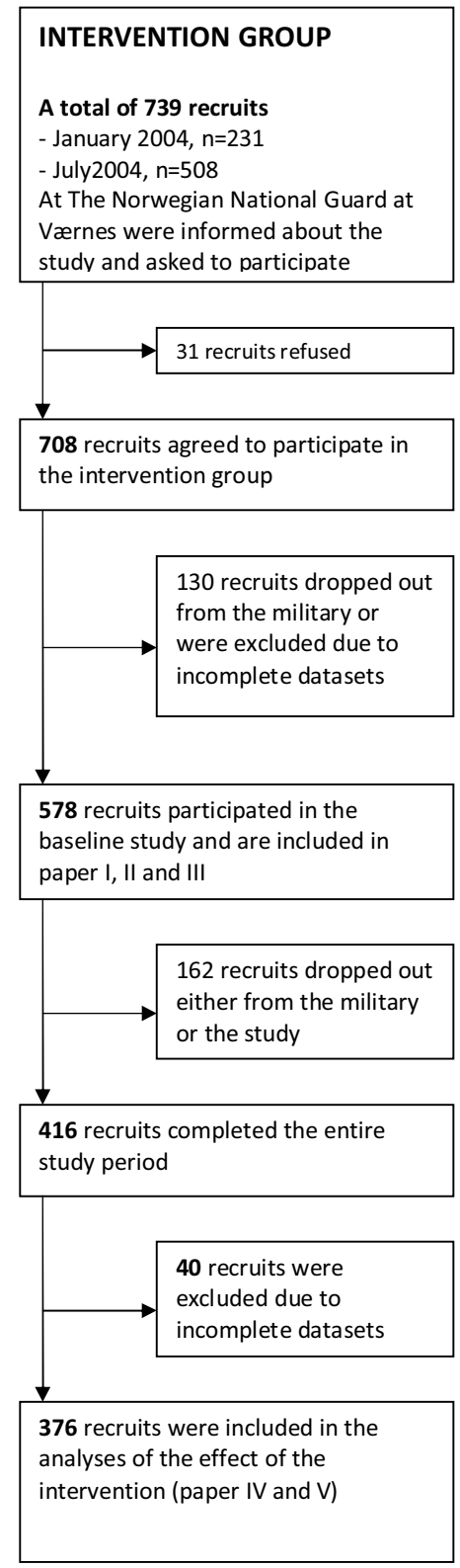

\section{CONTROL GROUP}

237 recruits in the Norwegian Army Bardufoss (Heggelia and Rusta) were informed about the study and asked to participate
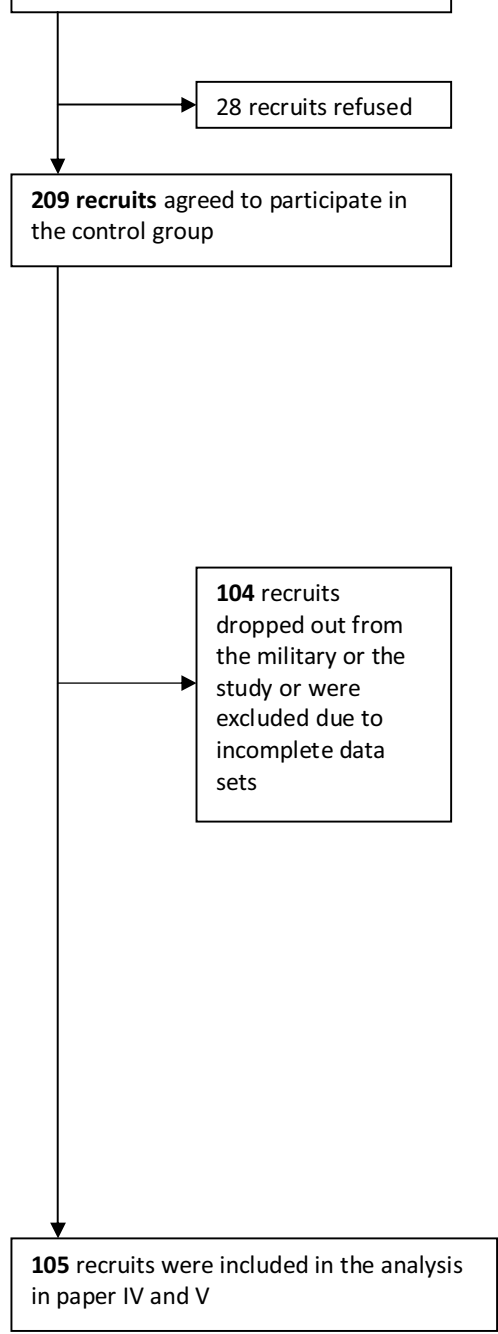

Figure 3: Flow chart of the participants included in the study 


\subsection{Intervention strategies}

The design of the intervention was inspired by the theoretical framework of the Social Cognitive Theory (128) and the ASE-model (73). In our intervention, personal factors with focus on increased knowledge, socio-environmental factors with focus on availability and several behavioural factors like meal patterns were included. The intervention was directed both towards the kitchen personnel and towards the recruits. The kitchen personnel were guided to change environmental factors, especially the availability and presentation of vegetables and semi whole grain bread. The recruits were addressed with nutrition information related to vegetables, fruits and whole grain cereals.

For this study, several new recipes were composed according to the Nordic Nutritional Recommendations (33). They were developed for the intervention group in cooperation with professional cooks from BAMA (Norwegian supplier of fruit and vegetables) and the Gastronomic Institute of Stavanger. The recipes contained a considerable amount of vegetables and limited amounts of fat, especially saturated fat. Prior to the intervention, the kitchen personnel at the military training centre, where the intervention was conducted, was trained to prepare the meals and to present them in an appealing way. Furthermore, a salad bar consisting of selected vegetables served in small bowls was offered to the recruits for the lunch meal. Semi whole grain bread (fibre content $>4 \mathrm{~g} / 100 \mathrm{~g}$ ) with different choices of spreads was offered for all meals. Attempts were made to increase the availability of more whole grain bread, but the supplier of bread was not willing to deliver bread with a whole grain content of $75 \%$ or higher. In the control group, no changes were made in the meals offered to the recruits. 
Information about the health benefits of a diet rich in vegetables, fruits and whole grain cereals were given to the recruits through posters and brochures. Posters were placed in strategic places in the mess hall where the recruits could read them. Three different posters were present at the same time and they were replaced after about 6 weeks. The posters contained information about main health effects of vegetables and whole-grain bread. The posters also gave information about the Norwegian recommendations of fruit and vegetables, "5-a-day", and about antioxidants.

Brochures from several Norwegian health organizations and agricultural boards were placed in the mess hall, available for the recruits to read. Furthermore, the two PhD-students were present for two days about every sixth week to answer questions from the recruits. The recruits could also write questions and comments about the study and put these in a mail box in the mess hall. The questions were answered the next time the $\mathrm{PhD}$ students met with the recruits or it was communicated to the kitchen personnel if it was wishes regarding the menus or the food availability.

The control group was visited only during the data collection periods. No changes in the availability of vegetables, whole grain cereals and fruits were made and no nutritional information was given.

\subsection{Research instruments}

At baseline and follow up the following types of data were collected:

1) A food diary was used to collect data on dietary intake in the military with focus on the intake of vegetables, fruits and cereals. 
2) An attitudinal questionnaire was developed for collection of data on the participant's socio economic status, predictors of vegetable intake, nutritional knowledge, satisfaction with the military mess hall and self-reported physical activity. The questionnaire also included questions on food frequency when still living at home

3) A clinical questionnaire was used for collection of data on the recruits smoking habits and use of food supplements. Anthropometric measures (weight and height) were examined by the military personnel.

4) Blood samples were obtained after minimum twelve hours of fasting for analysis of homocysteine, cysteine, folate, vitamin B2, FAD, FMN, and lipid analyses. Only the data from analysis of homocystein are used in this thesis.

\subsubsection{Food diary}

A diary, developed and validated at Department of Nutrition, University of Oslo (sef.no/assets/11002260/vedlegg1_ungkost.PDF) was modified to capture the food offered in the mess hall. The modifications included the following changes: for hot dishes the diary had questions where the participants filled in a number code for the day's special served at lunch and dinner instead of pre-printed choices of dishes. Bread spreads were excluded. The diary also included questions about how often and what they ate in the canteen in the camp and/or cafeterias/restaurants outside the military camp.

The diary gave pre-printed choices of frequency and size to capture the participants' consumption of bread and other cereals, fruits, vegetables, and drinks. When appropriate, the participants stated their consumption as pieces of vegetables and fruits and slices of bread. A piece was for example one apple or a carrot. For dishes served at lunch and dinner and some other items, like salad, the participants stated their intake as number of servings and serving 
sizes (small, medium, large or extra-large). To decide their own serving sizes, the subjects were asked to refer to photographs or weighed portion-sizes placed on a table in the mess room. Two $\mathrm{PhD}$-students were also present at every meal in the data collection period to guide the recruits.

To obtain estimates of the participants' consumption of vegetables and fruits in gram, pieces of most food items printed in the diary were pre-weighed. For some items, like potatoes and slices of bread, Norwegian standard measures were used (129). To collect data of the participants' consumption of vegetables and fruits included in the dishes, recipes and estimates of the amounts of the ingredients used in every dish were handed over from the kitchen personnel to the researchers.

The average daily consumption of each food item (in g/day) was calculated as the product of frequency of intake and serving sizes. For example, their vegetable intake is the sum of all vegetables consumed by each participant divided by the number of days they kept record. Their intake of semi-whole grain bread and whole grain bread is treated as one variable, which was called semi-whole grain bread, because the recruits had problems to distinguish between the bread due to colouring. Malted flour was used to give some of the bread a dark appearance and the recruits stated this bread also to be whole grain bread.

The participants completed the diary on four working days. Data on food intake during weekends (when the recruits were off duty) were also collected, but due to incomplete datasets, these data were not reported. Only those who completed the dairy at least three days are included in the study. 


\subsubsection{Attitudinal questionnaire}

The attitudinal questionnaire, which focussed on factors which may have an impact on vegetable intake, was developed based on the theoretical framework of Social Cognitive Theory and the ASE-model. In addition, several behavioural factors were included, such as the choice of meals, snacking and smoking/snuffing, since these have been connected to vegetable intake in earlier research $(130,131)$ (Figure 4). Three main domains were used: 1) socio-environmental factors including items on social influence and socio-economic status of the recruits' family 2) personal factors including items on the recruits' beliefs about vegetables, perceived control of eating vegetables, preferences, awareness of a diet-disease relationship, knowledge and perceived availability of vegetables in the mess hall, and 3) behavioural factors, such as recruits' meal frequency in the mess hall and camp canteen, the participants' snack consumption, smoking habits and physical activity.

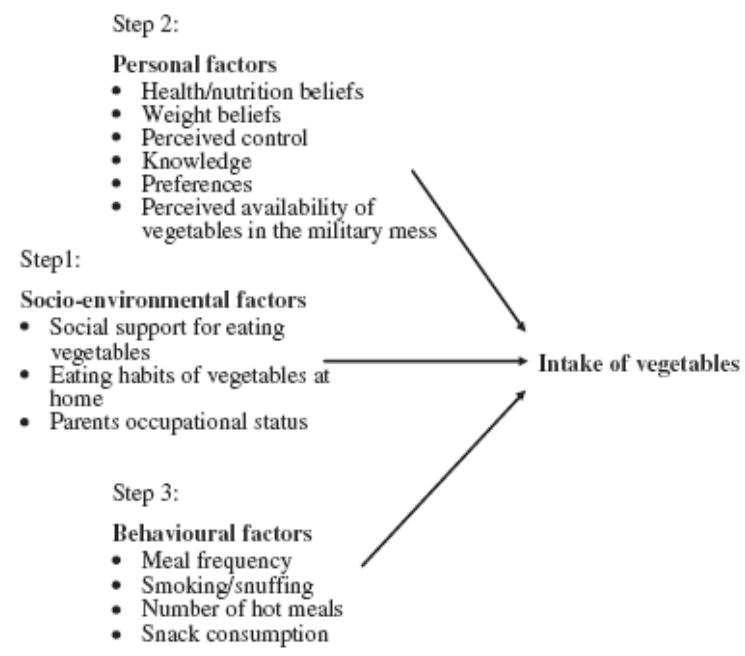

Figure 4: The model used in this study 
Occupation or education of the recruits' parents was used as indicators of socio-economic status. The parent with the highest occupational or educational level was included in the analyses. The occupational level of the parent was scored on three point scales (low, middle, high). In the lowest category unskilled employees were placed. The second category included employees like teachers, nurses and employees in offices. The highest category included among others doctors and dentists. Education was scored on a four-point scale (primary school, high school, university/college up to 3 years, university/college 3 years or more). The recruits' own educational level or occupation was not considered useful for this purpose because most young Norwegian men complete their military service right after high school. Furthermore, their income was not considered useful, since all recruits had the same salary while completing their military service.

For social influence items and all personal factors except knowledge, responses were scored on five-point scales (strongly disagree to strongly agree). For constructs measured with more than one item, like beliefs, scores for each item were added up and divided by the total number of items to form scales.

Eating habits at home were measured on a six-point scale ranging from less than one serving a week to several servings a day. The meal frequency variable combines the recruits' meal frequency in the mess hall and the camp canteen and was divided into five groups. A continuous variable was used to assess the recruit's number of hot meals during the survey period. The recruits could have up to 8 hot meals during the survey period (4 lunches and 4 dinners). A scale with five points assessed participants snack consumption. Self-reported physical activity was assessed as numbers of hours of light and hard activity 


\subsubsection{Pre-testing of the questionnaires}

The modifications of the diary and the attitudinal questionnaire were tested in a pilot study with 12 recruits in a military camp in Norway (Lutvann). For the diary only minor revisions of the question assessing foods eaten other places than in the mess hall, were necessary based on the comments from the group. The attitudinal questionnaire was revised on the basis of the results and comments from this group.

The revised survey instruments (diary and attitudinal questionnaire) were test-retested with fairly acceptable responses over a three-week period among 63 recruits in another military camp in Norway (Heistadmoen). Correlations between time 1 and 2 were from 0.11 to 0.55 .

\subsubsection{Clinical questionnaire}

Smoking habits, height and weight were measured with a questionnaire at the same time when the blood samples from the recruits were taken. Current smoking status, number of cigarettes per day and number of years of smoking were assessed.

\subsubsection{Anthropometric measurements}

Body weight and height were measured by trained nurses. Body weight was measured to the nearest kilogram and height to the nearest centimetre. Weight and height were measured with light military clothing without shoes after an overnight fast. BMI $(\mathrm{kg} / \mathrm{m} 2)$ was calculated from the measured data.

\subsection{Blood samples}

Blood samples for analyses of homocysteine and blood lipids were collected from the recruits after an overnight fast by trained nurses. Plasma concentrations of homocysteine were 
measured by reduction of disulfides with sodium borohydride, derivatization with monobrombimane, separation with HPLC and quantification with fluorescence detection (126).

\subsection{Statistical analyses}

Table 1 gives a summary of the measures and statistical analyses for each of the five papers.

Paper I - III were based on baseline data from the intervention group. Paper IV includes data from both the baseline and follow up data collections in the intervention and the control group. Paper V includes food intake data and blood samples from baseline and follow up in the intervention and the control group.

All analyses were performed using SPSS versions $12-18$. 
Table 1: Statistical analyses and measurements for each paper

\begin{tabular}{|l|l|l|l|}
\hline Paper & Sample & Measurements & Statistical analyses \\
\hline Paper I & $\begin{array}{l}\text { Cross sectional study based } \\
\text { on baseline data from the } \\
\text { intervention group }\end{array}$ & $\begin{array}{l}\text { Vegetable intake } \\
\text { Main vegetable sources } \\
\text { Preferences } \\
\text { Perception of own intake }\end{array}$ & $\begin{array}{l}\text { Descriptive statistics } \\
\text { Chi square tests } \\
\text { ANOVA } \\
\text { Tukey's post hoc test }\end{array}$ \\
\hline Paper II & $\begin{array}{l}\text { Cross sectional study based } \\
\text { on baseline data from the } \\
\text { intervention group }\end{array}$ & $\begin{array}{l}\text { Predictors of vegetable } \\
\text { intake: } \\
\text { - socio-environmental } \\
\text { personal } \\
\text { - behavioural }\end{array}$ & $\begin{array}{l}\text { Descriptive statistics } \\
\text { Multiple linear } \\
\text { regression } \\
\text { ANOVA } \\
\text { Tukey's post hoc test }\end{array}$ \\
\hline Paper III & $\begin{array}{l}\text { Cross sectional study based } \\
\text { on baseline data from the } \\
\text { intervention group }\end{array}$ & $\begin{array}{l}\text { BMI } \\
\text { Health perceptions } \\
\text { Weight perceptions }\end{array}$ & $\begin{array}{l}\text { Descriptive statistics } \\
\text { Pearsons x -test } \\
\text { T-test } \\
\text { ANCOVA }\end{array}$ \\
& $\begin{array}{l}\text { Food intake patterns } \\
\text { Physical activity } \\
\text { analyses }\end{array}$ \\
& $\begin{array}{l}\text { Multiple linear } \\
\text { the results from baseline and } \\
\text { follow-up in the intervention } \\
\text { and control group }\end{array}$ & $\begin{array}{l}\text { Changes in intake of } \\
\text { fruit, vegetables and } \\
\text { bread } \\
\text { Changes in nutritional } \\
\text { knowledge }\end{array}$ & $\begin{array}{l}\text { Chi-square tests } \\
\text { T-test } \\
\text { ANCOVA }\end{array}$ \\
$\begin{array}{l}\text { Pinear regression } \\
\text { Mc Nemar tests }\end{array}$ \\
\hline Paper V \\
$\begin{array}{l}\text { Intervention study based on } \\
\text { the results from intake data } \\
\text { and blood samples from } \\
\text { the intervention and the } \\
\text { control group }\end{array}$ & $\begin{array}{l}\text { Changes in nutrients } \\
\text { Changes in biomarkers }\end{array}$ & $\begin{array}{l}\text { Descriptive statistics } \\
\text { Multiple linear } \\
\text { regression (natural } \\
\text { logarithm } \\
\text { transformation of p- } \\
\text { thcy as dependent } \\
\text { variable) }\end{array}$ \\
\hline
\end{tabular}




\section{Results}

The data for this thesis have been collected through two different approaches, and are presented in five papers:

1) Cross sectional studies based on the baseline data from the intervention group. These studies include young men's preferences and perceptions of own vegetable intake (paper I) correlates of young men's intake of vegetables (paper II), and body weight, weight perceptions and food intake patterns (paper III)

2) Study of the effects of a five-month dietary intervention to increase the intake of vegetables, fruits and whole-grain bread (paper IV) and changes in nutrient intake and biomarker (paper V)

\section{Paper I. Preferences and perceptions of personal vegetable consumption: A study among young men in the Norwegian National Guard.}

The aims were to 1) assess vegetable intake and main sources of vegetables among all the recruits and among low ( $\leq 182 \mathrm{~g} /$ day) and high ( $\geq 282 \mathrm{~g} /$ day) consumers, 2$)$ assess preferences for vegetables and correlation with vegetable intake, and 3) to investigate perceptions of own vegetable intake, and the need to increase it among all recruits and between high and low consumers.

The average vegetable intake was $244 \mathrm{~g} /$ day, $43 \%$ of which was potatoes. The most important sources of vegetables among all participants were vegetables in the composite dishes served for lunch and dinner. The hot dinner meals were more important sources of vegetables for the low ( $\leq 182 \mathrm{~g} /$ day) than for the high $(\geq 282 \mathrm{~g} /$ day) consumers $(\mathrm{p}<0.01)$. The high consumers 
showed more variability in their vegetable intake, and had a higher intake of vegetables from lunch dishes and carrots $(\mathrm{p}<0.01)$.

More recruits reported high preferences for raw (76\%) than for cooked (58\%) vegetables. For both raw and cooked vegetables, the recruits reporting high preference scores had higher intakes than those reporting low preference scores $(\mathrm{p}<0.05)$.

Six percent of the recruits consumed $450 \mathrm{~g} /$ day or more of vegetables, which was in accordance with the officially recommended amount at the time of the study. Nearly one-third of all recruits stated that they consumed enough vegetables. Even among the lowest intake group ( $\leq 182 \mathrm{~g} /$ day), nearly one-fourth perceived that they consume enough vegetables. However, $62 \%$ stated a need to increase their consumption of vegetables.

Young men have a low intake of vegetables, but an optimistic view of own intake. Increasing awareness of the recommendations may help young adult men to prevent diet-related diseases.

\section{Paper II. Correlates of vegetable consumption among young men in The Norwegian National Guard}

The aim of this study was to investigate correlates of vegetable consumption among young male recruits. The model included personal, socio-environmental and behavioural factors and explores the most important factors and single correlates.

Overall, $32 \%$ of the variance in vegetable consumption was explained by factors included in the model. The behavioural factors explained $17 \%$ of the variance in vegetable intake. The 
socio environmental and personal factors explained additional variations of $10 \%$ and $5 \%$, respectively. The strongest correlates, all positively associated with total intake of vegetables, were:

- Number of hot meals eaten in the military mess hall $(\mathrm{p}<0.001)$

- Earlier habitual intake of vegetables $(\mathrm{p}<0.001)$

- Taste preferences for cooked vegetables $(\mathrm{p}<0.001)$

- Socio economical status $(\mathrm{p}<0.005)$

In addition the score on weight beliefs $(\mathrm{p}<0.05)$ was positively associated with the intake of vegetables, while the social influence score $(\mathrm{p}<0.01)$ and smoking $(\mathrm{p}<0.05)$ were negatively correlated with the recruit's intake of vegetables. Behavioural factors were the most important correlates. Targeting behavioural factors in future interventions may be effective.

Paper III. Body weight, weight perceptions and food intake patterns. A cross-sectional study among recruits in the Norwegian National Guard.

The aim of this paper was to identify food intake patterns and explore the relationship between these patterns and BMI, weight and health perceptions. The paper also investigates the relationship between the recruit's food patterns at home and in the military camp.

A significant relationship was observed between the recruit's consumption at home and in the military camp for the following food items: vegetables, fruits, breakfast cereals, semi and whole grain bread and soft drinks ( $\mathrm{p}<0.001$ for all). Based on the intake data from the military camp, three food patterns were explored with a principal component analysis. These were called: 1) plant foods, 2) fast food/soft drinks and 3) milk/cereals. 
Twenty-eight percent of the recruits had a BMI $>25 \mathrm{~kg} / \mathrm{m}^{2}$. BMI was inversely associated with the highest tertile of the plant foods pattern $(\mathrm{p}=0.01)$ and with attitudes towards slenderness $(\mathrm{p}<0.05)$.

Two-thirds of the participants reported that it was important for them to be slender. Seventy percent of the recruits strongly agreed that it was important for them to have good health. No association was seen between the attitude towards slenderness and the food intake patterns. However, when studying single food items, those who agreed that it was important for them to be slender, had a higher intake of fruit and juice $(\mathrm{p}<0.05)$. Furthermore, the recruits who reported that it was important for them to be slender, reported both more light and hard physical activity $(\mathrm{p}<0.05)$.

The majority of the recruits found it important to be slender. This orientation had a bearing on their physical activity pattern, but less on the food intake pattern.

\section{Paper IV. A nutrition intervention focusing on vegetables, fruits and bread among young men.}

This paper aims to evaluate the results from the 5-month dietary intervention focusing on increased availability of vegetables, whole grain bread and fruits, and nutritional information.

A significant increase in the consumption of vegetables ( $82 \mathrm{~g} /$ day), semi-whole grain bread (47 g/day) and fruits (16 g/day) was observed among the recruits in the intervention group $(\mathrm{p}<0.05)$. In the control group, only a significant increase in fruit juice consumption was 
observed $(\mathrm{p}<0.05)$. The intervention effect was significant for vegetables, fruits and semiwhole grain bread when controlling for baseline values, and seasonal variation $(\mathrm{p}<0.001)$. The recruits in the intervention group scored higher on the questions concerning nutritional knowledge after the intervention. The percentage of recruits who had three out of four correct answers was nearly four-doubled compared to baseline levels $(\mathrm{p}<0.001)$.

This environmental and educational intervention was effective to increase the intake of vegetables, fruits and whole grain cereals among young men towards the official recommendations in Norway.

\section{Paper V. Associations between folate intake from different food sources in Norway and homocysteine status in a dietary intervention among young male adults.}

The objective of this paper was to evaluate changes in intake of folate and dietary fibre after the five month dietary intervention. The study also evaluated the association between changes in folate intake from vegetables, fruits, juice, bread and changes in plasma homocysteine concentration.

The increased consumption of vegetables, fruits, juice and bread resulted in increases in estimated intake of dietary fibre $(\mathrm{p}<0.001)$ and folate $(\mathrm{p}<0.001)$ in the intervention group after the intervention. The intervention effect was significant for both fibre and folate $(\mathrm{p}<0.001)$ and the intervention effect for changes in folate from vegetables, fruit and bread was significant $(\mathrm{p}<0.001)$. The single food item that contributed most to folate intake both before and after the intervention was whole grain bread. The increased intake of total folate as well 
as folate from the whole grain bread was reflected in a reduced concentration of plasma total homocysteine $(\mathrm{p}<0.05)$.

The dietary intervention resulted in increases in consumption of some healthy food items with a reflected increase in folate and dietary fibre and reduction in concentration of homocysteine. Reduction in the concentration of plasma total homocysteine was significantly related to an increased folate intake from bread. 


\section{Discussion}

The results are discussed in detail in each paper. In this chapter, some methodological considerations and the main findings will be discussed.

\subsection{Methodological considerations}

\subsubsection{The military as a research setting}

The military is a unique setting to conduct a dietary intervention, offering several advantages:

1. The ability to reach young men, a group which is generally considered hard to reach when trying to change/improve eating habits.

2. The ability to reach the kitchen personnel directly and guide the preparation and presentation of the food for the group that was the goal for the intervention

3. The opportunity for the recruits to sit in classroom facilities and record the diary each day of the registration period, with guidance from project workers

4. The opportunity to collect all recipes and thereby record amounts of vegetables and fruits in main courses and side dishes served for lunch and dinner

5. The opportunity to be present at all meals served in the mess hall in the data collection period.

However, this setting and the methods used give some challenges and limitations which are important to consider when interpreting the results. The study personnel had to follow to the schedules and logistics of the military regarding which camps could be included in the study and periods for the data collections. 


\subsubsection{Generalisability}

The generalisability of a study conducted in the military need to be discussed in relation to young men in other settings. The generalisability of this study is strengthened by the compulsory military service that is practiced in Norway. In this way young men with different socio economical status, from different geographical areas and different cultures and religions are allocated to the military camps located across the country.

The somewhat restricted food choices may limit the interpretation of the results compared to young men in other situations. The young men participating in our study ate most of their meals in the military mess hall and thereby had restrictions in their food choices. However, for both lunch and dinner they had the choice of a hot dish or bread with different spreads. They could choose whether to eat vegetables with their meals, and they decided their own serving sizes. For lunch they also had the choice of a salad bar. The recruits had the possibility to buy food in a commercial canteen or in restaurants or grocery stores outside the military camp on their own expenses. The results from the baseline studies showed large variations in intake of vegetables, fruits and semi whole grain bread between the recruits in the same camp, which indicates that their own choices are important also in the military setting. Young men outside the military are also restricted in their food choices; by parents, canteens at school/work, economy and skills on how to prepare food.

\subsubsection{Selection errors}

Selection error is a problem in most population studies because of low response-rates and difficulties in reaching certain groups of the population. Highly motivated people and people who are concerned with diet and health tend to participate to a higher extent than less motivated people and this may give bias in the selection. Young people and especially young 
men have been described as difficult to reach both with nutritional information and with participation in surveys (1). In the present study, we had the possibility to reach participants regardless of their concern about nutrition, also those who could have been difficult to reach outside the military camp. The response rate for the baseline data $(78 \%)$ can be considered satisfactory.

We acknowledge that selection errors may exist and in this way influence the interpretation of the results. This study presents the results from both baseline data (paper I, II and III) and the intervention study (paper IV and V) and the selection errors may differ with regard to the study design because of dismissal from the military.

First, the selection of the camps and the fact that only two camps were included in the study may give rise to selection errors. The camp that was selected for the intervention group and for the control group respectively may have influenced the results to some degree. Second, differences in background characteristics of the participants in the two camps may also have given rise to selection errors between the intervention group and the control group. Randomisation of the recruits to the two camps based on their background characteristics could have limited the potential selection errors. However, the allocation of the recruits to the different camps was conducted by the military with no possibilities for us to exert any influence. Further, in the military camp where the intervention was conducted, there was only one kitchen and one mess hall. This means that we could not split the recruits into an intervention and a control group in the same camp, and implement the intervention for only a part of them. 
Large variations between the recruits in several of the baseline data were observed in both the intervention and the control group. This includes both parent's socio economic status and the food intake data when still living at home. This is in line with the ideas of the compulsory military service that young men from various socio economical backgrounds are arbitrarily allocated to the two camps. However, the baseline characteristics showed significant differences in some health related factors between the two camps, which may have implications for the results. At baseline a lower BMI was observed among the subjects in the intervention group (126). Regarding smoking habits, a higher prevalence of smokers, an earlier smoking start and a higher number of cigarettes smoked were observed in the intervention group (126). In addition, the participants in the intervention group had a higher intake of vegetables and fruits, and a better folate status than those in the intervention group. Therefore, we made adjustments for the baseline values in all analyses where the two groups were compared. This would reduce this potential bias.

\subsubsection{Attrition}

Participants dropping out of a study are a concern, since healthier subjects traditionally remain in a study to a greater extent than less healthy ones $(4,132-134)$. In addition, those who are most motivated may be more likely to participate for a longer time. In a recent metaanalysis on drop-outs in randomized controlled trials, evidence that bias was introduced by attrition was not found (135). However, since the design of our study was different, the results are not fully comparable. A relatively high proportion of the subjects dropped out from our study after the baseline collection. The main reason for dropping out was dismissal from military service due to health problems and not refusals to take part in the study per see. 
Analyses of drop outs in the intervention group showed that they on average had a higher intake of vegetables and fruits and a lower intake of semi-whole grain bread at baseline than those who completed the entire study. These differences were not observed in the control group. Regarding socio-economic status, no differences were observed between those who completed the entire study and those who dropped out. Since baseline values are controlled for both in the intervention and the control group, these differences are not expected to affect the results to any great extent

\subsubsection{Statistical power}

There were relatively few participants in the control group, which weakens the strength of the study. Ideally, the intervention group and the control group should be as equal as possible when comparing the two groups. Unfortunately, structural changes in the military made it impossible to include more subjects in the control group.

In order to be able to detect significant differences, the study had to include a sufficient sample size. Serum folate was in focus for one part of the present project, and the relatively small expected difference in folate was considered to be a limiting factor. Thus, when planning the overall project, sample size calculations were performed for serum folate. The calculations showed that in order to detect folate differences of $0.20,0.16$ and 0.10 with a power of $95 \%-86,133$ and 338 persons respectively, were needed in both the control and the intervention group (126). The highest number was met in the intervention group, but in the control group only 105 recruits participated at follow up, giving rise to some concern about the statistical power for the blood data. Larger differences between baseline and follow up were expected for the food intake data, compared to the blood data. Thus, it is expected that a 
smaller sample would suffice for the food intake data. However, it cannot be ruled out that a larger control group would have resulted in more significant changes also in this group.

\subsubsection{Validation of the diary and the questionnaires}

To minimize data errors, the validity and reliability of the data collection instruments are of importance (136). Low validity and reliability may limit the ability to detect differences between the intervention and the control group. In addition, associations between the exposure and the outcome variables might be limited.

A modified version of a previously validated diary (137) was used to capture the recruit's diet in this study, as described in the methods section. To guide the recruits to decide the serving size, pictures from a validated booklet were used. It was decided that it was not necessary to validate the dairy again, with exception of getting comments on the question assessing unhealthy food items that had been eaten outside the mess hall and the ability to report the right number of today's special served for lunch and dinner. These items were tested with a group of soldiers. Only minor changes in the question capturing the food eaten in other places than the military mess hall was done based on the comments from the group.

The instruments used in this study were tested both in focus group discussions and in testretest analyses. The soldiers participating in the test-retest had no problems in reporting the right number for the main courses for lunch and dinner. Both the results from the test-retest study and the internal consistency of the scales were acceptable. An internal consistency coefficient (cronbachs alpha) of 0.7 or higher is considered as acceptable for large scales. Cronbachs alpha values, are however, quite sensitive to the number of items in the scale. With short scales (e.g. fewer than ten items) it is common to find Cronbach values around 0.5 
(138). In the present study Cronbachs alpha values were in the range 0.6 to 0.8 , except for the social influence items which were 0.3 (paper II). The poor internal consistency of the social influence item is not surprising since the scale probably measured two dimensions, both what persons who were important for the recruits meant and what the other recruits meant.

\subsubsection{Information errors}

Measuring food intake correctly is difficult and there are errors with all dietary assessment methods (139). Self-reported dietary data rely on the subject's ability and motivation to report correct data. The subjects may have misunderstood questions, forgotten to record food items or been unwilling to report certain data. Furthermore, several studies have reported social desirability bias, such as over reporting of healthy foods and under reporting of unhealthy food items (140-142). Smoking habits, physical activity and self-reported weight/height are other variables that may have been subject to social desirability bias.

When collecting the dietary data in this study, both the burden on the part of the respondents and the need for accurate data were considered. Thus, a short version of the diary developed at the Department of Nutrition, University of Oslo, was used with the modifications described in section 3.4.1. The diary was chosen instead of a food frequency questionnaire since it was supposed that the recall bias was reduced if the recruits recorded their intake from day to day instead of giving an estimate of their usual intake. Furthermore, the diary was assumed to give better estimates to explore the differences between baseline and follow up than a food frequency questionnaire, since it would be easier to capture composite dishes and other hidden vegetables with the diary. When using a diary it must be kept in mind that food intake on a specific day is not representative for the food pattern over a longer period (143) and therefore more than one day of data collection is necessary. Other researchers have argued 
that 3 to 10 days are necessary to give estimates of long-term intake $(144,145)$. Given the aims of this study, it was assumed that three to four days would be sufficient to evaluate the differences in intake before and after the intervention and to explore predictors of vegetable intake.

A strength of the intake data in the present study, is that all recipes and ingredients in composite dishes were known to the researchers who could calculate the amount of vegetables and fruits in stews and casseroles. The recruits could otherwise have forgotten to record these "hidden sources of vegetables" or may have had problems in estimating the amount in the different meals. The two project workers were present at all meals and when the recruits completed the diaries, and could guide the recruits when estimating serving sizes. During the data collections we observed that the largest picture of serving sizes was too small for those who had very large portions. However, we discussed with them alternatives to report their intake, for example by reporting the number of portions that would be equal to one very large portion, and thereby limited the information errors. The project workers also informed the recruits of the names of unfamiliar vegetables and helped them to record all food items.

Intake data was collected on weekdays only and thereby limited the ability to investigate differences in food intake between weekends and weekdays. The relationships in paper 3 may have been influenced by the missing intake data on weekends since unhealthy food items are mostly eaten during weekends. We tried to collect data during weekends while the recruits were off duty, but these were omitted due to largely incomplete data sets.

Another limitation was the collection of data on the food eaten outside the military mess hall. This was mainly fast food, beverages and snacks. A short question at the end of the diary 
captured the food eaten outside the military mess hall, such as the canteen or kiosk in the camp, grocery stores or restaurants outside the military camp. It is possible that the recruits forgot to record these food items, since they were not reminded about them from pre-printed choices. The main focus of the study was on the targeted food in the intervention: vegetables, fruit and whole-grain bread, and therefore the diary was designed to provide high quality data on these food items. The registration of the unhealthy food items may therefore not be of the same good quality as the targeted food items.

A source of information errors in the attitudinal questionnaire was the question assessing parental education. The participants were asked to record their parent's education on fourpoint scales and they may have had problems to distinguish between the two parameters exploring education at college/university of 1-3 years or more than three years. Thus, parental occupational status was considered as a better variable to study the associations of socio economic status with the other factors and behaviours in this study. Another source of information error in the attitudinal questionnaire was the question about physical activity. The participants were asked to record their light and hard physical activity and they may have had problems to distinguish between these two.

\subsubsection{Seasonal variations}

Since the participants in the intervention group entered military service in January and July and the control group in September, the question could be raised if seasonal variations may bias the data. However, according to the head of the kitchens, the menus in the mess hall are influenced by seasonal variation only to a minor extent. Furthermore, analyses of intake showed only minor differences between the groups regardless of time of entering military 
service. In paper 3 and 4, the data are adjusted for seasonal variations which would further minimize this potential source of error.

\subsubsection{Measuring attitudes and perceptions of vegetables}

Vegetables and fruits may be included in a persons eating pattern in many different ways (146). Norwegians typically eat fruits mainly as snacks at any time of the day or as deserts after a meal, while vegetables are eaten mainly for dinner $(147,148)$. Thus, attitudes and preferences for vegetables and fruits may differ considerably. Most often studies have assessed attitudes to and perceptions of fruits and vegetables in combination in psychosocial items. We chose to relate these questions only to vegetables since vegetables were one of the main focused food items in this project. By not combining fruits and vegetables in the questions we ensured that the participants had vegetables (and not fruits) in mind when they gave their statements. Thereby the study added important information about underlying factors of vegetable intake among young men.

\subsubsection{Blood samples}

To reduce the risk of errors the blood samples were centrifuged within 4 hours and serum was transferred to blood collection tubes. The samples were then frozen and stored at $-70^{\circ} \mathrm{C}$ until analyzed. Validated reference methods were used to analyse the data. In addition, the samples from the intervention and control group were analyzed at the same time and they were blinded when analyzed. 


\subsection{Discussion of main findings}

\subsubsection{Baseline eating habits of vegetables, fruits and whole grain cereals}

At baseline, the average intake of vegetables including potatoes in the intervention group was $244 \mathrm{~g} /$ day (Paper I). This was far below the recommendation, which at that time was 450 gram daily (33). The low intake of vegetables among young men is in accordance with other studies $(3,146,149)$. A study among Finnish conscripts showed that only $8 \%$ of the conscripts had a daily consumption of vegetables (149)

The baseline intake of fruits was $128 \mathrm{~g} /$ day, juice $153 \mathrm{~g} /$ day and semi whole grain bread 160 $\mathrm{g} /$ day among the recruits in the intervention group. The fruit intake was below the recommendations, which at that time were two 150 gram servings (33). However, fruit juice was included in those recommendations with no limitations. The collected intake of fruit and juice is in accordance with another Norwegian study (3). The Norkost study (3) report the total intake of cereals (including breakfast cereals, biscuits, and bread) and is therefore not comparable to our study where only intake of semi whole grain bread was reported.

\subsubsection{Factors associated with the intake of vegetables and other foods}

In paper I and II predictors and other factors associated with young men's intake of vegetables at baseline in the intervention group were studied. The results indicated that many of the recruits had positive attitudes towards eating vegetables even before the implementation of the intervention. For example, $76 \%$ of the recruits stated that they like raw vegetables (paper I) and the mean score of the vegetable and health scale was 1.16 (the scale ranged from -2 to 2) (paper II). However, the positive attitudes were reflected in the intake for only a small part of the subjects since only $6 \%$ had an intake in line with the official recommendation (33) 
(paper I). The results from paper I showing that $33 \%$ of the recruits stated that they consumed enough vegetables, suggest that they had an optimistic view of their own intake.

Most studies using psychosocial models to explain vegetable and fruit intake have accounted for less than $30 \%$ of the variance (80). What constitutes a feasible percent of explained variance is a question for further debate, but the psychosocial models used have shown limitations to explain the variance in dietary behaviour and in exploring potential determinants (80). The model in the present study (paper II) explained $32 \%$ of the variance in the recruit's intake of vegetables, with behavioural factors (number of hot meals and eating habits of vegetables at home) as the strongest correlates.

The model in our study is based on the theoretical framework of the ASE-model and Social Cognitive Theory. However, we also included items that do not strictly fit in with the theoretical framework of the psychosocial models, such as eating habits of vegetables when still living at home and number of hot meals a day when in the military. This is in agreement with the literature, where models combining and eliminating constructs (150) and more situational determinants (151) have been proposed to better explain dietary behaviour.

The inclusion of eating habits at home as a predictor of current eating habits is an example of a construct that do not fit strictly into the models. However, the inclusion of past behaviour as a predictor of current behaviour has received much attention in the last decades $(95,97)$. Researchers have argued that frequent performed behaviours become habitual and are determined by past behaviour rather than cognitions (152). Eating pattern is an example of a behaviour that has become rather habitual for most people and this may explain the strong 
relationship between the intake in the military camp and the intake at home in spite of the new environment for the subjects.

Since a food diary reflecting the current diet, and not a FFQ estimating habitual or usual intake, was used for collecting intake data in the present study, we decided to include former eating habits as an explanatory variable in our model. Based on the literature described above $(95,97,102)$, we assumed that it was important to study former eating habits to understand the current diet as basis for designing an effective intervention. Those with low intake of vegetables both at home and in the camp will most probably need other strategies and more effort to change their habits towards increasing their vegetable intake than others.

Earlier eating habits also showed strong associations with eating habits in the military camp for several other foods than vegetable, both those who can be regarded as healthy and unhealthy. Recruits who had a high intake of specific food items at home also had the highest intake of the same foods in the camp, even though they were no longer under control of their parents (paper III). The results further strengthen the assumption of past behaviour as a predictor of current behaviour. In paper II these assumptions were confirmed for vegetables in a multivariate analysis. The results showing past behaviour to be a predictor of current behaviour are in agreement with findings from other studies, which indicate tracking of eating habits from childhood to adulthood. $(4,98)$.

Our results indicate a socio economic difference in the intake of vegetables and other health related factors among the young men (126). Recruits with high parental occupation status had higher intakes of vegetables (paper II). In addition, BMI was inversely associated with paternal education level (126). The results are in line with a recently published study among 
Finnish conscripts who showed that eating habits that were in line with the Finnish recommendation were associated with a higher educational level among the conscripts (149).

People with high socioeconomic status seem to have eating habits that are more in line with the recommendations compared with those with low socioeconomic status (53-58). Thus, the habitual intake of healthy and unhealthy food items at home and the recruit's socioeconomic status probably exerts a mutual influence on each other. The results imply that parents with high socio economic status may act as positive role models for young men attempting healthy eating habits, even after they have moved away from home. Furthermore, the results suggest that targeting young men with low socio economic status with messages and interventions to increase their intake of healthy food items is important.

Preferences are often learned during childhood trough repeated exposures of food and may therefore be related to a habitual intake. Other studies have shown that preferences are important for food intake among children $(81,85,99)$, but this relationship with fruit and vegetable intake is inconsistent for adults (80). It is possible that with increased age, preferences become less important and other factors such as price, quality, slimness and healthiness may become more important. The present study (paper II) shows that preferences for vegetables still influence the intake among the young men. The results are consistent with findings from a Polish study among university students of more or less the same age, showing that preference was a significant factor when choosing vegetables (87).

Preferences for cooked vegetables were associated with the recruit's intake of vegetables in both univariate and multivariate analyses while preferences for raw vegetables showed an association in univariate analyses only (Paper I and II). The results suggest that preference for 
cooked vegetables was a stronger predictor for vegetable intake since it remained significant also when other factors were controlled for. In the present study, preferences for raw and cooked vegetables were assessed separately, since cooked vegetables often include the more bitter tasting ones and the liking of these vegetables seemed to be lower. The results suggest that more efforts to increase the preferences for cooked vegetables among young adult men are important when trying to increase their total vegetable intake.

Breakfast, lunch and dinner were served at regular times in the mess hall. The hot meals included vegetables, or vegetables were served as side dishes. The recruits could also compose their own salads. The number of hot meals eaten for lunch and dinner was identified as a significant correlate of vegetable intake (paper II), and as an important source of vegetables, especially among low consumers (paper I). To our knowledge, meal patterns are rarely included in models explaining vegetable intake. Most studies focus on the intake during the whole day and do not investigate in what situations and at what meals vegetables are eaten or if vegetables are eaten as a snack, main meal or as an ingredient in composite dishes.

Among the few studies that have looked into this issue is a study among children in the US (153). This study showed that fruit and vegetables are mostly consumed at weekday lunch and second most frequent at dinner. A study by Larson and co-workers (154), showed that frequency of family meals in adolescence, and frequency of dinner meals during young adulthood, predicted intake of fruits and vegetables. A study among Finnish adults also showed that vegetables were most often eaten with hot meals (130). This was also supported by a study that showed that composite dishes were important for the vegetable consumption (131). All these studies concerned family meals. 
Important eating situations for vegetable intake may vary in different food cultures, age groups, household situations, and whether or not meals are eaten at home or outside home. Whether or not vegetables and fruits are investigated together may also affect the results. However, many results point in the same direction, that hot meals, dinner meals and composite dishes are important for vegetable intake regardless of setting.

Norwegians usually eat one hot meal for dinner and three bread/cereal meals during the day (155). Given the importance of the hot meals for vegetable intake, the tendency that young Norwegian adults do not eat dinner every day is of concern. In 2005, about $20 \%$ of young Norwegians reported that they did not have dinner daily (156). Packed lunch, consisting of bread with different spreads is a typically Norwegian lunch. In a food culture with few hot meals as in Norway, special efforts are necessary to increase vegetable intake. The results suggest that increasing the availability of vegetables through low priced mixed hot dishes with a high content of vegetables, side dishes or salads at work/school canteens may increase the consumption of vegetables, also for those who are low consumers. In addition, knowledge and training in how to cook food seem important in this regard. Lack of confidence in own ability to prepare vegetables has been associated with being male, low socio economic status and living with other adults (157). A question of concern is the relative low proportion of home economics classes that exist in the Norwegian education at school today, resulting in few opportunities to learn how to make tasty vegetable dishes.

\subsubsection{Eating patterns and weight and health perceptions}

The complexity of dietary intake makes analyses of food intake patterns more suitable than single food items to study the association with other health related factors and attitudes. In recent years, increased attention has been given to studies using factor analyses, cluster 
analyses (158) and eating indexes to derive food intake patterns. The advantages of these studies and especially factor analyses and cluster analysis, which are data driven, are that they take the complexity of food habits into account. The disadvantages with the data-driven analyses are that they are somewhat subjective (63); the results depend on the variables you put into the analysis.

In the present study, factor analysis was used to explore food intake patterns among the recruits in the intervention group at baseline (paper III). Three different intake patterns were derived among the recruits: 1) plant foods 2) fast food/soft drinks and 3) milk/cereals. The first factor loaded high on healthy food items, such as vegetables, fruits, juices, potatoes, and bread, while factor 3 loaded high on unhealthy food items such as fast food and sugared soft drinks. The patterns formed may have been influenced by the fact that we did not have data on the entire diet. The existence of other patterns that we did not extract due to lack of data on the entire diet is also possible. However, similar patterns have been found in other studies $(62,63)$.

The three factors identified in the present study explained $42 \%$ of the variance. Compared with other studies, the explained variance in the present study was relatively high. In a study among French men (63), the explained variance was $26 \%$ and in another study among US adult men the explained variance of the two factors presented was $17 \%(62)$.

Those recruits who had high scores on the plant food pattern in the present study had lower BMI (paper III). A high proportion of the recruits stated that it was important for them to be slender. Those who responded that it was important for them to be slender were also less likely to have a high BMI. However, the results suggested that physical activity was more 
important than food choices for young men who desire a slim body, since physical activity was positively related to the statement about slenderness whereas food patterns were not. It is possible that the relationship with health and weight attitudes, would have been stronger if the total diet of the recruit's had been explored.

\subsubsection{Effects of the intervention}

The results from the intervention indicate that a combination of nutritional information and increased availability of vegetables, fruits and whole grain cereals was an effective strategy to increase the intake of these foods among the participants who belong to a population group that is considered difficult to reach with conventional nutrition information (1).The young men participating in the intervention group showed a significant increase in their intake of vegetables of $82 \mathrm{~g} /$ day, semi-whole grain bread of $47 \mathrm{~g} /$ day and fruits of $16 \mathrm{~g} /$ day (paper IV). No significant increase in the intake of these foods was observed among the recruits in the control group. At follow up, the intake of these foods were significantly higher in the intervention group compared to the control group, when adjusting for baseline values.

What constitutes a feasible increase in vegetable, fruit and semi-whole grain consumption is an issue for further discussion. No specific target, except a significant increase in the consumption of the food items studied, was the goal of the project. The recruits increased their intake of vegetables with 0.8 servings a day and their intake of semi whole grain bread with nearly one slice a day. In comparison with intervention studies conducted in other population groups, this is a medium to large increase $(120,159)$.

The increased intake of vegetables, fruits and whole grain bread were also reflected in the nutrient intake and a subsequent increase in folate and dietary fibre was observed (paper V). 
The present study showed that bread was a more important contributor to both folate and dietary fibre than vegetables or fruits.

The dietary intervention showed a reduction in the concentration of total plasma homocysteine (paper V). This reduction was associated with an increase in estimated intake of folate from bread, but no association with the estimated increase in intake of folate from fruits and vegetables was observed. A possible explanation for the lack of association between homocysteine and estimated intake of folate from fruits and vegetables is reduction in the concentration of folate due to losses during cooking or low bioavailability of naturally occurring folate from foods (126).

Diverging results are shown for the association between increased intake of folate and a reduced concentration of homocysteine in blood (35). Some studies do not show effects on either plasma folate concentration or homocysteine concentration (35). On the other hand, other studies have found effects on increased serum and erythrocyte folate concentrations and reduced homocysteine concentrations after interventions with focus on folate rich foods $(36,113)$.

The intervention was designed to target some of the correlates that were found to be important predictors of vegetable consumption in the baseline survey and international literature. These included preference for cooked vegetables, and behavioural factors like the eating pattern of hot meals. The predictors were targeted by improving the availability of vegetables through increased amount of vegetables in composite dishes and serving vegetables as side dishes. In addition, a salad bar was offered for the lunch meal. 
Furthermore, mediating factors like knowledge were targeted in the intervention. Knowledge about vegetables and health was not associated with vegetable intake at baseline (paper II). However, the study showed that increased knowledge from baseline to follow up was associated with an increase in vegetable intake (Paper IV). The nutritional messages used in the intervention were simple, easily understood messages placed in strategic places in the mess hall so the participants were reminded about them several times a day. As the nutritional information was expressed as messages that were easy to understand, it hopefully also reached the participants with low socio economic status and those with a diet low in vegetables, fruits and whole grain cereals at home and in the beginning of the study.

To place the nutritional messages at strategic places in the mess hall was an effective way to increase nutritional knowledge and it turned out to have an impact on the intake of vegetables. The knowledge-intake association is debated and other researchers have questioned if knowledge alone is enough to make people increase their intake of fruit and vegetables (76). The results from our study are consistent with findings from other studies showing a positive association between knowledge and intake $(79,80)$.

Since this study used a combination of improved availability and nutrition information, we do not know if increased knowledge alone would have resulted in higher intake among these young men. However, based on the results on the predictors of vegetable intake from this study, and on results from other interventions (77), it is probable that the effect of knowledge had been weaker without the increased availability of vegetables in the military mess hall. 


\section{Concluding remarks and implications for further research}

This thesis presents the results from a cross sectional baseline survey and from a five-month dietary intervention with focus on a combination of nutritional information and increased availability of vegetables, fruit and whole grain cereals among young men in the military. The baseline results show that young men have an intake of vegetables and fruits that is below the Norwegian recommendations. There was a large variation in vegetable intake among the recruits at baseline, even though they had most of their meals in the military mess hall.

Healthy dietary changes are needed among young Norwegian men to make them meet the recommendations of "five-a-day" and of whole grain consumption. The present study has contributed with knowledge on factors influencing the intake of vegetables, fruits and whole grain cereals among young men. Important factors associated with vegetable intake among the recruits were eating habits of vegetables when still living at home, and parents occupation status, even though the young men were in another setting and not under parental control. Other important factors were number of hot meals eaten in the mess hall as well as preferences for cooked vegetables. There is a need for better understanding of the factors influencing the intake of healthy food items among young men in order to identify barriers to change and to design effective interventions. The results suggest that inclusion of factors that do no fit strictly into the psychosocial models may be useful when developing models to explain food intake among young adult men. In this regard, it seems important to include behavioural factors, like number of hot meals eaten, in models explaining vegetable intake.

The food intake patterns found in this study give useful information to understand the complexity of young men's eating behaviour and the associations with lifestyle factors, health 
and weight perceptions. The results also indicate that young men are preoccupied with weight issues, since a high percentage stated that it was very important for them to be slender. Physical activity seemed to be more important for those who valued a slim body than having a healthy food intake pattern. Healthy dietary advices may be important to young adult men to prevent future overweight and obesity and diet-related diseases.

This study has demonstrated one successful approach to change dietary habits among young adult men. The five months intervention with increased availability in conjunction with nutritional information was effective to increase the intake of vegetables, fruit and whole grain cereals among the young adult men, but still the intake of vegetables and fruits at follow up was lower than the recommendations. In addition, the intervention gave favourable increases in the intake of folate and dietary fibre and a reduction in total plasma homocysteine concentration reflecting the observed increases in intake of folate. The results imply that multi-component interventions may be effective to promote healthy dietary habits among young adult men, but since the intervention was gender and age specific, other factors may be more effective among other age groups and among women. The results suggest that cooperation between health promotion practitioners and canteen staff in workplaces, school canteen and cafeterias to promote a healthy eating environment may be successful in increasing consumption of healthy food items

Unhealthy dietary habits developed in young age may have implications for development of diet-related diseases and overweight later in life. It is questionable if young men pay enough attention to a healthy diet and future health, as prevention may seem irrelevant since the problems seem far away. On the other hand, the positive results from the intervention presented in this study indicate that young men are willing to undertake dietary changes. 
Suggestions for further research

- More detailed analyses of the characteristics and changes in mediating variables of those who increased their intake of vegetables are a topic for further investigations. More specific, further studies should investigate if the increased availability and increased exposure have affected the preferences and given more positive attitudes towards vegetables.

- Further research is needed to find out if the factors derived as important in this study are determinants also in long term studies.

- Research is necessary to confirm the eating patterns found in the present study. In addition, investigations on the clustering of other unhealthy lifestyle factors in relation to food intake patterns would be of interest.

- More research is needed to investigate body image problems in young men and to investigate whether focus is mainly on weight gain or weight loss.

- Changes in the food intake patterns derived from factor analysis before and after the intervention is a topic for further investigations. Further, the associations between the food intake patterns and the biomarkers, such as plasma homocysteine or blood lipids, should be further analysed.

- Repeating the intervention with focus on increased availability and nutritional education in another setting, other population groups and with a longer time span would expand the applicability of the effectiveness of the intervention strategies. 


\section{References}

1. Fagerli R, Wandel M. Gender differences in opinions and practices with regard to a healthy diet. Appetite, 1999: 32; 171 - 190

2. Biltoft-Jenssen A, Groth MV, Matthiessen J et al. Diet quality: associations with health messages included in the Danish Dietary Guidelines 2005, personal attitudes and social factors. Public Health Nutrition, 2008; 12 (8): 1165 - 1173

3. Johansson L, Solvoll K. Norkost 1997: Nationwide dietary survey in Norway [Nor]. Oslo: National Nutrition Council 1999.

4. Kvaavik E. From childhood to adulthood - stability and prediction of body weight and eating habits. PhD thesis, University of Oslo, Oslo, Norway. 2005

5. Mikkilä V, Räsänen L, Raitakari OT, Pietinen P, Viikari J. Longitudinal changes in diet from childhood into adulthood with respect to risk in cardiovascular diseases: The cardiovascular risk in young Finns study. European Journal of Clinical Nutrition, 2004; 58: 1038 - 1045

6. World Cancer Research Fund. Food, Nutrition, Physical Activity and the Prevention of Cancer: a Global Perspective. Washington DC. 2007

7. World Health Organization. Diet, nutrition and the prevention of chronic diseases. Geneva. 2003

8. Chan AT, Giovannucci EL. Primary prevention of colorectal cancer. Gastroenterology, 2010: 138; 2029 - 2043

9. Bingham SA, Day NE, Luben R et al. Dietary fibre in food and protection against colorectal cancer in the European Prospective Investigation into cancer and nutrition (EPIC): an observational study. Lancet, 2003: 361; 1496 - 1501

10. Aune D, Lau R, Chan DSM, Vieira R, Greenwood D, Kampman E, Norat T. Nonlinear reduction in risk for colorectal cancer by fruit and vegetable intake based on meta-analysis of prospective studies. Gastroenterology, 2011: 141; 106 - 118

11. Steinmetz KA, Potter JD. Vegetables, fruit and cancer prevention: a review. Journal of the American dietetic association. 1996; 96; 1027 - 1039

12. Levi F, Pasche C, Lucchini F, La Vecchia C. Dietary fibre and the risk of colorectal cancer. European journal of Cancer, 2001: 37: 2091 - 2096 
13. Schatzkin A, Park Y, Leitzmann MF, Hollenbeck AR, Cross AJ. Prospective study of dietary fibre, whole grain foods, and small intestinal cancer. Gastroenterology, 2008: $135 ; 1163-1167$

14. Ness AR, Powles JV. Fruit, vegetables and cardiovascular disease: a review. International Journal of Epidemiology, 1997: 26; 1-13

15. Temple NJ, Gladwin KK. Fruit, vegetables and the prevention of cancer. Research challenges. Nutrition, 2003:19; $467-470$

16. Gonzales CA, Riboli E. Diet and cancer prevention: Contributions from the European Prospective Investigation into cancer and nutrition (EPIC) study. European Journal of Cancer, 2010: 46; 2555 - 2562

17. National Nutrition Council. Kostråd for å fremme folkehelsen og forebygge kroniske sykdommer. Metodologi og vitenskapelig kunnskapsgrunnlag [Nor]. Oslo. 2011

18. Cox DN, Anderson AS, Reynolds J, McKellar S, Lean, MEJ, Mela, DJ. Take five, a nutrition education intervention to increase fruit and vegetable intakes: impact on consumer choice and nutrient intakes. British Journal of Nutrition, 1998: 80; 123 131

19. Manios Y, Panagiotakos DB, Pitsavos C, Polychronopoulos E, Stefanadis C. Implication of socio-economic status on the prevalence of overweight and obesity in Greek adults: The ATTICA study. Health Policy, 2005; 74: 224 - 232

20. Rana C, Herman VO, Stefaan D. Trends in social inequalities in obesity: Belgium, 1997 - 2004. Preventive Medicine, 2009; 48 : 54 - 58

21. Kark M, Rasmussen F. Growing social inequalities in the occurrence of overweight and obesity among young men in Sweden. Scandinavian Journal of Public Health, $2005 ; 33: 472-477$

22. Sing GK, Siahpush M, Kogan MD. Rising social inequalities in US childhood obesity. Annuals of Epidemiology, 2010; 20 (1): 40 - 52

23. Mackenbach JP, Stirbu I, Roskam AJ, Scaap MM, Menvielle G, Leinsau M et al. Socioeconomic inequalities in health in 22 European countries. New England Journal of Medicine, 2008; 358 (23): 2468 - 2481

24. The Norwegian Directorate of Health. Folkehelsepolitisk rapport 2010 [nor]. http://www.helsedirektoratet.no/sosiale_uliketer_helse/publikasjoner/helsedirektoratet s_rlige_rapport_om_arbeidet_med__utjevne_sosiale_helseforskjeller__folkehelsep olitisk_rapport_2010_780914?dummy=null 
25. Rodriges-Rodriges E, Lopez-Sobaler AM, Ortega RM. Weight loss due to fruit and vegetable use. In Bioactive foods in promoting health. 2010

26. Crujeras AB, Goyenechea J, Marinez, JA. Fruit, vegetables and legumes consumption. Role in preventing and treating obesity. In: Bioactive foods in promoting health. 2010

27. Van Horn L, McCoin M, Kris-Etherton PM, Burke F, Carson JAS, Champagne CM, Karmally W, Sikand G. The evidence of dietary prevention and treatment of cardiovascular disease. Journal of the American Dietetic Association, 2008; 108 (2): $287-331$

28. Park Y, Subar AF, Hollenbeck A, Schatzkin A. Dietary fibre intake and mortality in the NIH-AARP diet and health study. Archives of Internal Medicine, 2011: 171; 1061 $-1068$

29. Mann JI, De Leeuw I, Hermansen K et al. Evidence-based nutrition approaches to the treatment and prevention of diabetes mellitus. Nutrition, Metabolism and Cardiovascular Disease, 2004; 14: 373 - 394

30. Bantle JP, Wylie-Rosett J, Albright AL. Nutrition recommendations and interventions for diabetes. Diabetes Care, 2008; 31 (1): S61 - S78

31. Colorectal cancer report summary 2010. Food, nutrition, physical activity and the prevention on colorectal cancer. WCRF/AICR. 2011.

32. Whitney EN, Rolfes SR. The water-soluble vitamins: B vitamins and vitamin C. In Understanding nutrition, seventh edition. West Publishing Company, Minneapolis/St Paul, 1996.

33. National Nutrition Council. Anbefalinger for $\varnothing \mathrm{kt}$ inntak av frukt og grønnsaker [nor]. National Nutrition Council, 1996. Oslo

34. Ueland PM, Refsum H, Stabler SP, Malinow MR, Andersson A, Allen RH. Total homocysteine in plasma or serum: methods and clinical applications. Clinical chemistry, 1993; 39: 1764 - 1769

35. Bogers RP, Dagnelie PC, Bast A, van Leeuwen M, van Klaveren JD, van den Brandt PA. Effect of increased vegetable and fruit consumption on plasma folate and homocysteine concentrations. Nutrition, 2007; 23: 97 - 102

36. Silaste MJ, Rantala M, Alfthan G, Aro A, Kesäniemi A. Plasma homocysteine concentration is decreased by dietary intervention. British Journal of Nutrition, 2003; 89: $295-301$ 
37. McNulthy H, Pentieva K, Hoey L, Ward M. Symposium on diet and CVS.

Homocysteine, B-vitamins and CVD. Proceedings of the Nutrition Society, 2008; 67: $232-237$

38. Verhoef P. Homocysteine - an indicator of a healthy diet? American Journal of Clinical Nutrition, 2007; 85: 1446 - 1447.

39. Wald DS, Law M, Morris JK. Homocysteine and cardiovascular disease: evidence on causality from a meta-analysis. British Medical Journal, 2002; 325: 1202 - 1206

40. Norwegian Directorate for Health and Social Affairs. Utviklingen i norsk kosthold 2010. [Nor].

http://www.helsedirektoratet.no/vp/multimedia/archive/00322/Utviklingen_i_norsk_3 22149a.pdf

41. Keim KS, Stewart B, Voichick J. Vegetable and fruit intake and perceptions of selected young adults. Journal of nutrition education, 1997; 29: 80-85

42. Thompson RL, Margetts Bm, Speller VM, McVey D. The health education Authority's health and lifestyle survey 1993. Who are the low fruit and vegetable consumers?. Journal of Epidemiology and Community Health, 1999; 53: 294 - 299

43. Lallukka T, Lahti-Koski M, Ovaskainen ML. Vegetable and fruit consumption and its determinants in young Finnish adults. Scandinavian Journal of Nutrition, 2001; 45: $120-126$

44. Billson H, Pryer JA, Nichols R. Variation in fruit and vegetable consumption among adults in Britain. An analysis from the dietary and nutritional survey of British adults. European Journal of Clinical Nutrition, 1999; 53: 946 - 952

45. Agudo A, Amiano P, Barcos A, Barricarte A et al.. Dietary intake of vegetables and fruits among adults in five regions of Spain. EPIC Group of Spain. European Prospective Investigation into Cancer and Nutrition. European Journal of Clinical Nutrition., 1999; 53(3):174-80.

46. Soerjomataram I, Oomen D, Lemmend V et al. Increased consumption of fruit and vegetables and future cancer incidence in selected European countries. European Journal of Cancer, 2010; 46: 2563 - 2580

47. Hall JN, Moore S, Harper SB, Lynch JW. Global variability in fruit and vegetable consumption. American Journal of Preventive Medicine, 2009; 36 (5): 402 - 409

48. DTU Fødevareinstituttet 2010. Dietary habits in Denmark 2003 - 2008. http://www.foedevarestyrelsen.dk/SiteCollectionDocuments/25_PDF_word_filer\%20t i1\%20download/07kontor/DanskernesKostvaner2010.pdf 
49. Statens Folkhelsoinstitutt, Sverige 2011. Frukt - og grønsakskonsumptionen i Sverige. Utdrag från den nationella folkhelsoenkäten over läns- och kommundata 2007 - 2010. http://www.fhi.se/PageFiles/11941/A2011-05-Frukt-och-gronsakskons-iSv,\%20HLV-2007-2010.pdf

50. Opplysningskontoret for brød og korn. http://www.brodogkorn.no/

51. Bugge AB, Lavik R, Lillebø K. Nordmenns brød og kornvarer - i stabilitet og endring. SIFO-rapport nr 2-2008 [nor].

52. Galobardes B, Lynch J, Smith GD. Measuring socioeconomic position in health research. British Medical Bulletin, 2007; 81 and 82: 21 - 37

53. Holmboe-Ottesen G, Wandel M, Mosdøl A. Sosiale ulikheter og kosthold. Tidsskrift for den Norske Lægeforening, 2004; 11 (124): 1526 - 1528

54. Ball K, Crawford D. Socioeconomic inequalities in fruit and vegetable intakes. In Bioactive foods in promoting health. Academic press, Amsterdam. 2010. pp 195 - 203

55. Hulshof KFAM, Brussaard JH, Kruizinga AG, Telman J, Löwik MRH. Socioeconomic status, dietary intake and 10y trends: the Dutch national food consumption survey. European Journal of Clinical Nutrition, 2003; 57: 128 - 137

56. De Irila-Estevez J, Groth M, Johansson L, Oltersdorf U, Prättäla R, Martinez-Gonzales MA. A systematic review of socio-economic differences in food habits in Europe: consumption of fruit and vegetables. European Journal of Clinical Nutrition, 2000; 54 : 706- 714

57. Guagliardo V, Lions C, Darmon M, Verger P. Eating at the university canteen. Association with socioeconomic status and healthier self-reported eating habits in France. Appetite, 2011; 56: 90 - 95

58. Desmuhk-Taskar P, Nicklas TA, Yang SJ, Berenson GS. Does food group consumption vary by differences in socioeconomic, demographic and lifestyle factors in young adults. The Bogalusa Heart Study. Journal of the American Dietetic Association, 2007; 107: $223-234$

59. Delva J, O'Malley PM, Johnston LD. Racial/Ethnic and socio-economic status differences in overweight and health-related behaviours among American students. National Trends 1986 - 2003. Journal of Adolescent Health, 2006; 39: 536 - 545

60. Mosd $\varnothing 1$ A. Dietary assessment - the weakest link? A dissertation exploring the limitations to questionnaire based methods of dietary assessment. $\mathrm{PhD}$-thesis, University of Oslo, 2004 
61. Newby PK, Muller D, Hallfrisch J, Andres R, Tucker KL. Food patterns measured by factor analysis and anthropometric changes in adults. American Journal of Clinical Nutrition, 2004; 80: $504-513$

62. Hu FB, Rimm EB, Stampfer MJ, Ascherio A, Spiegelmann D, Willett WC. Prospective study of major dietary patterns and risk of coronary heart disease in men. American Journal of Clinical Nutrition, 2000; 72: 912 - 921

63. Perrin AE, Dallongeville J, Ducimetiere P, Ruidavets JB, Schlienger JL, Arveiler D, Simon C. Interactions between traditional regional determinants and socio-economic status on dietary patterns in a sample of French men. British Journal of Nutrition, 2005; 93: 109 - 114

64. Råberg Kjøllesdal MK, Holmboe-Ottesen G, Wandel M. Associations between food patterns, socio-economic position and working situation among working women and men in Oslo. European Journal of Clinical Nutrition, 2010; 64: 1150 - 1157

65. Mikkilä V, Räsänen L, Raitakari OT, Viikari J. Consistent dietary patterns identified from childhood to adulthood: the Cardiovascular Risk in Young Finns study. British Journal of Nutrition, 2005; 93: 923 - 931

66. Bellisle F, Monneuse MO, Steptoe A, Wardle J. Weight concerns and eating patterns: a survey of university students in Europe. International Journal of obesity, 1995; 19: 723- 730

67. Cohane GH, Pope HG. Body image in boys: a review of the literature. International Journal of eating disorders, 2001;29.373 - 379

68. O'Dea J, Rawatorne PR. Male adolescents identify their weight gain practiced, reasons for desired weight gain, and sources of weight gain information. Journal of the American Dietetic Association, 2001; 101 (1):105 - 107

69. Neumark-Sztainer D, Story M, Falkner NH, Beuhring T, Reshnick MD. Sociodemographic and personal characteristics of adolescents engaged in weight loss and weight/muscle gain behaviours: who is doing what? Preventive Medicine, 1999; 28: $40-50$

70. Montano DE, Kasprzyk D, Taplin SH. The theory of reasoned action and the theory of planned behaviour. In Glanz K, Lewis FM, Rimer BK eds. Health Behaviour and Health Education: Theory, research and practice. pp $85-112$

71. Ajzen I. The theory of planned behaviour. Organizational Behaviour and Human Decision Process, 1991; 50: 179 - 211 
72. Baranowski T, Perry CL, Parcel GS. How individuals, environments, and health behaviour interact. In Glanz K, Lewis FM, Rimer BK eds. Health Behaviour and Health Education: Theory, research and practice. pp. 153 - 178

73. De Vries H, Dijkstra M, Kuhlman P. Self-efficacy: The third factor besides attitudes and subjective norm as a predictor of behavioural intentions. Health Education Research, 1988; 3: 273 - 282

74. Brug J, Lechner L, De Vries H. Psychosocial determinants of fruit and vegetable consumption. Appetite, 1995; 25; 285 - 296

75. Bolman C, de Vries H. Psycho-social determinants and motivational phases in smoking behaviour of cardiac inpatients. Preventive Medicine, 1998; 27: 738 - 747

76. Steptoe A, Perkins-Porras L, McKay C, Rink E, Hilton S, Cappuccion FP. Psychological factors associated with fruit and vegetable intake and with biomarkers in adults from a low-income neigborhood. Health Psychology, 2003; 22 (2): 148 - 155

77. Ha EJ, Caine-Bish N. Effect of nutrition intervention using a general nutrition course for promoting fruit and vegetable consumption among college students. Journal of Nutrition education and behaviour, 2009; 41(2): 103 - 109

78. Krebs-Smith SM, Kantor LS. Choose a variety of fruits and vegetables daily: understanding the complexities. The Journal of Nutrition, 2001, Supplement, 487 501

79. Kolodinsky J, Harvey-Berino JR, Berlin L, Johnson RK, Reynolds TW. Knowledge of current dietary guidelines and food choice by college students: better eaters have higher knowledge of dietary guidelines. Journal of the American Dietetic Association, 2007; 107: 1409 - 1413

80. Shaikh AR, Yaroch AL, Nebeling L, Yeh MC, Resnicow K. Psychosocial predictors of fruit and vegetable consumption in adults. A review of the literature. American Journal of Preventive Medicine, 2008; 34 (6): 535 - 543

81. Baranowski T, Weber Cullen K, Baranowski J. Psychosocial correlates of dietary intake: Advancing dietary intervention. Annual Review of Nutrition, 1999; 19: 17 - 40

82. Harnack L, Block G, Subar A, Lane S, Brand R. Association of cancer preventionrelated nutrition knowledge, beliefs, and attitudes to cancer prevention dietary behaviour. Journal of the American Dietetic Associations, 1997; 97: 957 - 965

83. Glanz K, Basil M, Maibach E, Goldberg J, Snyder D. Why Americans eat what they do: taste, nutrition, cost, convenience, and weight control concerns as influences on 
food consumption. Journal of the American Dietetic Association, 1998; 98: 1118 1126

84. Satia JA, Kristal AR, Patterson RE, Neuhoser ML, Trudeau E. Psychosocial factors and dietary habits associated with vegetable consumption. Nutrition, 2002; 18: 247 254

85. Perez-Rodrigo C, Ribas L, Serra-Majem LI, Aranceta J. Food preferences of Spanish children and young people: the enKid study. European Journal of Clinical Nutrition, 2003; 57 (supplement 1): S45 - S48

86. Larson NI, Neumark-Sztainer DR, Harnack L, Wall MM; Story MT, Eisenberg ME. Fruit and vegetable intake correlates during the transition to young adulthood. American Journal of Preventive Medicine, 2008; 35 (1): 33 - 37

87. Babicz-Zielinska E. Food preferences among the Polish young adults. Food Quality and preference, 1999; 10: 139 -145

88. Drewnowski A, Henderson SA, Levine A, Hann C. Taste and food preferences as predictors of dietary practices in young women. Public Health Nutrition, 1999; 2 (4): $513-519$

89. Dinehart ME, Hayes JE, Bartoshuk LM, Lanier SL, Duffy VB. Bitter taste markers explain variability in vegetable sweetness, bitterness and intake. Physiology and behaviour, 2006; 87: $304-313$

90. Kaminski LC, Henderson SA, Drewnowski A. Young women's food preferences and taste responsiveness to 6-n-propylthiouracil (PROP). Physiology and behaviour, 2000; 68: $691-697$

91. Blanchard CM, Fisher J, Sparling PB, Shanks TH, Nehl E, Rhodes RE, Courneya KS, Baker F. Understanding adherence to 5 servings of fruits and vegetables per day: A theory of planned behaviour perspective. Journal of Nutrition Education and Behaviour, 2009; 41 (1): 3 - 10

92. Herbert G, Kennedy O, Lobb A, Butler LT. Gender differences in young adults beliefs and behaviour towards fruit and vegetable consumption. Appetite, 2008; 51 (3): 758

93. Horacek TM, White A, Betts NM, Hoerr S, Georgiou C, Nitzke S, Ma J, Greene G. Self-efficacy, perceived benefits, and weight satisfaction discriminate among stages of change for fruit and vegetable intakes for young men and women. Journal of The American Dietetic Association, 2002; 102: 1466 - 1470

94. Chung SJ, Hoerr SL. Predictors of fruit and vegetable intakes in young adults by gender. Nutrition Research, 2005; 25: 453 - 463 
95. Connor M, Armitage CJ. Extending the theory of planned behaviour: A review and avenues for further research. Journal of Applied Social Psychology, 1998; 28: 1430 1464

96. Conner M, Norman P, Bell R. The Theory of planned behaviour and healthy eating. Health Psychology, 2002; 21 (2); $194-201$

97. Oulette JA, Wood W. Habit and intention in everyday life: The multiple processes by which past behaviour predicts future behaviour. Psychological Bulletin, 1998; 24 (1): $54-74$

98. Lien N. Stability and predictors of eating behaviours during adolescence and early adulthood. PhD-thesis, University of Oslo, 2002

99. Bere E. Increasing school-children's intake of fruit and vegetables. Fruit and vegetables make the marks. PhD-thesis, University of Oslo, 2004

100. Backman D, Gonzaga G, Sugerman S, Francis D, Cook S. Effect of fresh fruit availability at worksites on the fruit and vegetable consumption of low-wage employees. Journal of Nutrition Education and Behaviour, 2011; 43: S113 - S121

101. Lassen AD, Ernst L, Poulsen S, Andersen KK, Hansen GL, Biltoft-Jensen A, Tetens I. Effectiveness of a canteen take away concept in promoting healthy eating patterns among employees. Public Health Nutrition, 2001; 1: 1 - 7

102. Lassen A, Thorsen AV, Trolle E, Elsig M, Ovesen L. Successful strategies to increase the consumption of fruits and vegetables: results form the Danish '6-a-day' work-site canteen model study. Public Health Nutrition, 2003; 7 (2): 263 - 270

103. Brug J, Debie S, van Assema P, Weijts W. Psychosocial determinants of fruit and vegetable consumption among adults: results from focus groups interviews. Food Quality and Preferences, 1995; 6: 99 - 107

104. Franko DL, Cousineau TM, Trant M, Green TC, Rancourt D, Thompson D, Ainscough J, Mintz LB, Ciccazzo M. Motivation, self-efficacy, physical activity and nutrition in college students: randomized controlled trial of an internet-based education program. Preventive Medicine, 208; 47: 369 - 377

105. Ha EJ, Caine-Bish N. Interactive introductory nutrition course focusing on disease prevention increased whole grain consumption by college students. Journal of Nutrition Education and Behaviour, 2011, in press

106. Ruud JS, Betts N, Kritch K, Nitzke S, Lohse B, Boeckner L. Acceptability of stagetailored newsletters about fruit and vegetables by young adults. Journal of the American Dietetic Association, 2005; 105: 1774 - 1778 
107. Cousineau TM, Franko DL, ciccazzo M, Goldstein M, Rosenthal E. Web-based nutrition education for college students: is it feasible. Evaluation and Program Planning, 2006; 29.23 - 33

108. Brevik A. Biomarkers for the intake of fruits, vegetables and diary fat. PhD-thesis, University of Oslo, Faculty of Medicine, 2005

109. Brouwer IA. Folic acid, folate and homocysteine: human intervention studies. European Journal of Obstetics \& Gynecology and Reproductive Biology, 2000; 92: $183-184$

110. Sandström B, Marckmann P, Bindslev N. An eight-month controlled study of low-fat high-fibre diet: effects on blood lipids and blood pressure in healthy young subjects. European Journal of Clinical Nutrition, 1992; 46: 95 - 109

111. Djuric Z, Ren J, Blythe J, VanLoon G, Sen A. Mediterranean dietary intervention in healthy American women changes plasma carotenoids and fatty acid in distinct clusters. Nutrition Research, 2009; 29: 156 - 163

112. Brevik A, Vollset SE, Tell GS, Refsum H, Ueland PM, Løken EB, Drevon CA, Andersen LF. Plasma concentration of folate as a biomarker for the intake of fruit and vegetables: the Hordaland homocysteine study. American Journal of Clinical Nutrition, 2005; 81: $434-439$

113. Venn BJ, Mann JI, Williams SM, Riddell RJ, Chisholm A, Harper MJ, Aitken W. Dietary counselling to increase natural folate intake: a randomized, placebo-controlled trial in free-living subjects to assess effects on serum folate and plasma total homocysteine. American Journal of Clinical Nutrition, 2002; 76: 758 - 765

114. Do M, Kattelmann K, Boekner L, Greene G, White A, Hoerr S, Horacek T, Lohse B, Philips B, Nitzke S. Low-income young adults report increased variety in fruit and vegetable intake after a stage-tailored intervention. Nutrition Research, 2008; $28: 517$ $-522$

115. Sorensen G, Linnann L, Hunt MK. Worksite-based research and initiatives to increase fruit and vegetable consumption. Preventive Medicine, 2004; 39: S94 - S100

116. Sorensen G, Stoddard A, Hunt MK et al. The effects of a health promotion - health protection intervention on behaviour change: The WellWorks Study. American Journal of Public Health, 1998; 88 (11): 1685 - 1690

117. Lassen AD, Thorsen AV, Sommer HM, Fagt S, Trolle E, Biltoft-Jensen A, Tetens I. Improving the diet of employees at blue-collar worksites: results from the 'food at work' intervention study. Public Health Nutrition, 2011; 14 (6): 965 - 974 
118. Tilley BC, Glanz K, Kristal AR, Hirst K, Li S, Vernon SW, Myers R. Nutrition intervention for high-risk auto-workers: results of the Next Step Trial. Preventive Medicine, 1999, 28: 284 - 292

119. Beresford SAA, Thompson B, Feng Z, Christianson A, McLerran D, Patrick DL. Seattle 5 a day Worksite Program to increase fruit and vegetable consumption. Preventive Medicine, 2001; 32: 230 - 238

120. Pomerleau J, Lock K, Knai C, McKee M. Interventions designed to increase adult fruit and vegetable intake can be effective: a systematic review of the literature. Journal of Nutrition, 2005; 135: $2486-2495$

121. Jeffery RW, French SA, Raether C, Baxter J. An environmental intervention to increase fruit and salad purchases in a cafeteria. Preventive Medicine, 1994; 23: 788 792

122. Borg P, Fogelholm M, Kukkonen-Harjula K. Food selection and eating behaviour during weight maintenance intervention and 2-y follow up among obese men. International Journal of Obesity, 2004; 28, 1548 - 1554

123. Parker L, Fox A. The Peterborough Schools Nutrition Project: a multiple intervention programme to improve school-based eating in secondary schools. Public Health Nutrition, 2001; 4 (6): 1221 - 1228

124. Evans AE, Sawyer-Worse MK. The Right Bite Program: A theory-based nutrition intervention at a minority college campus. Journal of The American Dietetic Association, 2002; 102 (supplement 3): S89 - S93

125. O’Neil CE, Nicklas TA. Gimme 5: an innovative, school-based nutrition intervention for high school students. Journal of The American Dietetic Association, 2002; 102 (supplement 3): S93 - S96

126. Stea TH. Changes in health risk profile after a 5-months dietary intervention focusing on increased intake of fruits, vegetables and whole grain bread among young male adults. PhD-thesis, University of Oslo, 2009

127. Stea TH, Mansoor MA, Wandel M, Uglem S, Frølich W. Changes in predictors and status of homocysteine in young male adults after a dietary intervention with vegetables, fruits and bread. European Journal of Nutrition, 2008; 47 (4): 201 - 209

128. Bandura A. Social foundations for thought and action: A social cognitive Theory. Prentice Hall, Englewood cliffs. 1986

129. Blaker, Aarsland. Household measures and weight of food, The Norwegian National Association for Nutrition and Health, 1989. 
130. Roos E, Prättäla R. Meal pattern and nutrient intake among adult Finns. Appetite, 1997; 29: 11- 24

131. O'Brien MM, Kiely M, Galvin M, Flynn A. The importance of composite foods for estimates of vegetable and fruit intakes. Public Health Nutrition, 2003; 6 (7): 711 726

132. Kemper HC, Koppes LL, de Vente V, van Lenthe FJ, van Mechelen V, Twisk JW, Post GB. Effects of health information in youth and young adulthood on risk factors for chronic diseases: 20 year study results from the Amsterdam Growth and Health Longitudinal Study. Preventive Medicine, 2002; 35: 533 - 539

133. Siddiqui O, Flay BR, HU FB. Factors affecting attrition in longitudinal smoking prevention study. Preventive Medicine, 1996; 25: 554 - 560

134. Goldberg M, Chastang JF, Zins M, Niedhammer I, Leclerc A. Health problems were the strongest predictor of attrition during follow up of the GAZEL cohort. Journal of Clinical Epidemiology, 2006; 59: 1213 - 1221

135. Hewitt CE, Kumaravel B, Dumville JC, Torgerson DJ. Assessing the impact of attrition in randomized controlled trials. Journal of Clinical Epidemiology, 2010; 63: $1264-1270$

136. Willet W, Lenart E. Reproducibility and validity of food frequency questionnaires. In Nutritional Epidemiology, second edition. Editor Walter Willett. New York, Oxford University Press. p.101 - 141

137. Lillegaard IT. Validation of dietary assessment methods used among Norwegian children and adolescents. PhD-thesis, University of Oslo, 2009

138. Pallant J. SPSS survival manual. SPSS inc, Chicago. 2001. p 6 -7

139. Nelson M, Bingham S. Assessment of food consumption and nutrient intake. In Design concepts in nutritional epidemiology, second edition. Edited by: BM Margetts and M Nelson. Oxford University Press, 1997. p 123 - 169

140. Nelson M. The validation of dietary assessment. Edited by: BM Margetts and M Nelson. Oxford University Press, 2001. p 241 - 272

141. Hebert JR, Clemow L, Pbert L, Ockene IS, Ockene JK. Social desirability bias in dietary self-report may compromise the validity of dietary intake measures. International Journal of Epidemiology, 1995, 24: 389 - 398

142. Baxter SD, Smith AF, Litaker MS, Baglio ML, Guinn CH, Shaffer NM. Children's social desirability and dietary reports. Journal of Nutrition Education and Behaviour, 2004; 36: $84-89$ 
143. Tarasuk V, Beaton GH. The nature and individuality of within-subject variation in energy intake. American Journal of Clinical Nutrition, 1991; 54: 120 - 130

144. Yunsheng MA, Olendzki BC, Pagoto SL, Hurley TG, Magner MP, Ockene IS, Schneider KL, Merriam PA, Hèbert JR. Number of 24-hour diet recalls needed to estimate energy intake. Annals of Epidemiology, 2009; 19: 553 - 559

145. Buzzard M. 24-hour recall and food records methods. In Nutritional Epidemiology, second edition. Editor Walter Willett. New York, Oxford University Press. p. 50 - 73

146. Trudeau E, Kristal AR, Li S, Patterson RE. Demographic and psychosocial predictors of fruit and vegetable intakes differ: implications for dietary interventions. Journal of the American Dietetic Association, 1998; 98: 1412 - 1427

147. Andersen LF, Bere E, Kolbjørnsen N, Klepp KI. Validity and reproducibility of selfreported intake of fruit and vegetables among 6th graders. European Journal of Clinical Nutrition, 2004; 58: 771 - 777

148. Lien N, Lytle LA, Klepp KI. Stability in consumption of fruit, vegetables and sugary foods in a cohort from age 14 to age 21. Preventive Medicine, 2001; 33: $217-226$

149. Bingham CML, Jallinoja P, Lahti-Koski M, Absetz P, Paturi M, Pihlajamäki H, Sahi T, Uutela A. Quality of diet and food choices of Finnish young men: a sociodemographic and health behaviour approach. Public Health Nutrition, 2010; 13 (6A): $980-986$

150. Achterberg C, Miller C. Is one theory better than another in nutrition education? A viewpoint: more is better. Journal of Nutrition Education and Behaviour, 2004; 36 (1): $40-42$

151. Baranowski T, Lin LS, Wetter DW, Resnicow K, Hearn M. Theory as mediating variable: Why aren't community interventions working as desired? Annals of Epidemiology, 1997; 7: 89-95

152. Conner M, Sheeran P, Norman P, Armitage CJ. Temporal stability as a moderator of relationships in the Theory of Planned Behaviour. British Journal of Social Psychology, 2000; 39: 469 - 493

153. Baranowski T, Smith M, Hearn MD, Lin LS, Baranowski J, Doyle C et al. Patterns of childrens fruit and vegetable consumption by meal and day of week. Journal of the American College Nutrition, 1997; 16: 216 - 223

154. Larson NI, Neumark-Sztainer D, Hannan PJ, Story M. Family meals during adolescence are associated with higher diet quality and healthful meal patterns during 
young adulthood. Journal of the American Dietetic Association, 2007, 107: 1502 1510

155. Mäkelä J, Kjærnes U, Ekström MP, Fürst EL, Gronov J, Holm L. Nordic Meals: methodological notes on a comparative survey. Appetite, 1999; 32: 73 - 79

156. Statistisk Sentralbyrå. Levekårsunders $\varnothing$ kelsen 2005. Levevaner etter alder [nor]. http://www.ssb.no/emner/03/01/helseforhold/tab/sb_3_2005_1.html

157. Winkler E, Turrell G. Confidence to cook vegetables and the buying habits of Australian Households. Journal of the American Dietetic Association, 2009; 109 (10), 1759-1768

158. Berg CM, Lappas G, Strandhagen G, Wolk A, Torèn K, Rosengren A, Aires N, Thelle DS, Lissner L. Food patterns and cardiovascular disease risk factors: The Swedish Intergene research program. American Journal of Clinical Nutrition, 2008; 88: 289 297

159. Ammermann AS, Lindquist CH, Lohr KN, Hersey J. The efficacy of behavioural interventions to modify dietary fat and fruit and vegetable intake: a review of the evidence. Preventive Medicine, 2002; 35: 25 - 41 
Appendices 

Paper I

Preferences and perceptions of personal vegetable consumption: A study among young men in the Norwegian National Guard 

Paper II

Correlates of vegetable consumption among young men in the Norwegian National Guard 



\section{Paper III}

Body weight, weight perceptions and food intake patterns. A cross-sectional study among male recruits in the Norwegian National Guard 



\title{
Body weight, weight perceptions and food intake patterns. A cross-sectional study among male recruits in the Norwegian National Guard
}

\author{
Solveig Uglem ${ }^{1}$, Tonje H Stea ${ }^{2}$, Wenche Frølich ${ }^{3}$ and Margareta Wandel ${ }^{{ }^{*}}$
}

\begin{abstract}
Background: Young men tend to have a low intake of vegetables and fruit. Unfortunately, this group is difficult to reach with health information. Furthermore, knowledge about weight perceptions and the relationship to food behaviour among young men is scant. The purpose of this study was to explore the relationship between BMI, health and weight perceptions and food intake patterns among young men in the military.

Methods: Data were collected with a 4-day food diary among 578 male recruits (age 18-26, mean 19.7) in the Norwegian National Guard (response rate 78\%), in addition to a questionnaire, including questions about health and weight perceptions, and food frequency when still living at home. Weight and height were objectively measured. Food patterns were explored with principal component analysis, based on the diary data. A multivariate linear regression analysis determined the association between BMI and food patterns, and attitudes to health and slenderness, adjusting for smoking, physical activity and phase of data collection.

Results: Twenty eight percent of the recruits were overweight/obese (BMl $\left.>25 \mathrm{~kg} / \mathrm{m}^{2}\right)$. Two-thirds meant that it is important for them to be slender, and these recruits reported more of both light $(p=0.025)$ and hard $(p=0.016)$ physical activity than the others. It was a positive association between the recruits' food frequency at home, and the amount of intake in the military camp for several food items. A principal component analysis identified three distinct food patterns, loading on 1) plant foods, 2) fast food/soft drinks, 3) milk/cereals. Those who stated that it is important for them to be slender, or to have good health, did not have significantly different food intake patterns than the others. BMI was inversely related to scores on the plant food pattern, and positive attitudes to slenderness.

Conclusion: The majority of the recruits find it important to be slender. This orientation had a bearing on their physical activity pattern, but less on the food intake pattern. The data also indicate that subjects with high intakes of plant foods were less likely to have a high BMI than others. It is important to raise awareness of healthy eating in young men.
\end{abstract}

Keywords: weight perception BMI, food intake patterns

\section{Background}

Young men are among the population groups that are most difficult to reach with health and nutrition information. They are also among the groups with the lowest intake of fruits and vegetables [1,2]. This is alarming since dietary patterns formed during early years may

\footnotetext{
* Correspondence: margareta.wandel@medisin.uio.no

'Department of Nutrition, Institute for Basic Medical Sciences, University of Oslo, P.O Box 1046 Blindern, N-0316 Oslo, Norway

Full list of author information is available at the end of the article
}

have implications for the risk of overweight/obesity and non-communicable diseases later in life [3,4]. Early adulthood, when moving away from home, is the time when changes in food behaviour are most likely to occur. However, there are also studies showing that dietary habits formed early in life track into adulthood [5-8].

There is limited knowledge about weight perceptions and how this is related to food behaviour among young men. Research has shown that men are less concerned about body image and weight than women $[9,10]$. In 
recent years, however, an increased concern about body image among men is observed. In a review from 2001, Cohane and Pope [10] observed that the ideal body image among boys varied; some boys had a thin ideal while others had a heavier one. Data from some Western societies indicate that a slender, but muscular body shape often is valued for men [11]. A survey among European university students showed restriction in intake of snacks among both men and women who were dieting [12]. However, studies have shown that women rely more on dieting and are more likely to avoid fattening food than men.

The aims of the present study were to assess food intake patterns, health and weight perceptions and BMI, and to explore the relationships between these aspects in a group of young men in the military service of Norway. The specific questions were: Does the food intake in the military reflect food consumption at home? How important is it for young men to be slender, and does the preference for slenderness influence the food and the physical activity patterns? To which extent do food patterns and attitudes towards health and slenderness relate to $\mathrm{BMI}$ ?

A military camp is one of the best places to reach a broad variety of young men in Norway, as compulsory military service is practised (Act of 17 July 1953). At Vaernes Military Training Centre, where our data were collected, the recruits came from all over the country and all social classes were represented.

\section{Methods}

\section{Participants}

A total of 739 eligible recruits (aged 18 to 26) from The Norwegian National Guard at Vaernes, a military training centre near Trondheim, Norway, were asked to participate in the baseline surveys in January 2004 ( $\mathrm{n}=$ 231 ) and July 2004 ( $n=508)$. A total of 89 recruits refused to participate in the study. Of the remaining 650 subjects, 72 were excluded from the analysis due to incomplete data sets. The analyses are based on the remaining 578 subjects, $78 \%$ of the original sample.

\section{Setting}

Most young men in Norway enrolled in the military service, come there directly after finishing high school and a life at home with their parents. Our data support this: $80 \%$ were 20 years or younger, and $94 \%$ had completed high school, but had no other education. Only 14 participants were above 23 years of age.

In most military camps in Norway, the soldiers have the opportunity to have free meals in a mess hall, or they can buy foods and beverages on their own expenses in a canteen. Both the mess hall and the canteen are located in the camp at Vaernes. The soldiers may also choose to buy foods, snacks and beverages in cafeterias/ restaurants or grocery stores outside the military camp. Vending machines offering sugar-sweetened soft drinks and snacks were available at several places in the camp.

\section{Height, weight and body mass index}

Body mass index, BMI, was computed from measured height and weight by personnel at Vaernes Military Training Centre, as weight/height ${ }^{2}$ in $\mathrm{kg} / \mathrm{m}^{2}$ (Quetelet's index). BMI was classified into underweight (BMI < 18.5), normal (BMI 18.5 - 25), overweight (BMI 25-30) and obesity (BMI > 30), according to WHO [13].

\section{Survey instruments}

Two survey instruments, a questionnaire about food habits, perceptions and attitudes and a diary, were used to assess the participants' consumption of foods and drinks and to identify their weight perceptions. The survey period started one week after enrollment (for both groups of enrollment) in the military service. The participants filled in the questionnaire on the first day in the survey period and completed the diary each day on four consecutive working days. Because it was important to keep the setting the same for all recruits, and the consumption at home and in the military separate from each other, they were asked to record food intake only on weekdays.

Both the diary and the questionnaire were tested in a pilot study with 12 soldiers in another military camp in Norway (Lutvann), and small amendments were made on the basis of the results and comments from this group. The participants did not report problems in remembering the frequency of consumption of the selected food items when still living at home. The revised survey instruments were test-retested with fairly acceptable responses over a three-week period among 63 recruits in a third military camp in Norway (Heistadmoen). Correlations between time 1 and 2 were from 0.11 to 0.55 , however most responses were $0.50-0.55$. Study procedures were approved from the necessary authorities; The Norwegian Social Science Data Services, The Ministry of Health and Care Services, and The Regional Committee for Medical Research Ethics.

\section{Consumption of foods and beverages}

A validated diary developed at Department of Nutrition, University of Oslo http://www.helsedirektoratet.no/vp/ multimedia/archive/00003/IS-1019_Ungkost_vedle_3757a.pdf was modified to assess the recruits' intake of selected food items like bread and other cereals, fruits, vegetables, meat and fish for lunch and dinner, in addition to fast food, snacks and beverages, as described in Uglem et al. [14]. The diary included pre-printed questions where the participants recorded their 
consumption during the day. The modification of the diary implied that the participants filled in a number for the chosen hot dish. Furthermore, to help participants determine serving sizes, the subjects were asked to refer to photographs or weighed portion-sizes placed on a table in the mess hall. Two researchers were also present at every meal to guide the recruits in determining serving sizes. The diary also included open-ended questions where the participants recorded their consumption of fast food, cakes/biscuits or snacks bought in the canteen in the camp or in groceries/cafeterias/restaurants outside the camp. These data gave the number of days on which the participants consumed fast food, cakes/biscuits or snacks in the survey period.

To estimate the ingredients included in hot dishes, recipes were collected from the kitchen personnel. Intake of beverages (soft drinks, juice and milk in g/day) was calculated based on the frequency intake of glasses of the beverage, multiplied by the serving size of a glass. One glass was defined as 150 gram. The intake of vegetables, fruits and cereals (in g/day) were calculated as the product of frequency of intake and serving sizes, and total consumption of bread as number of bread slices and sizes of the slices. Average daily consumption (g/day) of each food item for each recruit in the survey period was obtained by adding their total consumption and divide by the number of days on which each subject kept records. The recruits' consumption of fast food and snacks in the survey period was counted from the food diaries. The scale ranged from 0 to 4 days.

\section{Scales and coding}

Weight perception was measured by the statement: 'It is important for me to be slender' and was scored on a fivepoint bipolar scale (strongly disagree to strongly agree). It was coded to two dichotomous variables; the first coded those who strongly agree versus the others. The second coded those who agree (strongly and to some extent) versus the others. Health perception was measured with the statement 'It is important for me to be in good health'. The response categories and coding were the same as for the question about slenderness. The time that the recruits presently spent in light or hard physical activity was measured with the question: "How would you describe your physical activity. Please give the average number of hours per week in each category of light and hard physical activity: Light activity (not sweating/out of breath); Hard activity (sweating/out of breath)". Their smoking habits were measured with questions about number of cigarettes/day and length of smoking, and recoded to current smokers and current non-smokers

Frequency of consumption of vegetables, fruit, breakfast cereals and snacks when still living at home, was collected through the question 'How often did you eat (the food) when you still lived at home'. Responses were measured on a six-point scale ranging from less than once a week to several times a day, and recoded to 3 categories 1) two or less servings/week 2) 3-6 servings/ week 3 ) one or more daily servings.

\section{Data analysis}

All analyses were performed using SPSS for windows, version 18. For description of participant characteristics and intake of different foods in the military camp, frequencies and means with $95 \%$ confidence intervals were reported, Pearsons $\chi 2$ test was used to analyse differences in consumption of snacks and fast foods in different groups, Independent samples t-tests were used to determine differences in means of food intake in grams, BMI in $\mathrm{kg} / \mathrm{m}^{2}$ and physical activity in hours/week between groups. ANCOVA was used to analyze differences between groups according to frequency of consumption at home and amount of consumption of the same foods in the military camp, adjusted for the phase of data collection.

A principal component analysis was carried out in order to study whether distinct food patterns could be discerned from the food intake data in the military camp. The factors were rotated by an orthogonal transformation. Both the eigenvalue $(>1)$ and the scree plot was used to decide the number of factors extracted. In order to adjust for potential seasonal variation, the scores from each phase of data collection (January and July) were divided into tertiles which designated high, medium and low groups of scoring on the three food patterns. These were entered into a multivariate regression analysis in order to determine the association between BMI and food patterns, and attitudes to health and slenderness. The analysis was adjusted for possible confounders, such as smoking, physical activity. Since BMI may vary according to season, this model was also adjusted for phase of data collection.

\section{Results \\ Participant characteristics}

The recruits were between 18 and 26 years of age, with a mean age of 19.7 years (Table 1 ). The majority were within normal weight (BMI 18.5-25 kg/m²). Mean BMI was $23.2 \mathrm{~kg} / \mathrm{m}^{2} ; 28.2 \%$ had BMI $>25 \mathrm{~kg} / \mathrm{m}^{2}$, including $4 \%$ that had BMI $>30 \mathrm{~kg} / \mathrm{m}^{2}$. Thirty three per cent of the recruits were current smokers. About $40 \%$ reported that they had hard physical activity two hours per day or less, and $14 \%$ reported that they hardly performed any hard activity at all during the week.

\section{Food consumption at home and in the military}

The results showed a positive association between the recruits' frequency of consumption when still living at 
Table 1 Participant characteristics $(\mathrm{N}=\mathbf{5 7 8})$

\begin{tabular}{lc}
\hline Variable & Recruits \\
\hline Age, mean years, (Cl) & 23.7 (19.6-19.8) \\
BMI, mean kg/m², (Cl) & 5.4 \\
BMI $<18.5, \%$ & 66.4 \\
BMI 18.5-25, \% & 24.2 \\
BMI $>25-30, \%$ & 4.0 \\
BMI >30, \% & \\
Smoking status, \% & 33.2 \\
Current smokers & 66.4 \\
Nonsmokers & \\
Light physical activity, \% & 7.0 \\
$<1$ h/week & 22.6 \\
1-2 h/week & 27.5 \\
$3-4$ h/week & 42.9 \\
$\geq 5$ h/week & \\
Hard physical activity, \% & 13.6 \\
$<1$ h/week & 27.4 \\
1-2 h/week & 27.4 \\
$3-4$ h/week & 31.7 \\
$\geq 5$ h/week & \\
\hline &
\end{tabular}

home and the amount of intake in the military camp with regard to several food items (table 2). Those who reported daily consumption of vegetables, fruits, breakfast cereals and sugared soft drinks when living at home, had considerable higher intake of these food items and drinks in the military camp, compared to those who had less consumption of these foods at home. Among those who had a daily consumption of snacks at home, there were $37 \%$ who bought snacks during the 4 days of registration, compared to $16 \%$ among those who had snacks less than once/week at home (not shown in the table).

\section{Attitudes towards health and slenderness}

The majority of the recruits (70\%) strongly agreed that it was important for them to have a good health. Furthermore, 31\% strongly agreed, and 35\% agreed to some extent that it was important for them to be slender. Thirty seven percent of those who strongly agreed that it was important for them to have good health, also strongly agreed that it is important for them to be slender. There were only small and insignificant differences in the consumption of snacks, fast food and soft drinks, between those who agreed (strongly or to some extent) that it was important for them to be slender, and the others. A higher intake of fruits was observed among subjects who agreed that it was important for them to be slender compared to those who disagreed (average difference $34 \mathrm{~g} /$ day $(\mathrm{p}<0.05)$ ). The same relationship was shown for juice, with a mean difference of $52 \mathrm{~g} /$ day $(\mathrm{p}<0.05)$. Those who meant that it was important for
Table 2 Frequency intake of selected food items at home related to amount intake in the camp, adjusted for phase of intake into the military.

\begin{tabular}{|c|c|c|c|}
\hline \multirow{2}{*}{$\begin{array}{l}\text { Food intake at home } \\
\text { Frequency of intake }\end{array}$} & \multicolumn{2}{|c|}{ Intake in the camp } & \multirow[t]{2}{*}{ p-value } \\
\hline & $\%$ & g/day & \\
\hline \multicolumn{4}{|l|}{ Vegetables } \\
\hline$<1 /$ week & 8 & 178 & $<0.001$ \\
\hline 1 - 2 times/week & 22 & 229 & \\
\hline 3 - 4 times/week & 32 & 238 & \\
\hline 5 - 6 times/week & 18 & 254 & \\
\hline Daily & 15 & 282 & \\
\hline Several times a day & 6 & 284 & \\
\hline \multicolumn{4}{|l|}{ Fruits } \\
\hline$<1 /$ week & 14 & 70 & $<0.001$ \\
\hline 1 - 2 times/week & 31 & 95 & \\
\hline 3 - 4 times/week & 22 & 113 & \\
\hline 5 - 6 times/week & 14 & 168 & \\
\hline Daily & 9 & 151 & \\
\hline Several times a day & 10 & 225 & \\
\hline \multicolumn{4}{|l|}{ Breakfast Cereals } \\
\hline$<1$ times/week & 65 & 55 & $<0.001$ \\
\hline 1 - 2 times/week & 22 & 67 & \\
\hline 3 - 4 times/week & 6 & 152 & \\
\hline 5 - 6 times/week & 3 & 88 & \\
\hline Daily & 2 & 178 & \\
\hline Several times a day & 1 & 119 & \\
\hline \multicolumn{4}{|c|}{ Semi- and whole grain bread } \\
\hline Seldom & 5 & 125 & $<0.001$ \\
\hline 1 - 2 slices/day & 10 & 143 & \\
\hline 3 - 4 slices/day & 28 & 156 & \\
\hline 5 - 6 slice/day & 29 & 170 & \\
\hline 7 - 8 slices/day & 15 & 192 & \\
\hline$\leq 9$ slices/day & 11 & 205 & \\
\hline \multicolumn{4}{|l|}{ Soft drinks } \\
\hline Seldom/never & 8 & 41 & $<0.001$ \\
\hline 1 - 6 glasses/week & 40 & 74 & \\
\hline 1 glass/day & 18 & 107 & \\
\hline 2 - 3 glasses/day & 22 & 152 & \\
\hline$\leq 4$ glasses/day & 11 & 227 & \\
\hline
\end{tabular}

them to be slender, reported more of both light ( $\mathrm{p}=$ $0.025)$ and heavy $(p=0.016)$ physical activity than the others.

\section{Association between BMI and life style factors}

Current smokers had a higher average BMI $\left(24 \mathrm{~kg} / \mathrm{m}^{2}\right)$ than current non-smokers (never smoked and former smokers) $\left(23 \mathrm{~kg} / \mathrm{m}^{2}\right), \mathrm{p}<0.05$. There were no significant differences in BMI between those who reported high levels of physical activity and those who reported lower levels. The same was the case for hard or light physical activity. 
Soldiers with BMI $<25 \mathrm{~kg} / \mathrm{m}^{2}$ had a higher intake of bread (average difference of $25 \mathrm{~g} /$ day, $\mathrm{p}<0.01$ ) than those with BMI $>25 \mathrm{~kg} / \mathrm{m}^{2}$. The same relationship was shown for vegetables (potatoes not included) (an average difference of $19 \mathrm{~g} /$ day, $\mathrm{p}<0.05$ ). For other food items no significant differences were observed.

\section{Food patterns, and the relationship to weight perceptions and BMI}

Three main food patterns were observed among the recruits, based on their intake in the military camp (Table 3). A positive loading refers to a positive association between the food item and the factor, and a negative loading an inverse association [15]. The first pattern loaded positively on fruits, juices, potatoes, vegetables and bread, and was called Plant foods. The second pattern loaded positively on fast food and soft drinks and negatively on bread and was called Fast food. The last pattern loaded positively on all types of breakfast cereals and milk with an inverse association with snacks and was called Milk/cereals. Together these three patterns explained $42 \%$ of the total variance in the consumption of the selected food items among the recruits.

The scores on the three food patterns obtained in the principal component analysis were divided into tertiles and used to make variables with the same names (Plant foods, Fast foods, Milk/cereals) which were then used in further analyses. No significant differences were found in the scores of these patterns between those who stated that it is important for them to be slender or to have good health, and the others.

A regression analysis with BMI as dependent variable showed a significantly negative relationship with the highest tertile of the plant food scale obtained in the factor analysis (Table 4). The results showed that subjects who had a higher score on factor 1 indicating

Table 3 Factor loadings for the three food patterns obtained in the study

\begin{tabular}{lccc}
\hline Food item & $\begin{array}{c}\text { Plant food } \\
\text { Pattern 1 }\end{array}$ & $\begin{array}{c}\text { Fast food } \\
\text { Pattern 2 }\end{array}$ & $\begin{array}{c}\text { Milk/cereals } \\
\text { Pattern 3 }\end{array}$ \\
\hline Vegetables & 0.70 & & \\
Potatoes & 0.66 & & 0.40 \\
Fruit & 0.58 & & \\
Juice & 0.55 & & 0.58 \\
Bread & 0.35 & -0.49 & 0.62 \\
Breakfast cereals & & & -0.55 \\
Milk & & 0.70 & \\
Fast food & & & 10.64 \\
Candies & 0.34 & 0.75 & \\
Sugared soft drinks & & 13.84 & \\
\hline Explained variance(\%) & 17.76 & & \\
\hline
\end{tabular}

Table 4 BMI in relation to food patterns and attitudes towards health and slenderness

\begin{tabular}{lcc}
\hline & beta-value & p-value \\
\hline Plant food (pattern 1) & -0.123 & \\
$\quad$ Medium tertile & -0.171 & 0.060 \\
$\quad$ High Tertile & & 0.012 \\
Fast food (pattern 2) & 0.055 & 0.401 \\
$\quad$ Medium tertile & 0.093 & 0.154 \\
$\quad$ High Tertile & & \\
Milk/cereals (pattern 3) & 0.005 & 0.935 \\
$\quad$ Medium tertile & 0.031 & 0.621 \\
High Tertile & 0.055 & 0.348 \\
Attitudes towards health & -0.142 & 0.013 \\
Attitudes towards slenderness & 0.278 & \\
R & 0.042 & \\
R $^{2}$ &
\end{tabular}

Multivariate linear regression analysis. The 3 food patterns were entered as tertiles with the lowest tertile as reference. The 2 attitudes were entered as continous variables. The model was adjusted for smoking status (current smoker or not), light and hard physical activity (both in hours per week) and phase of data collection.

higher intakes of vegetables, potatoes, bread, fruits and juices, were significantly more likely to have low BMI. The two other food patterns obtained in the factor analysis, showed no relationship with BMI. In addition, those who meant that it was important for them to be slender had a significantly lower BMI. The attitudes towards health were not significantly related to BMI.

\section{Discussion}

The data from the present study showed that slenderness was a highly valued attribute among the recruits; $66 \%$ agreed (strongly or to some extent) that it was important for them to be slender. Although the attitudes towards slenderness had more bearing on physical activity than on food behaviour, BMI was negatively associated with the intake of a plant food pattern defined using a principal component analysis.

The findings concerning the importance of slendernes are in line with studies in some other Western societies [11]. In the present study, the consideration for slenderness did not lead to notable restrictions in intake of fast food, snacks or soft drinks compared to those who disagreed with the statement. This is in agreement with the observation that young men are less likely to be on a diet than women of the same age [12]. This may explain why only small differences in intake of unhealthy foods were observed among the recruits with different perceptions about the importance of being slender. There is also a possibility for underreporting these types of food items, which may have affected this relationship. 
The results from the present study showed that high consumers of unhealthy food items in the military camp also were high consumers of these foods when living at home. The same results were shown for healthy food items; those in the highest intake groups of fruits, vegetables and breakfast cereals at home continued to have higher intakes also in the camp. This suggests a substantial degree of stability in consumption habits even though they encountered a new environment. The data are in accordance with other studies from Norway reporting stability in food consumption from adolescence to young adulthood [5,7].

The principal component analysis identified three food patterns. These patterns had both similarities and differences compared with patterns derived in other studies $[8,16]$. The 'plant food' pattern had high positive factor loadings on food items considered healthy, like vegetables, potatoes, bread, fruits and juice. This pattern had some similarities with the 'prudent food pattern' derived in a study by $\mathrm{Hu}$ and co-workers [8] among men aged 40-75 years old. The mentioned factor loaded on vegetables, legumes, fruits, fish, poultry and whole-grain. The 'fast food' patterns in the present study, loaded on unhealthy food items such as fast food and soft drinks. This factor had similarities with the 'western diet pattern' observed in the study by Newby et al. [17], which had high loadings on red meat, refined grains, sweets, soft drinks and butter/margarine.

The average BMI in the present study was higher $\left(+0.7 \mathrm{~kg} / \mathrm{m}^{2}\right)$ than in an earlier study of young men in the same age group in Norway [18], but lower than among American men in the same age group [19]. A relatively high proportion (28\%) in the present study was classified as overweight or obese (BMI $>25)$.

The regression analysis showed an inverse relationship between BMI and the the highest score on the plant food pattern. This indicates that subjects with a high BMI have a lower intake of fruits, vegetables, potatoes, bread and juices compared to subjects with low BMI. Those who reported that it is important for them to be slender, also had a lower BMI. Thus, it could be argued that the higher scoring on the plant food pattern among those with lower BMI could be due to restrained eating rather than the food pattern. However, the results indicated that those who agreed strongly that it is important for them to be slender, did not score higher on the plant food pattern. Other studies have shown similar results as found in the present study $[16,17]$. In the 1982-1997 FINRISK studies, daily consumption of vegetables were inversely associated with obesity (BMI > 30) among both men and women [16]. That study also showed that obesity was associated with smoking history.
A strength of our study is the way in which the dietary data were collected. The fact that the food analyses for the hot dishes were based on known recipes which included the amounts of all ingredients, that the glass sizes were known, and that recruits could use pictures and weighed portion sizes in the mess hall when reporting portion sizes, would most likely have increased the validity of the dietary data substantially. The guidance offered by the two research workers may also have increased the validity of the intake data. However, the food intake outside the mess hall would not be of the same high quality.

A limitation of the study is that the cross-sectional design does not provide evidence of a causal relationship between food consumption pattern and BMI. Another problem may relate to underestimation of food intake. Studies have shown that overweight and obese people tend to underestimate their food intake [20-22]. Nelson [22] has argued that subjects may choose not to record food items considered as unhealthy. This may have a bearing on the relationship between BMI and food intake patterns.

Furthermore, the fact that the data on food consumption in the military was measured on weekdays, whereas the data on food consumption at home referred to the entire week may have attenuated the association between these two measures of food consumption. However, this study showed a relationship between the intake at home and the intake in the military camp for many food items, suggesting some degree of continuity in food habits.

The use of BMI as an indicator of overweight or obesity has been questioned [15]. It is possible that some of the high BMI observed might be due to muscular mass rather than body fat, which could have blurred the relationship between BMI and physical activity. Another limitation of the study is the crude measurements of physical activity, which also could have blurred the relationship between BMI and physical activity.

In interpreting the results from the present study, some aspects of the setting and study sample should be noted. Firstly, the data were collected in a military camp where the subjects have some restrictions regarding their food and beverage choices. However, they have the possibility to have their meals both in the military mess hall and the canteen, and vending machines with soft drinks were available on several places in the camp. They could also buy foods, snacks and beverages outside the military camp. Secondly, limited generalisability of the results may be due to the fact that data were collected in just one military camp. However, compulsory military service is practised in Norway and young men from all over the country and all social classes are in 
the same military camp, and thereby represented in the study sample.

\section{Conclusions}

The findings indicate that the majority of the recruits find it important to be slender. This orientation seems to have a bearing on their physical activity pattern, but less on the food intake pattern. Further, the study demonstrated that a high intake of some food items at home had a tendency to continue also in the military camp. In the principal component analysis a factor loading on plant foods was derived and further analysis showed that subjects with high intakes of plant foods had low BMI. More studies are needed to investigate the stability in food patterns over time, and to investigate the relationship between food patterns and risk factors for chronic diseases.

\section{Acknowledgements}

The work was funded by The Norwegian Research Council. The authors want to thank the personnel at The Norwegian Home Guard Training Centre Vaernes for helping us organizing the data collections.

\section{Author details}

'Department of Nutrition, Institute for Basic Medical Sciences, University of Oslo, P.O Box 1046 Blindern, N-0316 Oslo, Norway. ${ }^{2}$ Department of Public Health, Sport and Nutrition, Faculty of Health and Sport, University of Agder, 4604 Kristiansand, Norway. ${ }^{3}$ Norwegian School of Hotel Management, University of Stavanger, N-4036 Stavanger, Norway.

\section{Authors' contributions}

WF and MW were responsible for the study concept and design. SU and THS acquired the data. SU was responsible for analysis and drafting of the manuscript. All authors participated in interpretation of data and critical revision of the manuscript for important intellectual content.

\section{Competing interests}

The authors declare that they have no competing interests.

Received: 26 November 2010 Accepted: 19 May 2011

Published: 19 May 2011

\section{References}

1. Lallukka T, Lahti-Koski M, Ovaskainen ML: Vegetables and fruit consumption and its determinants in young Finnish adults. Scand J Nutr 2001, 45:20-126.

2. Thompson RL, Margetts BM, Speller VM, McVey D: The Health Education Authority's health and lifestyle survey 1993: who are the low fruit and vegetable consumers. J Epidemiol Community Health 1993, 53:294-299.

3. Ritchie LD, Spector P, Stevens MJ, Schmidt MM, Shreiber GB, StriegelMoore $\mathrm{RH}$, Wang MC, Crawford PB: Dietary patterns in adolescence are related to adiposity in young adulthood in black and white females. $J$ Nutr 2003, 137(2):399-406.

4. Jeffreys M, Mc Carron P, Gunnell D, Mc Ewen J, Smith GD: Body mass index in early and mid - adulthood, and subsequent mortality. A historical cohort study. Int J Obes Relat Disord 2003, 27(11):1391-7.

5. Kvaavik E: From childhood to adulthood - stability and prediction of body weight and eating habits. PhD thesis University of Oslo, Oslo, Norway; 2005.

6. Mikkilä V, Räsänen L, Raitakari OT, Pietinen P, Viikari J: Consistent dietary patterns identified from childhood to adulthood: The cardiovascular risk in young Finns study. Br J Med 2005, 93:923-931.
7. Lien N, Lytle LA, Klepp Kl: Stability in consumption of fruits, vegetables, and sugary foods in a cohort from age 14 to age 21. Prev Med 2001 33:217-226.

8. Hu FB, Rimm EB, Stampfer MJ, Ascherio A, Spiegelman D, Willett W: Prospective study of major dietary patterns and risk of coronary heart disease in men. Am J Clin Nutr 2000, 72:912-921.

9. O'Dea JA, Caputi P: Association between socioeconomic status, weight, age and gender, and the body image and weight control practice of 6to 19- year old children and adolescents. Health Educ Res 2001, 16:521-532.

10. Cohane $\mathrm{GH}$, Pope HG: Body image in boys: a review of the literature. Int J Eat Disord 2001, 29:373-379.

11. Conner M, Johnson C, Grogan S: Gender, sexuality, body image and eating behaviours. J Health Psychol 2004, 9:505-515.

12. Bellisle F, Monneuse MO, Steptoe A, Wardle J: Weight concern and eating patterns: A study of university students in Europe. Int J Obes 1995, 723-730

13. World Health Organization: Global Database on Body Mass Index; BMI Classification. WHO; 2008 [http://www.who.int/bmi].

14. Uglem S, Frølich W, Stea TH, Wandel M: Correlates of vegetable consumption among young men in the Norwegian National Guard. Appetite 2007, 48:46-53.

15. Tolstrup JS, Heitmann BL, Tjønneland AM, Overvad OK, Sørensen TIA Grønbak MN: The relation between drinking pattern and body mass index and hip circumference. Int J Obes (London) 2005, 29(5):490-497.

16. Lahti-Koski M, Pietinen P, Heliövaara M, Vartiainen E: Association of body mass index and obesity with physical activity, food choices, alcohol intake, and smoking in the 1982-1997 FINRISK studies. Am J Clin Nutr 2002, 75:809-817.

17. Newby PK, Muller D, Hallfrisch J, Andres R, Tucker KL: Food patterns measured by factor analysis and anthropometric changes in adults. Am Clin Nutr 2004, 80:504-513.

18. Bjerkedal T, Beckstrøm JR, Brevik Jl: Høyde, vekt og kroppsmasseindeks ved sesjon for menn født i årene 1967-80. [Height, weight and body mass index at examination of men liable for military service among men born during the years 1967-80.]. Tidsskr Nor Læegeforen 2001, 121:674-677.

19. Flegal K, Troiano R: Changes in the distribution of body mass index of children and adults in the US population. Int $J$ Obes Rel Metab Disord 2000, 24:807-818

20. Subar AF, Kipnis $V$, Troiano RP, Midthune D, Schoeller DA, Bingham S Sharbaugh CO, Trabulsi J, Runswick S, Ballard-Barbash R, Sunshine J, Schatzkin A: Using intake biomarkers to evaluate the extent of dietary misreporting in a large sample of adults: the OPEN study. Am J Epidem 2003, 158:1-13.

21. Goris AHC, Westerterp-Plantenga M, Westerterp KR: Undereating and underrecording of habitual food intake in obese men: selective underreporting of fat intake. Am J Clin Nutr 2000, 71:130-134

22. Nelson M: The validation of dietary assessment. In Design concepts in nutritional epidemiology. Edited by: Margetts BM, Nelson M. Oxford, Oxford University Press; 2001:241-272.

\section{Pre-publication history}

The pre-publication history for this paper can be accessed here: http://www.biomedcentral.com/1471-2458/11/343/prepub

doi:10.1186/1471-2458-11-343

Cite this article as: Uglem et al: Body weight, weight perceptions and food intake patterns. A cross-sectional study among male recruits in the Norwegian National Guard. BMC Public Health 2011 11:343. 



\section{Paper IV}

A nutrition intervention focusing on vegetables, fruit and bread among young men 



\section{Paper V}

Association between folate intake from different food sources in Norway and homocysteine status in a dietary intervention among young male adults 



\title{
Association between folate intake from different food sources in Norway and homocysteine status in a dietary intervention among young male adults
}

\author{
Tonje Holte Stea ${ }^{1}$, Solveig Uglem ${ }^{2}$, Margareta Wandel ${ }^{2}$, Mohammad Azam Mansoor ${ }^{3}$ and Wenche Frølich ${ }^{1}$ \\ ${ }^{1}$ Norwegian School of Hotel Management, University of Stavanger, N-4036 Stavanger, Norway \\ ${ }^{2}$ Department of Nutrition, Institute for Basic Medical Sciences, University of Oslo, N-0316 Oslo, Norway \\ ${ }^{3}$ Department of Natural Sciences, Agder University, N-4604 Kristiansand, Norway
}

(Received 13 October 2008 - Revised 4 February 2009 - Accepted 5 February 2009 - First published online 31 March 2009)

The aim of the present investigation was to study the effect of a dietary intervention which combined nutrition information with increased availability of vegetables, fruits and wholegrain bread. The effect of the intervention was determined by changes in the intake of vegetables, fruits, wholegrain bread and estimated nutrients. Furthermore, the study investigated whether changes in relative contribution from different food sources of folate were related to changes in the concentration of plasma total homocysteine (p-tHcy). The 5-month intervention study included 376 male recruits from the Norwegian National Guard, Vaernes (intervention group) and 105 male recruits from the Norwegian National Guard, Heggelia (control group). The study resulted in an increase in the total consumption of vegetables, fruits, berries and juice $(P<0 \cdot 001)$ and of wholegrain bread $(P<0.001)$. The participants in the intervention group showed a higher increase in the intake of dietary fibre $(P<0.001)$ and folate $(P<0.001)$ compared with the control group. The relative contribution of folate intake from fruits, vegetables and wholegrain bread was higher in the intervention group compared with the control group $(P<0.001$ for all). The increased intake of folate from wholegrain bread was inversely associated with a reduced concentration of p-tHcy $(P=0 \cdot 017)$. In summary, the dietary intervention resulted in an increased intake of vegetables, fruits and wholegrain bread and a subsequent increase in folate intake from these food components. Reduction in the concentration of p-tHcy was significantly related to an increased folate intake due to an increased consumption of wholegrain bread.

Dietary intervention studies: Homocysteine: Young male adults

Young male adults are an important but difficult target group to reach when promoting healthy diets. The period when young men are moving away from home for the first time, for example, when they are enrolled in military service, often involves changes in dietary habits ${ }^{(1)}$.

In several European countries, descriptive studies have shown that subjects in all age groups, including children and adolescents, have an increased intake of high-energy foods, lower intakes of vegetables, fruits and wholegrain products and lower level of physical activity ${ }^{(2-6)}$. Unhealthy dietary habits from childhood and adolescence (11-16 years of age) have been demonstrated to be carried over into adulthood and thereby affect the prevalence of cardiovascular risk factors $^{(7-9)}$. A follow-up study of young men and women (mean age 25 and 33 years, respectively) showed that their eating behaviour from childhood was a significant predictor for their intake of fruits, vegetables, wholegrain and sugar-rich foods ${ }^{(10)}$. These studies have confirmed the need to promote and improve healthy eating habits in early age and with special focus on individuals with low intakes of fruits, vegetables and wholegrain products.

A literature review suggested that improved eating habits can be achieved by a variety of approaches in different subgroups in a population ${ }^{(11)}$. Dietary interventions among adults have often been focused on strategies to increase nutritional knowledge ${ }^{(12,13)}$. A significant improvement in dietary habits has been shown to require a combination of different approaches when targeting specific population groups ${ }^{(14-16)}$. Intervention studies in the age group of 6-18 years have proved most effective when dietary information has been combined with increased availability of fruits and vegetables ${ }^{(17,18)}$. Despite positive effects from these studies mentioned, an intervention programme focusing on both nutritional information and increased availability of healthier foods among pupils in secondary schools showed no significant changes in school-based eating over a 2-year period ${ }^{(19)}$. Data from various intervention programmes have demonstrated how difficult it is to achieve changes in dietary habits in children and adolescents.

Previously, adults have been the main target group in studies that have evaluated the effects of dietary interventions on changes in cardiovascular risk factors. An 8-month intervention study with a low-fat $(<30 \%$ energy from fat) and high-dietary fibre $(>3 \mathrm{~g} / \mathrm{MJ})$ diet showed a reduction in the concentration of total cholesterol among young men and women (mean age 24 years $)^{(20)}$. Dragsted et al. ${ }^{(21)}$ also confirmed a significant decrease in the concentration of total cholesterol and LDL 
after providing $600 \mathrm{~g}$ fruit and vegetables per $\mathrm{d}$ to forty-three volunteers for $24 \mathrm{~d}$. Other studies have shown that an increased intake of dietary fibre through vegetables, fruits and wholegrain cereals beneficially affected the lipid profile and the concentration of homocysteine ${ }^{(22,23)}$. Despite the uncertainty whether plasma total homocysteine ( $\mathrm{p}$-tHcy) concentration may be a marker of vascular risk or a causal factor, studies have shown that elevated p-tHcy concentration is associated with an increased risk of $\mathrm{CVD}^{(24,25)}$.

The target group of the present intervention study was men between 18 and 26 years of age, since this group seldom has been the focus of nutrition interventions. The aim of the study was to promote an increased intake of vegetables, fruits and wholegrain bread by focusing on both nutrition information and increased availability of these food items. The effect of the intervention was determined by changes in the intake of selected food items and nutrients. Previously it was reported that this dietary intervention had shown a significant increase in the total intake of vegetables, fruit, berries and fruit juice and wholegrain bread $(P<0.001$ for both) and a reduction in the concentration of p-tHcy $(-10 \% ; P=0.002)$ during the study period ${ }^{(26)}$. The present study further investigated whether the reduction in p-tHcy was associated with changes in folate intake from specific foods, such as vegetables, fruits, juice and wholegrain bread.

\section{Methods}

\section{Study design and participants}

In the intervention group, $541(81.6 \%)$ male recruits (aged 18-26 years) from Værnes military camp agreed to participate in the data collection at baseline and $416(62.7 \%)$ of the recruits completed the entire study period. In the control group, $209(88.2 \%)$ newly enrolled male recruits in the Norwegian Army at Heggelia agreed to participate, but only 105 recruits $(44.4 \%)$ completed the entire study period. Most of the recruits $(89.6 \%)$ who did not complete the entire study had been excluded from military service due to health problems. Supplement use and incomplete datasets were exclusion criteria for the present study. We did not find any sociodemographic differences between participants in the intervention group and the control group that could explain the differences in participation rate.

As Norwegian military service is compulsory for men from the age of 19 years, recruits from different geographical areas and social classes in Norway are randomly distributed to different military camps. The military camps where our data were collected were chosen due to similar levels of physical training during military service. The intervention group was provided with information regarding the benefits of healthy eating habits, as well as easy access to a diet rich in vegetables, fruits and wholegrain bread, and low in fat content. The control group received only practical information regarding the data collection. Blood samples, measurements of body weight and height and information about dietary habits and age were collected during week 1 after the enrolment and after 5 months. The present study was conducted according to the guidelines laid down in the Declaration of Helsinki. All procedures involving human subjects were approved by the Ministry of Health and Care Services, Regional Committee for Medical Research Ethics and the Data Inspectorate. Written informed consent was obtained from the recruits before participation in the study.

\section{Diet}

All recruits were offered free breakfast, lunch, dinner and evening meal in a mess hall or they could choose to buy food in a commercial canteen, both of which were located at the military camps. In the canteen, the recruits had the option to buy fast food, snacks and candies, whereas the availability of fruits and vegetables was very limited. Alternative places to buy food included restaurants, cafeterias and grocery stores located outside Værnes and Heggelia military camps. In the mess hall at Værnes military camp, the commonly used recipes were prepared focusing on vegetables, fruits, wholegrain bread and dietary fat content in line with the Nordic Nutritional Recommendations. The breakfast and evening meals consisted of wholegrain bread and various sandwich spreads. The amount of wholegrain varied between 50 and $100 \%$ in the different bread products. In Norway, folate fortification of bread is not yet allowed. It is also important to notice that refined white flour that is used in Norwegian bread has a high extraction rate (close to $80 \%$ ). For lunch, the recruits could choose between a hot dish, wholegrain bread, various sandwich spreads and a salad bar consisting of some selected vegetables. For dinner they were offered one hot dish and they could also choose to have vegetables (cooked or a mixed salad) and wholegrain bread. In the military mess hall, the recruits selected their own food and portion size. The military chefs were trained in how to prepare and present healthy meals. To avoid differences in the composition of meals due to limited seasonal availability of ingredients, the meals were mainly based on ingredients that were available during all seasons. In the control group at Heggelia military camp, there was no change in the food regimen during military service. This food contained therefore more fat, especially saturated fat, and fewer vegetables and fruits were available, compared with the food offered to the intervention group.

\section{Food diary and calculation of nutrient intake}

A validated food diary developed at the Department of Nutrition, University of Oslo (sef.no/assets/11002260/ vedlegg1_ungkost.PDF) was modified to appropriately reflect the diet served in the military mess hall ${ }^{(27)}$. Frequency and portion sizes of selected food items available in the mess hall were pre-printed choices in the food diary. The food items included vegetables, fruits, wholegrain bread and other cereals, butter, milk products and drinks. When appropriate, the recruits reported their intakes of vegetables, fruits and wholegrain bread in pieces. To assist the recruits and to obtain estimates of the consumption in grams, most of the food items that were printed in the food diary were also preweighed. The estimates are the average of ten weighed pieces. Hot dishes offered at lunch and dinners were included in the diary as open-ended questions in which the recruits filled in a number for the menu of the day. To estimate the consumption of different ingredients included in the hot meals, recipes and estimates of the amounts of the ingredients used in every dish were collected. An average content of 
ingredients in all dishes and in the small, medium, large and extra-large serving sizes was calculated from these data. For registration of side dishes served at lunch and dinner, the recruits stated the size (small, medium, large or extra-large) and number of servings. Serving sizes for these food items were decided with the help from the kitchen staff at the camp and from other Norwegian surveys ${ }^{(28)}$. For determination of serving size, the recruits were asked to refer to photographs and/or weighed portion sizes placed in the military mess during the meals in the food diary period. In addition, two research workers were present at every meal to help the recruits to determine their own portion sizes. This support was given to the recruits in both the intervention group and the control group. The food diary also included questions about how often and what they did eat in the military canteen and/or cafeterias and restaurants outside the military camp.

The nutritional values of recipes and intakes of food and nutrients from the food diaries were calculated using the computer program Mat på Data (version 5.0; Matportalen, Oslo, Norway) and the Norwegian food composition table ${ }^{(29)}$. The average daily consumption for each recruit in the survey period was obtained by adding up their total consumption of selected foods and nutrients and dividing by the number of days during which the subject kept records.

\section{Blood sampling and biochemical analyses}

Blood samples were collected after an overnight fast ( $\geq 12 \mathrm{~h}$ ). The participants were restricted from drinking and using tobacco $12 \mathrm{~h}$ before blood sampling. All blood samples were centrifuged within $4 \mathrm{~h}$ at $2000 \mathrm{~g}$ for $10 \mathrm{~min}$ at $4^{\circ} \mathrm{C}$. Serum and plasma samples were immediately frozen in $1 \mathrm{ml}$ blood collection tubes at $-20^{\circ} \mathrm{C}$ before they were sent to Stavanger University Hospital, Norway and stored at $-70^{\circ} \mathrm{C}$ until analysed. Total serum cholesterol, TAG and HDL were measured with enzymic procedures (Roche, Mannheim, Germany) at Stavanger University Hospital. The concentration of LDL was estimated by using the Friedewald formula (total cholesterol $-\mathrm{HDL}-0.46 \times \mathrm{TAG}^{(30)}$. The plasma concentration of tHcy was determined by $\mathrm{HPLC}^{(31)}$. The CV for the measured variables were $<0.3 \%$ for total cholesterol, $<0.7 \%$ for TAG, $<2 \%$ for HDL and $6.4 \%$ for p-tHcy.

\section{Statistical analyses}

Changes in dietary intakes of food and nutrients are presented as means and corresponding $95 \% \mathrm{CI}$ (Tables 1-3). A multiple regression model calculated the intervention effects as the ratio of means of the intervention group relative to the control group, adjusted for baseline concentrations ${ }^{(32)}$ (Fig. 1 and Tables 1-3). The regression models were checked for normality of residuals, linearity and homogeneity of variance. A multiple regression model was also used to calculate the predictors of changes in p-tHcy concentration (Table 4). Because of skewed distribution, change in the concentration of p-tHcy (dependent variable) was transformed to the natural logarithm before fitting the regression model. All statistical analyses were conducted with SPSS (version 15.0; SPSS Inc., Chicago, IL, USA).

\section{Results}

Baseline characteristics of those participants who completed the entire study showed a significantly lower BMI in the intervention group than in the control group (Table $1 ; P=0.004$ ). The concentrations of p-tHcy and serum lipids, however, were not significantly different between the groups.

Changes in the dietary intake of energy from carbohydrates, proteins and different types of fat are listed in Table 2. The results showed a significantly increased energy intake in the intervention group compared with the control group $(P=0 \cdot 002)$. The percentage of energy derived from carbohydrates and PUFA increased in the intervention group compared with the control group $(P<0.001$ for both). On the contrary, a significantly reduced percentage of energy was derived from total fat, SFA, MUFA and proteins in the intervention group compared with the control group $(P<0 \cdot 001$ for all). The dietary intervention showed no effect on the serum concentration of total cholesterol, LDL and HDL in serum (data not shown). A minor increase in the concentration of TAG was shown in both groups at the end of the study period. The increase in the concentration of TAG, however, was significantly higher in the control group compared with the intervention group $(P=0 \cdot 045)$.

Baseline registration showed a total intake of vegetables, fruits, berries and juice of $434 \mathrm{~g} / \mathrm{d}$ in the intervention group and $450 \mathrm{~g} / \mathrm{d}$ in the control group. The total consumption of

Table 1. Baseline characteristics of the study participants who completed the entire study (Mean values and $95 \%$ confidence intervals)

\begin{tabular}{|c|c|c|c|c|c|}
\hline \multirow[b]{2}{*}{ Variable } & \multicolumn{2}{|c|}{ Intervention group } & \multicolumn{2}{|c|}{ Control group } & \multirow[b]{2}{*}{$P$} \\
\hline & Mean & $95 \% \mathrm{Cl}$ & Mean & $95 \% \mathrm{Cl}$ & \\
\hline Participants $(n)$ & \multicolumn{2}{|c|}{414} & \multicolumn{2}{|r|}{91} & \\
\hline Age (years) & $19 \cdot 6$ & $19 \cdot 4,19 \cdot 7$ & $19 \cdot 3$ & $19 \cdot 1,19 \cdot 5$ & 0.059 \\
\hline $\mathrm{BMI}\left(\mathrm{kg} / \mathrm{m}^{2}\right)$ & $23 \cdot 3$ & $23 \cdot 0,23 \cdot 6$ & 24.5 & $23 \cdot 8,25 \cdot 3$ & 0.004 \\
\hline tHcy $(\mu \mathrm{mol} / \mathrm{l})$ & $11 \cdot 3^{\star}$ & $10 \cdot 9,11 \cdot 7$ & $11 \cdot 5^{\star}$ & $10 \cdot 8,12 \cdot 3$ & 0.830 \\
\hline Total cholesterol (mmol/l) & 3.8 & $3.8,3.9$ & 3.9 & $3 \cdot 7,4 \cdot 0$ & 0.770 \\
\hline $\mathrm{TAG}(\mathrm{mmol} / \mathrm{l})$ & 0.7 & $0.7,0.7$ & 0.7 & $0.6,0.8$ & 0.655 \\
\hline $\mathrm{HDL}(\mathrm{mmol} / \mathrm{l})$ & $1 \cdot 3$ & $1 \cdot 3,1 \cdot 4$ & $1 \cdot 3$ & $1 \cdot 3,1 \cdot 4$ & 0.686 \\
\hline LDL (mmol/l) & $2 \cdot 2$ & $2 \cdot 1,2 \cdot 2$ & $2 \cdot 2$ & $2 \cdot 1,2 \cdot 4$ & 0.575 \\
\hline
\end{tabular}

tHcy, plasma total homocysteine.

* Concentration of thcy is presented as the geometric mean. 
Table 2. Changes in energy intake during the intervention study $\dagger$

(Mean values and $95 \%$ confidence intervals)

\begin{tabular}{|c|c|c|c|c|c|c|c|}
\hline & \multicolumn{2}{|c|}{ Baseline } & \multicolumn{2}{|c|}{ After 5 months } & \multirow[b]{2}{*}{ Change (\%) } & \multicolumn{2}{|c|}{ Intervention effectł } \\
\hline & Mean & $95 \% \mathrm{Cl}$ & Mean & $95 \% \mathrm{Cl}$ & & Mean & $95 \% \mathrm{Cl}$ \\
\hline \multicolumn{8}{|l|}{ Energy (kJ) } \\
\hline Intervention group & 8676 & 8354,8997 & 9349 & 8998,9700 & $+7 \cdot 8$ & & \\
\hline Control group & 10905 & 10295,11514 & 9234 & 8650,9818 & $-15 \cdot 3$ & $1006^{*}$ & 377,1635 \\
\hline \multicolumn{8}{|l|}{ Fat (\% energy) } \\
\hline Intervention group & $33 \cdot 1$ & $32 \cdot 2,34 \cdot 0$ & $27 \cdot 8$ & $26 \cdot 8,28.9$ & $-16 \cdot 0$ & & \\
\hline Control group & $36 \cdot 3$ & $35 \cdot 0,37 \cdot 7$ & $33 \cdot 8$ & $32 \cdot 4,35 \cdot 1$ & -6.9 & $-3 \cdot 4^{\star \star}$ & $-5 \cdot 1,-1 \cdot 7$ \\
\hline \multicolumn{8}{|l|}{ SFA (\% energy) } \\
\hline Intervention group & $13 \cdot 0$ & $12 \cdot 7,13 \cdot 3$ & $9 \cdot 6$ & $9 \cdot 3,10 \cdot 0$ & $-26 \cdot 1$ & & \\
\hline Control group & $13 \cdot 9$ & $13 \cdot 4,14 \cdot 4$ & 13.5 & $13 \cdot 0,14 \cdot 0$ & -2.9 & $-2 \cdot 9^{\star \star}$ & $-3 \cdot 6,-2 \cdot 3$ \\
\hline \multicolumn{8}{|l|}{ MUFA (\% energy) } \\
\hline Intervention group & 9.5 & $9 \cdot 3,9 \cdot 8$ & 6.5 & $6 \cdot 3,6 \cdot 7$ & $-31 \cdot 6$ & & \\
\hline Control group & $10 \cdot 8$ & $10 \cdot 4,11 \cdot 3$ & $10 \cdot 1$ & $9 \cdot 7,10.5$ & -6.5 & $-3 \cdot 0^{\star \star}$ & $-3.4,-2.5$ \\
\hline \multicolumn{8}{|l|}{ PUFA (\% energy) } \\
\hline Intervention group & 8.0 & $7 \cdot 6,8.5$ & $9 \cdot 1$ & $8 \cdot 6,9 \cdot 6$ & $+13 \cdot 7$ & & \\
\hline Control group & $8 \cdot 7$ & $8 \cdot 0,9 \cdot 3$ & $8 \cdot 0$ & $7 \cdot 3,8 \cdot 7$ & -8.0 & $1.5^{\star \star}$ & $0 \cdot 7,2 \cdot 2$ \\
\hline \multicolumn{8}{|c|}{ Carbohydrates (\% energy) } \\
\hline Intervention group & $51 \cdot 1$ & $50 \cdot 2,52 \cdot 0$ & $58 \cdot 3$ & $57 \cdot 4,59 \cdot 3$ & $+14 \cdot 1$ & & \\
\hline Control group & 47.4 & $46 \cdot 1,48 \cdot 8$ & $50 \cdot 6$ & $49 \cdot 2,52 \cdot 0$ & $+6 \cdot 7$ & $5 \cdot 0^{\star *}$ & $3 \cdot 3,6 \cdot 7$ \\
\hline \multicolumn{8}{|l|}{ Protein (\% energy) } \\
\hline Intervention group & $15 \cdot 8$ & $15 \cdot 5,16 \cdot 1$ & $13 \cdot 8$ & $13 \cdot 5,14 \cdot 1$ & $-12 \cdot 7$ & & \\
\hline Control group & $16 \cdot 2$ & $15 \cdot 6,16 \cdot 9$ & $15 \cdot 6$ & $15 \cdot 0,16 \cdot 2$ & -3.7 & $-1.4^{\star \star}$ & $-2.0,-0.9$ \\
\hline
\end{tabular}

The effect of the intervention was significant: ${ }^{*} P<0.05$, ${ }^{*} P<0.001$.

†Intervention group, $n$ 376; control group, $n 105$.

$\ddagger$ The intervention effect was calculated as the mean of the intervention group relative to the control group, adjusted for baseline values.

wholegrain bread at baseline was 175 and $188 \mathrm{~g} / \mathrm{d}$ in the intervention and control groups, respectively. After the 5-month dietary intervention, the total intake of vegetables, fruits, berries and juice increased to $538 \mathrm{~g} / \mathrm{d}(+24 \%)$ in the intervention group and $478 \mathrm{~g} / \mathrm{d}(+6 \%)$ in the control group (intervention effect; $P=0.014)$. The consumption of wholegrain bread increased to $225 \mathrm{~g} / \mathrm{d}(+29 \%)$ and decreased to $180 \mathrm{~g} / \mathrm{d}$ $(-4.2 \%)$ in the intervention and control groups, respectively (intervention effect; $P<0.001$ ). The estimated total intake of dietary fibre and folate increased significantly in the intervention group compared with the control group during the study period (Table 3; $P<0.001$ for both). A minor but significant reduction was shown in the dietary intake of vitamin $B_{2}$ (riboflavin) in the intervention group compared with the control group $(P=0.018)$. A positive correlation, however, was shown between changes in estimated total intake of dietary fibre and vitamin $\mathrm{B}_{2}\left(R_{\mathrm{p}} 0.502\right)$, dietary fibre and folate $\left(R_{\mathrm{p}} 0.720\right)$ and folate and vitamin $\mathrm{B}_{2}\left(R_{\mathrm{p}} 0.652\right)$ during the study period $(P<0.001$ for all).

The total intake of estimated dietary fibre from vegetables, fruits, berries and juice increased from $4.4 \mathrm{~g} / \mathrm{d}$ to $4.9 \mathrm{~g} / \mathrm{d}$ in the intervention group and decreased from $4.4 \mathrm{~g} / \mathrm{d}$ to $3.4 \mathrm{~g} / \mathrm{d}$ in the control group. At the same time, the total intake of estimated dietary fibre from wholegrain bread increased from $10 \cdot 2 \mathrm{~g} / \mathrm{d}$ to $13.2 \mathrm{~g} / \mathrm{d}$ in the intervention group and from $11.1 \mathrm{~g} / \mathrm{d}$ to $11.6 \mathrm{~g} / \mathrm{d}$ in the control group (Fig. 1). Thus, a significant effect of the intervention was shown in the relative contribution of dietary fibre from both vegetables, fruits, berries and juice $(P<0.001)$ and wholegrain bread $(P=0 \cdot 001)$. Furthermore, the study showed a significant increase in the estimated folate intake

Table 3. Changes in dietary intake of fibre, folate and vitamin $B_{2}$ during the intervention study $\dagger$ (Mean values and $95 \%$ confidence intervals)

\begin{tabular}{|c|c|c|c|c|c|c|c|}
\hline & \multicolumn{2}{|c|}{ Baseline } & \multicolumn{2}{|c|}{ After 5 months } & \multirow[b]{2}{*}{ Change (\%) } & \multicolumn{2}{|c|}{ Intervention effectł } \\
\hline & Mean & $95 \% \mathrm{Cl}$ & Mean & $95 \% \mathrm{Cl}$ & & Mean & $95 \% \mathrm{Cl}$ \\
\hline \multicolumn{8}{|l|}{ Fibre $(g / d)$} \\
\hline Intervention group & 24.7 & $23 \cdot 4,26 \cdot 0$ & 31.1 & $29 \cdot 6,32 \cdot 6$ & +25.9 & & \\
\hline Control group & 24.5 & $22 \cdot 8,26 \cdot 2$ & $24 \cdot 2$ & $22 \cdot 3,26 \cdot 0$ & $-1 \cdot 2$ & $5 \cdot 9^{* *}$ & $3 \cdot 6,8 \cdot 3$ \\
\hline \multicolumn{8}{|l|}{ Folate $(\mu \mathrm{g} / \mathrm{d})$} \\
\hline Intervention group & $196 \cdot 3$ & $188 \cdot 4,204 \cdot 2$ & 257.7 & $248.5,266.9$ & +31.3 & & \\
\hline Control group & 189.9 & $179 \cdot 4,200 \cdot 5$ & 209.8 & $196 \cdot 0,223 \cdot 5$ & +10.5 & $31 \cdot 0^{\star *}$ & $15 \cdot 3,46 \cdot 7$ \\
\hline \multicolumn{8}{|l|}{ Vitamin $B_{2}(\mathrm{mg} / \mathrm{d})$} \\
\hline Intervention group & 1.54 & $1.45,1.60$ & 1.49 & $1.43,1.56$ & $-2 \cdot 7$ & & \\
\hline Control group & 1.81 & $1.69,1.92$ & 1.76 & $1.64,1.92$ & $-2 \cdot 4$ & $-0 \cdot 1^{*}$ & $-0.3,0.0$ \\
\hline
\end{tabular}

The effect of the intervention was significant: ${ }^{*} P<0.05$, ${ }^{* *} P<0.001$.

$\dagger$ Intervention group, $n$ 376; control group, $n 105$.

$\ddagger$ The intervention effect was calculated as the mean of the intervention group relative to the control group, adjusted for baseline values. 


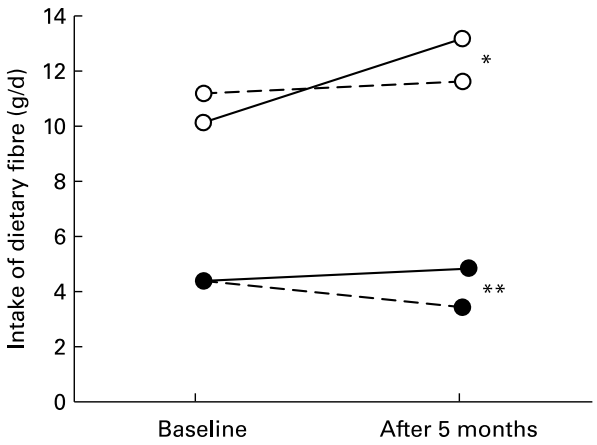

Fig. 1. Changes in intake of dietary fibre from wholegrain bread and vegetables, fruits, berries and juice in the intervention study in the intervention ( $n$ 376) and control ( $n$ 105) groups. (-O-), Wholegrain bread, intervention

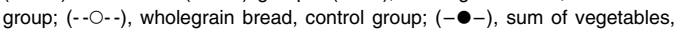
fruits, berries and juice, intervention group; (- - - -), sum of vegetables, fruits, berries and juice, control group. The intervention effect was calculated as the mean of the intervention group relative to the control group, adjusted for baseline values. The effect of the intervention was significant: ${ }^{*} P=0.001$, ${ }^{* *} P<0.001$.

from different food groups, including vegetables, fruits and wholegrain bread (intervention effect, $P<0.001$ for all; Table 4). The estimated folate intake from different food groups, both at baseline and after the 5-month intervention period, showed that wholegrain bread was the most important single contributor to total folate intake.

Furthermore, we investigated the association between changes in the concentration of p-tHcy and changes in absolute intakes of major food groups (fruits, vegetables, juice, wholegrain bread, milk products and potatoes) during the intervention study. There was an inverse relationship between the concentration of p-tHcy and the intake of wholegrain bread after adjustment for changes in BMI, physical fitness and the concentration of total cholesterol during the study period (data not shown; $P=0.034$ ). A significant association between the estimated increase in dietary intake of folate from wholegrain bread and the decrease in p-tHcy concentration was also shown $(P=0 \cdot 010$; Table 5). Changes in folate intake from fruits and vegetables were not significantly related to the changes in p-tHcy concentration. The variables included in the multivariate linear regression analysis explained in combination $16.2 \%$ of the variance in the change of p-tHcy concentration during the study period.

\section{Discussion}

The present study was performed to improve dietary habits and reduce cardiovascular risk factors among young men after a 5-month dietary intervention with a focus on vegetables, fruit and wholegrain bread. Despite the random distribution of recruits to different military camps, baseline results for those who completed the entire study showed a significantly lower BMI among recruits in the intervention group compared with the control group. Furthermore, the present study showed a significantly lower energy intake in the intervention group compared with the control group at baseline. However, there were no statistical differences in the concentration of p-tHcy and serum lipids.

A very limited number of studies have focused on reducing modifiable risk factors among young male adults, as this target group has been considered a difficult group to reach when promoting a healthy lifestyle. In the present study, we have demonstrated an inverse relationship between the estimated change in folate intake from wholegrain bread and the

Table 4. Changes in relative contribution of different food groups to total folate intake†

(Mean values and $95 \%$ confidence intervals)

\begin{tabular}{|c|c|c|c|c|c|c|c|}
\hline & \multicolumn{2}{|c|}{ Baseline $(\mu \mathrm{g} / \mathrm{d})$} & \multicolumn{2}{|c|}{ After 5 months $(\mu \mathrm{g} / \mathrm{d})$} & \multirow[b]{2}{*}{ Change (\%) } & \multicolumn{2}{|c|}{ Intervention effectł } \\
\hline & Mean & $95 \% \mathrm{Cl}$ & Mean & $95 \% \mathrm{Cl}$ & & Mean & $95 \% \mathrm{Cl}$ \\
\hline \multicolumn{8}{|l|}{ Vegetables } \\
\hline Intervention group & $16 \cdot 4$ & $14 \cdot 7,18 \cdot 0$ & $19 \cdot 6$ & $17 \cdot 5,21 \cdot 8$ & +19.5 & & \\
\hline Control group & $23 \cdot 6$ & $19 \cdot 2,28 \cdot 1$ & $11 \cdot 3$ & $8 \cdot 6,14 \cdot 0$ & $-52 \cdot 1$ & $10 \cdot 1^{\star *}$ & $5 \cdot 9,14 \cdot 2$ \\
\hline \multicolumn{8}{|l|}{ Fruits } \\
\hline Intervention group & $8 \cdot 2$ & $7 \cdot 1,9 \cdot 3$ & $16 \cdot 2$ & $14 \cdot 4,18 \cdot 0$ & +97.6 & & \\
\hline Control group & 8.4 & $5 \cdot 6,11 \cdot 2$ & $7 \cdot 6$ & $5 \cdot 4,9 \cdot 7$ & -9.5 & $8 \cdot 4^{\star *}$ & $4 \cdot 7,12 \cdot 1$ \\
\hline \multicolumn{8}{|l|}{ Juice } \\
\hline Intervention group & 13.9 & $11 \cdot 6,16 \cdot 2$ & 22.9 & $19 \cdot 6,26 \cdot 2$ & $+64 \cdot 7$ & & \\
\hline Control group & $15 \cdot 9$ & $11 \cdot 7,20 \cdot 1$ & $17 \cdot 8$ & $13 \cdot 4,22 \cdot 2$ & +11.9 & $5 \cdot 2$ & $-1 \cdot 7,12 \cdot 1$ \\
\hline \multicolumn{8}{|l|}{ Wholegrain bread } \\
\hline Intervention group & $44 \cdot 2$ & $42 \cdot 3,46 \cdot 1$ & $57 \cdot 3$ & $55 \cdot 0,59 \cdot 6$ & +29.6 & & \\
\hline Control group & $48 \cdot 7$ & $44 \cdot 9,52 \cdot 5$ & $47 \cdot 9$ & $43 \cdot 7,52 \cdot 1$ & -1.6 & $12 \cdot 0^{\star *}$ & $7 \cdot 4,16 \cdot 7$ \\
\hline \multicolumn{8}{|l|}{ VF } \\
\hline Intervention group & 41.9 & $38 \cdot 5,45 \cdot 4$ & $61 \cdot 8$ & $56 \cdot 9,66 \cdot 6$ & +47.5 & & \\
\hline Control group & 49.9 & $42 \cdot 1,57 \cdot 6$ & 40.9 & $34 \cdot 3,47 \cdot 4$ & -18.0 & $22 \cdot 1^{\star *}$ & $12 \cdot 4,31 \cdot 8$ \\
\hline \multicolumn{8}{|l|}{ Total } \\
\hline Intervention group & $82 \cdot 8$ & $78 \cdot 5,87 \cdot 0$ & $114 \cdot 3$ & $108 \cdot 7,119 \cdot 8$ & +38.0 & & \\
\hline Control group & $97 \cdot 0$ & $87 \cdot 3,106 \cdot 7$ & $84 \cdot 8$ & $76 \cdot 6,93 \cdot 1$ & $-12 \cdot 6$ & $35 \cdot 7^{\star \star}$ & $24.9,46 \cdot 5$ \\
\hline
\end{tabular}

$\mathrm{VF}$, sum of vegetables, fruits, berries and juice; Total, sum of vegetables, fruit, juice and wholegrain bread.

** The effect of the intervention was significant $(P<0.001)$

†Intervention group, $n$ 376; control group, $n 105$.

$\ddagger$ The intervention effect was calculated as the mean folate intake of the intervention group relative to the control group, adjusted for baseline values. 
Table 5. Unstandardised multiple linear regression coefficients as predictors of changes in plasma total homocysteine ( $\mathrm{p}$-tHcy) concentration during the intervention study for 340 subjects* $^{*}$

\begin{tabular}{|c|c|c|c|c|}
\hline \multirow[b]{2}{*}{ Predictor variables } & \multicolumn{2}{|c|}{ Univariate linear regression } & \multicolumn{2}{|c|}{ Multivariate linear regression $\dagger$} \\
\hline & $\mathrm{B}_{\text {unstandardised }}$ & $P$ & $\mathrm{~B}_{\text {unstandardised }}$ & $P$ \\
\hline Folate intake from fruits $(\mu \mathrm{g} / \mathrm{d})$ & 0.000 & 0.258 & 0.000 & 0.556 \\
\hline Folate intake from vegetables $(\mu \mathrm{g} / \mathrm{d})$ & 0.000 & 0.651 & 0.000 & 0.844 \\
\hline Folate intake from juice $(\mu \mathrm{g} / \mathrm{d})$ & 0.000 & 0.528 & 0.000 & 0.211 \\
\hline Folate intake from wholegrain bread $(\mu \mathrm{g} / \mathrm{d})$ & -0.001 & 0.007 & -0.001 & 0.010 \\
\hline
\end{tabular}

*The dependent variable $\mathrm{p}$-tHcy is $\log _{\mathrm{e}}$-transformed before comparison. The dependent variable ( $\mathrm{p}$-tHcy) and predictor variables are computed as follow-up concentrations minus baseline concentrations.

†Adjusted for changes in BMI, physical fitness and concentration of total cholesterol during the intervention study.

concentration of p-tHcy. Fat intake, particularly intake of SFA, has been positively associated with serum cholesterol and mortality from CVD in many epidemiological and longitudinal studies ${ }^{(33,34)}$. The present dietary intervention resulted in an estimated reduction in energy consumption from fat, more in line with the recommendations from the Nordic Council of Ministers ${ }^{(35)}$, but this was not confirmed by changes in the concentration of serum lipids. On the contrary, marginal increases in the concentration of TAG were shown in both the intervention group and the control group, but significantly higher in the latter group. Durstine et al. ${ }^{(36)}$ have demonstrated that an increase in physical capacity was associated with a reduced concentration of TAG. Recently published data from the present study showed that the intervention group significantly improved the result from the $3000 \mathrm{~m}$ run compared with the control group ${ }^{(26)}$. Thus, differences in physical exercise among the recruits may also have contributed to differences in the concentration of TAG at the end of the study period.

The baseline intake of vegetables, fruits, berries and juice and wholegrain bread was fairly low among all participants in the present study. The present dietary intervention, based on increased nutrition information and increased availability of vegetables, fruits and wholegrain bread, resulted in an increased consumption of both vegetables, fruits, berries and juice and wholegrain bread. These changes in dietary intake indicate that the main aim of our dietary intervention was achieved.

Another focus of the present study was to investigate baseline intakes of folate, vitamin $\mathrm{B}_{2}$ and dietary fibre and changes in intake of these nutrients during the study period. Baseline results showed a low daily intake of folate in both groups, whereas the mean intake of vitamin $\mathrm{B}_{2}$ was low in the intervention group and adequate in the control group compared with the Nordic nutritional recommendations for healthy male adults ${ }^{(35)}$. Compared with the present results, a higher intake of vitamin $B_{2}$ was shown in both Norkost II $(2.3 \mathrm{mg} / \mathrm{d})$ and among Irish young male adults $(2.2 \mathrm{mg} / \mathrm{d})$ in the Young Hearts Project ${ }^{(37,38)}$. The latter study also showed a considerable higher dietary intake of folate $(369 \mu \mathrm{g} / \mathrm{d})$ among men aged 20 25 years ${ }^{(37)}$ than what was found in the present study. The intake of dietary fibre, which has been shown to be inversely associated with the risk of CHD in both men and women ${ }^{(39)}$, should range between 25 and $35 \mathrm{~g} / \mathrm{d}$ according to the Nordic nutritional recommendations ${ }^{(35)}$. In the present study, the estimated baseline intake of dietary fibre (24.5 and $24.7 \mathrm{~g} / \mathrm{d}$ for the control and intervention groups, respectively) corresponded to the results from Norkost II ${ }^{(38)}$ which showed a lower dietary intake of fibre $(24 \mathrm{~g} / \mathrm{d})$ among men between 20 and 29 years old than recommended $^{(35)}$.

Our intervention study resulted in a significant increase in the estimated total intake of both dietary fibre and folate, which is an outcome of a higher consumption of vegetables, fruits and wholegrain bread. The present study also showed that the increased consumption of wholegrain bread contributed more to the estimated increase in intake of both dietary fibre and folate than the increased consumption of fruits and vegetables. Our findings were in agreement with previous studies, which have demonstrated that wholegrain bread is quantitatively one of the most important contributors to total intake of dietary fibre and folate among both men and women in Norway ${ }^{(38,40)}$. Despite a minor reduction in the estimated intake of vitamin $\mathrm{B}_{2}$ on a group level, a positive correlation was shown between the changes in intake of dietary fibre, folate and vitamin $\mathrm{B}_{2}$ on an individual level. Thus, the recruits who increased their intake of vitamin $B_{2}$ seemed to have a greater increase in the intake of dietary fibre and folate than the recruits who decreased their intake of vitamin $\mathrm{B}_{2}$ during the study period.

Previously reported results from this dietary intervention have demonstrated a significant relationship between an increased concentration of folate and a reduction in the concentration of p-tHcy during the study period ${ }^{(26)}$. Thus, we expect that the present results may be related to an increased intake of folate from unfortified foods. Few intervention studies have focused on the relationship between changes in folate intake from different food groups and the effect on p-tHcy concentration. Winkels et al. ${ }^{(41)}$ demonstrated that wholegrain bread fortified with folic acid significantly increased folate status and reduced p-tHcy concentrations. In Norway, however, fortification of foods with folate is not allowed. The results from the present study showed a weak, but statistically significant, relationship between the estimated increase in folate intake from wholegrain bread, which had not been fortified with folic acid, and the decreased concentration of p-tHcy. On the other hand, changes in the estimated intake of folate from vegetables, fruits or juice did not show any significant relationship with changes in the concentration of p-tHcy, respectively. A possible explanation for the lack of association between p-tHcy concentration and estimated 
intake of folate from fruits and juices is the low bioavailability of folate from these food sources ${ }^{(42,43)}$. Similar to the present results, large cross-sectional studies have not shown any association between the concentration of tHcy in plasma and serum and the folate intake from orange juice or fruits ${ }^{(42,44)}$. The Framingham Heart Study, however, showed that the intake of green leafy vegetables was related to lower concentrations of p-tHcy ${ }^{(44)}$. Ganji \& $\mathrm{Kafai}^{(42)}$ also demonstrated an inverse relationship between the serum concentration of tHcy and intake of cruciferous vegetables, but not with intake of other vegetables or wholegrain bread. The latter study suggested that the lack of association between serum concentration of tHcy and total intake of vegetables was due to the variable B-vitamin content in different vegetables ${ }^{(42)}$.

The lack of association between the p-tHcy concentration and the estimated intake of folate from vegetables in the present study may also be explained by a reduced concentration of folate due to food processing. This is in accordance with the results from a previous study which showed a decreased retention of folate in vegetables caused by different processes used in modern large-scale service systems, including the military service system ${ }^{(45)}$.

\section{Conclusion}

Our data showed that a simple, but targeted, nutrition intervention programme based on nutritional information and increased availability of vegetables, fruits and wholegrain bread was effective in modifying food intake of healthy young males. An increased intake of vegetables, fruits and wholegrain bread was associated with beneficial modifications in nutrient intake, with wholegrain bread as the best source of folate. A small, but significant, association was demonstrated between an increased intake of folate from wholegrain bread and a decreased concentration of p-tHcy. There is a debate on the positive and negative aspects of folic acid fortification in many countries. The present study showed evidence of an alternative policy approach based on nutrition education and a food-based alternative to supplementation and/or folic acid fortification.

\section{Acknowledgements}

The present study was supported by grants from the Norwegian Research Council (grant no. 154320).

W. F. and M. W. were responsible for the study concept and design. T. H. S. and S. U. acquired the data. M. A. M. organised p-tHcy analyses and helped to interpret the results. T. H. S. was responsible for the interpretation of data, statistical analysis and drafting of the manuscript. M. W. and M. A. M. were involved in the critical revision of the manuscript for important intellectual content.

The authors want to thank the personnel at The Norwegian Home Guard Training Centre Vaernes for helping to organise the data collections. The authors are grateful to Elin Skaarland Frøyland and Marte Råberg for their excellent cooperation during data processing.

There were no conflicts of interest.

\section{References}

1. Klepp K-I, Halvorsen M, Bjørneboe GEA, et al. (1996) Evaluating 'Food in the Schools' - changes over time in reported meal frequency among Norwegian school children. Scand $J$ Nutr 40, 113-116.

2. Andersen LF, Øverby N \& Lillegaard IT (2004) Intake of fruit and vegetables among Norwegian children and adolescents. Tidsskr Nor Laegeforen 124, 1396-1398.

3. Joffe M \& Robertson A (2001) The potential contribution of increased vegetable and fruit consumption to health gain in the European Union. Public Health Nutr 4, 893-901.

4. Thane CW, Jones AR, Stephen AM, et al. (2005) Whole-grain intake of British young people aged $4-18$ years. $\mathrm{Br} J$ Nutr 94, 825-831.

5. World Health Organization (2003) Diet, Nutrition and the Prevention of Chronic Diseases. Joint WHO/FAO Expert Consultation. WHO Technical Report Series no. 916. Geneva: WHO.

6. World Health Organization (2006) Physical Activity and Health in Europe: Evidence for Action. Copenhagen: WHO.

7. Biró L, Regöly-Mérei A, Nagy K, et al. (2007) Dietary habits of school children: representative survey in metropolitan elementary schools. Part two. Ann Nutr Metab 51, 454-460.

8. Chu NF, Rimm EB, Wang DJ, et al. (1998) Clustering of cardiovascular disease risk factors among obese schoolchildren: the Taipei Children Heart Study. Am J Clin Nutr 67, 1141-1146.

9. Gidding SS (2006) Cardiovascular risk factors in adolescents. Curr Treat Options Cardiovasc Med 8, 269-275.

10. Kvaavik E, Lien N, Tell G, et al. (2005) Psychosocial predictors of eating habits among adults in their mid-30s: The Oslo Youth Study follow-up 1991-1999. Int J Behav Nutr Phys Act 2, 9.

11. Pomerleau J, Lock K, Knai C, et al. (2005) Interventions designed to increase adult fruit and vegetable intake can be effective: a systematic review of the literature. $J$ Nutr $\mathbf{1 3 5}$, 2486-2495.

12. Hjermann I (1988) Strategies for dietary and anti-smoking advice: practical experiences from the Oslo Study. Drugs 36, $105-109$.

13. Manios Y, Moschonis G, Katsaroli I, et al. (2007) Changes in diet quality score, macro- and micronutrients intake following a nutrition education intervention in postmenopausal women. J Hum Nutr Diet 20, 126-131.

14. Frazao E \& Allshouse J (2003) Strategies for intervention: commentary and debate. J Nutr 133, Suppl. 3, S844-S847.

15. Heitmann BL \& Lissner L (2003) Controversies in Nutritional Epidemiology: Do We Have Evidence that Obesity Prevention Works? A Debate on Design and Methodologies, 9th European Nutrition Conference, Rome, Italy. Nutr Metab 47, 328 .

16. Van Duyn MA, Kristal AR, Dodd K, et al. (2001) Association of awareness, intrapersonal and interpersonal factors, and stage of dietary change with fruit and vegetable consumption: a national survey. Am J Health Promot 16, 69-78.

17. Baranowski T, Baranowski J, Cullen KW, et al. (2002) 5 a day Achievement Badge for African-American Boy Scouts: pilot outcome results. Prev Med 34, 353-363.

18. Perry CL, Bishop DB, Taylor GL, et al. (2004) A randomized school trial of environmental strategies to encourage fruit and vegetable consumption among children. Health Educ Behav 31, 65-76.

19. Parker L \& Fox A (2001) The Peterborough Schools Nutrition Project: a multiple intervention programme to improve schoolbased eating in secondary schools. Public Health Nutr 4, $1221-1228$.

20. Sandström B, Marckmann P \& Bindeslev N (1992) An eightmonth controlled study of a low-fat high-fibre diet: effects on 
blood lipids and blood pressure in healthy young subjects. Eur $J$ Clin Nutr 46, 95-109.

21. Dragsted LO, Krath B, Ravn-Haren G, et al. (2006) Biological effects of fruit and vegetables. Proc Nutr Soc 65, 61-67.

22. Erkkilä AT \& Lichtenstein AH (2006) Fiber and cardiovascular disease risk: how strong is the evidence? J Cardiovasc Nurs 21, $3-8$.

23. Lairon D, Arnault N, Bertrais S, et al. (2005) Dietary fiber intake and risk factors for cardiovascular disease in French adults. Am J Clin Nutr 82, 1185-1194.

24. Chambers JC, Obeid OA, Refsum H, et al. (2000) Plasma homocysteine concentrations and risk of coronary heart disease in UK Indian Asian and European men. Lancet 355, $523-527$.

25. Homocysteine Studies Collaboration (2002) Homocysteine and risk of ischemic heart disease and stroke: a meta-analysis. JAMA 288, 2015-2022.

26. Stea TH, Mansoor MA, Wandel M, et al. (2008) Changes in predictors and status of homocysteine in young male adults after a dietary intervention with vegetables, fruits and bread. Eur J Nutr 47, 201-209.

27. Uglem S, Frølich W, Stea TH, et al. (2007) Correlates of vegetable consumption among young men in the Norwegian National Guard. Appetite 48, 46-53.

28. Øverby NC, Lillegaard IT, Johansson L, et al. (2003) High intake of added sugar among Norwegian children and adolescents. Public Health Nutr 7, 285-293.

29. The Norwegian Food Safety Authority Directorate for Health and Social Affairs and the University of Oslo (2006) The Norwegian Food Composition Table. http://www. norwegianfoodcomp.no/

30. Friedewald WT, Levy RI \& Fredrickson DS (1972) Estimation of the concentration of low-density lipoprotein cholesterol in plasma, without use of the preparative ultracentrifuge. Clin Chem 18, 499-502.

31. Mansoor MA, Svardal AM \& Ueland PM (1992) Determination of the in vivo redox status of cysteine, cysteinglycine, homocysteine, and glutathione in human plasma. Anal Biochem 200, 218-229.

32. Vickers AJ \& Altman DG (2001) Statistics notes: analysing controlled trials with baseline and follow up measurements. BMJ 323, 1123-1124.

33. Caggiula AW \& Mustad VA (1997) Effects of dietary fat and fatty acids on coronary artery disease risk and total and lipoprotein cholesterol concentrations: epidemiologic studies. Am J Clin Nutr 65, Suppl. 5, S1597-S1610.
34. Kromhout D, Menotti A, Bloemberg B, et al. (1995) Dietary saturated and trans fatty acids and cholesterol and 25-year mortality from coronary heart disease: the Seven Countries Study. Prev Med 24, 308-315.

35. Nordic Council of Ministers (2005) Nordic Nutrition Recommendations 2004 - Integrating Nutrition and Physical Activity, 4th ed. Copenhagen: Nordic Council of Ministers.

36. Durstine JL, Grandjean PW, Davis PG, et al. (2001) Blood lipid and lipoprotein adaptations to exercise: a quantitative analysis. Sports Med 31, 1033-1062.

37. Gallagher AM, Robson PJ, Livingstone MB, et al. (2006) Tracking of energy and nutrient intakes from adolescence to young adulthood: the experiences of the Young Hearts Project, Northern Ireland. Public Health Nutr 9, 1027-1034.

38. Johansson L \& Solvoll K (1999), Norkost 1997. Landsomfattende Kostholdsunders $\phi k e l s e$ Blant Menn og Kvinner i Alderen 16-79 År (Norkost 1997. Nationwide Dietary Survey Among Men and Women aged 16-79 Years), Rapport nr. 2. Oslo: Statens Råd for Ernæring og Fysisk Aktivitet.

39. Pereira MA, O'Reilly E, Augustsson K, et al. (2004) Dietary fiber and risk of coronary heart disease: a pooled analysis of cohort studies. Arch Intern Med 164, 370-376.

40. Brevik A, Vollset SE, Tell GS, et al. (2005) Plasma concentration of folate as a biomarker for the intake of fruit and vegetables: the Hordaland Homocysteine Study. Am J Clin Nutr 81, 434-439.

41. Winkels RM, Brouwer IA, Clarke R, et al. (2008) Bread fortified with folic acid and vitamin B-12 improves the folate and vitamin B-12 status of healthy older people: a randomized controlled trial. Am J Clin Nutr 88, 348-355.

42. Ganji V \& Kafai MR (2004) Frequent consumption of milk, yogurt, cold breakfast cereals, peppers, and cruciferous vegetables and intakes of dietary folate and riboflavin but not vitamins B-12 and B-6 are inversely associated with serum total homocysteine concentrations in the US population. Am J Clin Nutr 80, 1500-1507.

43. Tamura T, Shin YS, Buehring KU, et al. (1976) The availability of folates in man: effect of orange juice supplement on intestinal conjugase. Br J Haematol 32, 123-133.

44. Tucker KL, Selhub J, Wilson PWF, et al. (1996) Dietary intake pattern relates to plasma folate and homocysteine concentrations in the Framingham Heart Study. J Nutr 126, 3025-3031.

45. Stea TH, Johansson M, Jagerstad M, et al. (2007) Retention of folates in cooked, stored and reheated peas, broccoli and potatoes for use in modern large-scale service systems. Food Chem 101, 1095-1107. 
Reproduced with permission of the copyright owner. Further reproduction prohibited without permission. 

Appendix 1

Information consent 



\section{FORESPØRSEL OM DELTAGELSE I FORSKNINGSPROSJEKTET: "BEDRE OG SUNNERE MATTILBUD I DET MILIT ERE"}

BAKGRUNN FOR PROSJEKTET. Gjennom tilbud av fristende og sunne matretter og kostholdsinformasjon ønsker vi å øke bevisstheten for kosthold hos unge menn i det militære. Initiativet er ment å virke forebyggende på sikt med tanke på risiko for utvikling av en rekke livsstilssykdommer som diabetes, hjerte-/karlidelser og kreft. Soldater er en gruppe som er interessant å unders $\varnothing \mathrm{ke}$ i denne sammenheng ettersom hovedmengden av maten spises i messa. Dermed kan vi følge utviklingen av kostvanene over en lenger periode under relativt kontrollerte betingelser. Det er også en spennende gruppe fordi mange soldater er i ferd med å etablere nye matvaner.

HVA BETYR DETTE FOR DEG? Gjennom et samarbeid med det militære kjøkken vil vi bedre mattilbudet i disse, slik at maten som tilbys er fristende og dessuten bra for kroppen! Studien vil bestå $\mathrm{i}$ introduksjon av nye sunne og spennende lunsj-/middagsretter over en periode på 6 måneder

Ved fors $\emptyset$ ksstart og etter 6 måneder ber vi deg om å være behjelpelig med å fylle ut et spørreskjema som måler inntak og holdninger/kunnskap om frukt/grønt/kornprodukter, bruk av spisemesse, kantine og kiosk. For å registrere eventuelle endringer av næringsopptak må vi også ta 2 blodprøver (en ved fors $ø$ ksstart og en etter 6 måneder). Disse vil undersøkes med hensyn til fettstoffer og andre næringsstoffer i blod som har betydning for helsetilstanden. Blodtrykk, vekt og høyde vil også registeres. For å kunne vurdere blodprøvesvarene er det nødvendig å vite alder, om du inntar vitaminer eller medisiner og til hvilket tidspunkt du inntok ditt siste måltid. Disse spørsmålene besvarer du ved avkryssing på et eget skjema. Det er mulig at vi mot slutten av prosjektet i 2005 vil gå ut med en oppfølgingsstudie. Du vil da bli kontaktet med forespørel om videre deltagelse.

BEHANDLING AV DATA. Innsamling og analyse av data vil være ferdig høsten $2004 \mathrm{og}$ prosjektet vil avsluttes 1.juli 2007. Resultatene fra forsøket vil publiseres i vitenskapelige artikler og i to doktorgrader. I disse vitenskapelige arbeidene er det ikke mulig å finne tilbake til hva du har svart eller til deg som person.

Alle data fra unders $\varnothing$ kelsen vil bli lagret konfidensielt. Prosjektet er meldt til Personvernombudet for forskning, Norsk samfunnsvitenskapelig Datatjeneste AS og til Regional komitè for medisinsk forskningsetikk. Ved forsøksslutt vil prøvene bli anonymisert. Hvis du gir tillatelse til det, vil prøvene i løpet av en tiårsperiode etter prosjektslutt kunne brukes til eventuelle tilleggsanalyser, som vil kunne gi ytterligere informasjon om ernæringsstatus på det tidspunktet prøvene ble tatt. Prøvene vil oppbevares uten mulighet for personidentifikasjon i disse 10 årene før de destrueres.

SKRIFTLIG SAMTYKKE. Dersom du ønsker å delta i studien, trenger vi ditt skriftlige samtykke. Deltakelsen er frivillig og hvis du ikke ønsker å delta, får dette ingen negative konsekvenser. Hvis du velger å delta, kan du likevel når som helst trekke deg fra studien. Prøvene, helseopplysninger og personopplysninger vil utleveres eller destrueres.

Med vennlig hilsen

Wenche Frølich Margareta Wandel Tonje Holte Stea Solveig Uglem (Prosjektleder) 

Appendix 2

Food diary 



\section{SPORRESKJEMA}

\section{OM FRUKT, GRØNNSAKER OG BRØD}

Kjære soldat!

I dette spørreskjemaet spør vi om dine spisevaner, med særlig fokus på frukt, grønnsaker og brød.

Spørreskjemaet er todelt. Hver dag i en uke skal du fylle ut et skjema der vi spør om dine spisevaner. Det er viktig at du tenker nøye igjennom hva du har spist og hvor mye du har spist i løpet av dagen og at du fører det inn i skjemaet. Skjemaets andre del skal kun besvares en gang. Dette er spørsmål om din sosiale bakgrunn og om dine holdninger og kunnskaper om kosthold og helse. For hvert spørsmål er det viktig at du finner det svaralternativet som passer best for deg.

Spørreskjemaet består stort sett av spørsmål hvor du kan svare ved å sette ett kryss. Noen spørsmål krever imidlertid at du svarer med enstavelsesord eller korte setninger.

Følg godt med når prosjektmedarbeideren går igjennom spørreskjemaet. Er det noe du lurer på underveis er det bare å spørre.

Det er frivillig å svare på disse spørsmålene og du kan trekke deg når som helst. Opplysningene er fortrolige og ingen får vite hva du har svart.

Takk for at du tok deg tid til å svare på sporsmålene!

Tonje Holte Stea

Stipendiat
Solveig Uglem

Stipendiat
Margareta Wandel

Professor
Wenche Frølich

Professor 


\section{Del 1}

Dato

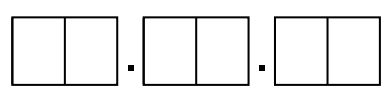

Kode etter navneliste fylles ut av den som analyserer skjemaet

Navn
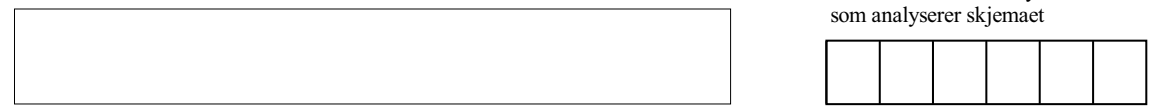

For hver dag skal du føre opp hvor mye og hva du har spist av de forskjellige matvarene som finnes i dette spørreskjemaet. Det er viktig at du tenker igjennom hva du har spist til alle måltider og mellom måltider før du fyller ut skjemaet.

1. Brødvarer (legg sammen det du har spist av brødvarer til alle måltider og fyll inn i de åpne rutene)

$1 / 2$ rundstykke $=1$ skive

Antall skiver i dag

Antall skiver i dag

Fint brød/rundstykker

(loff, baguetter o.l)

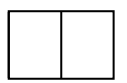

Mørkt knekkebrød

(husman o.l)

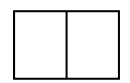

Mellomgrovt brød/rundstykker

(kneip o.1.)

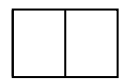

Lyst knekkebrød

(frokost o.l)

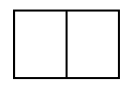

Grovt brød/rundstykker

(fiberkneipp o.l)

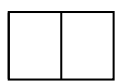

Flatbrod

2. Frokostblandinger og grot (legg sammen det du har spist til alle måltider)

Antall porsjoner i dag

$\begin{array}{llll}1 & 2 & 3 & 4\end{array}$

Havregrøt

\section{Kornblanding, usøtet}

(4-korn o.1)

Kornblanding, sotet

(Cornflakes, Honnikorn o.1)

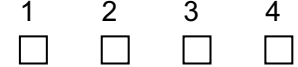

$\square$

\section{Annet}

Fyll inn hva, antall porsjoner og porsjonsstørrelse

Fylles ut av den som analyserer skjemaet

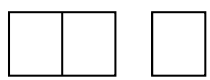

Porsjonsstørrelse

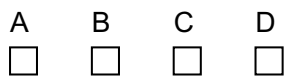

Husk! A er liten posjon, B er middels porsjon, $C$ er stor porsjon og $D$ er ekstra stor porsjon 
3. Poteter, ris og pasta (legg sammen det du har spist til alle måltider og mellommåltider)

Mengde i dag

Antall porsjoner i dag

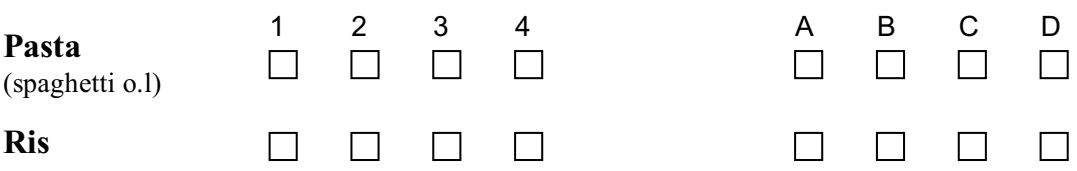

Potetstappe

4. Grønnsaker (her registreres det du har spist av "synlige grønnsaker". Grønnsaker som er en del av en rett, for eksempel gryteretter, registreres under punkt 6 og 7. Legg sammen det du har spist til alle måltider og mellommåltider og anslå det tallet som er nærmest det du har spist)

Antall i dag

$\begin{array}{lllllllllll} & 1 & 2 & 3 & 4 & 5 & 6 & 7 & 8 & 9 & 10 \\ \text { Gulrot (stk) } & \square & \square & \square & \square & \square & \square & \square & \square & \square & \square\end{array}$

Kålrot (skiver)

Tomat (båter/skiver)

Agurk (biter/skiver)

Løk (spiseskjeer) stekt og rå

Paprika (ringer)

Squash (biter/skiver)

Asparges (antall)

Reddik (stk)

Oliven (stk)

Selleri (staver)

Rosenkål (stk)

Brokkoli (dusker)

Blomkål (dusker)
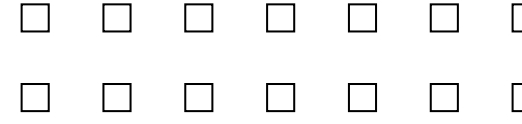
Kål (hodekål, hvitkål o.l)

$\begin{array}{llll}1 & 2 & 3 & 4\end{array}$

Ertestuing

\section{Surkål}

Bønner

Grønnsaksblanding, friske

eller frosne. Ikke grønnsaksretter med nummer på

\section{Fennikel}

Gronne erter

Spinat og andre kokte grønne blader

\section{Salatblanding}

(grønn salat/kinakål, tomat, agurk, mais etc.)

\section{Gronn salat}

\section{Sukkererter}

Sopp, fersk, hermetisk, stekt (champignon o.l)

\section{$\square \quad \square \quad \square \quad \square$ \\ $\square \quad \square \quad \square \quad \square$}

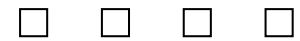

$\square \quad \square \quad \square \quad \square$
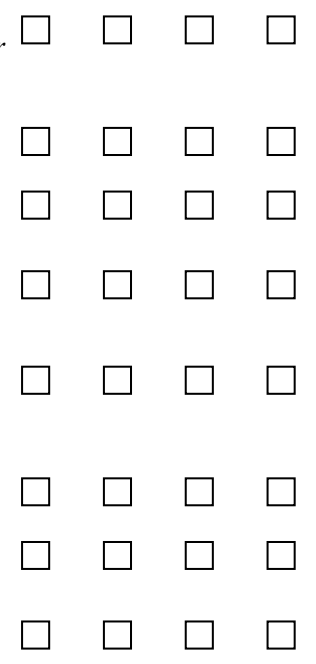

A $\quad$ B $\quad$ C $\quad$ D

$\square \quad \square \quad \square \quad \square$

$\square \quad \square \quad \square \quad \square$

$\square \quad \square \quad \square \quad \square$

$\square \quad \square \quad \square \quad \square$

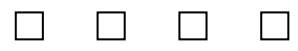

$\square \quad \square \quad \square \quad \square$

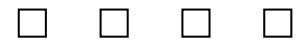

$\square \quad \square \quad \square \quad \square$

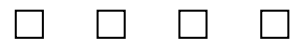

$\square \quad \square \quad \square \quad \square$
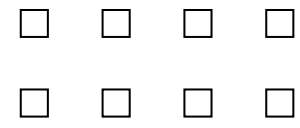

\section{Annet}

Fyll inn hva, antall porsjoner og porsjonsstørrelse

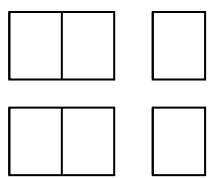


5. Frukt, bær, syltetøy og desserter bestående av frukt og bær (Her registreres det du har spist av frukt og bær. I tillegg registreres det du har spist av syltetøy og desserter hvor frukt og/eller bær inngår som ingredienser. Legg sammen det du har spist til alle måltider og mellommåltider.)

Mengde i dag

Mengde i dag

\begin{tabular}{|c|c|c|c|c|c|c|c|c|c|c|}
\hline Eple (stk) & $\begin{array}{l}1 \\
\square\end{array}$ & $\begin{array}{l}2 \\
\square\end{array}$ & $\begin{array}{l}3 \\
\square\end{array}$ & $\begin{array}{l}4 \\
\square\end{array}$ & $\begin{array}{l}5 \\
\square\end{array}$ & Banan (stk) & $\begin{array}{l}1 \\
\square\end{array}$ & $\begin{array}{l}2 \\
\square\end{array}$ & $\begin{array}{l}3 \\
\square\end{array}$ & $\begin{array}{l}4 \\
\square\end{array}$ \\
\hline Pære (stk) & $\square$ & $\square$ & $\square$ & $\square$ & $\square$ & Appelsin (stk) & $\square$ & $\square$ & $\square$ & [ \\
\hline $\begin{array}{l}\text { Fersken/ } \\
\text { Nektarin (stk) }\end{array}$ & $\square$ & $\square$ & $\square$ & $\square$ & $\square$ & $\begin{array}{l}\text { Mandarin/ } \\
\text { klementin (stk) }\end{array}$ & $\square$ & $\square$ & $\square$ & $\Gamma$ \\
\hline Kiwi (stk) & $\square$ & $\square$ & $\square$ & $\square$ & $\square$ & Melon (skive) & $\square$ & $\square$ & $\square$ & \\
\hline
\end{tabular}
Mengde i dag

Plommer (stk)

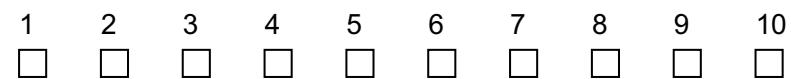

Druer (klaser på ca 10)

Moreller/

kirsebær (stilker)

Ananas (biter)

Syltetøy (spiseskjeer)

Frukt/bær-yoghurt (beger)

Go` morgenyoghurt

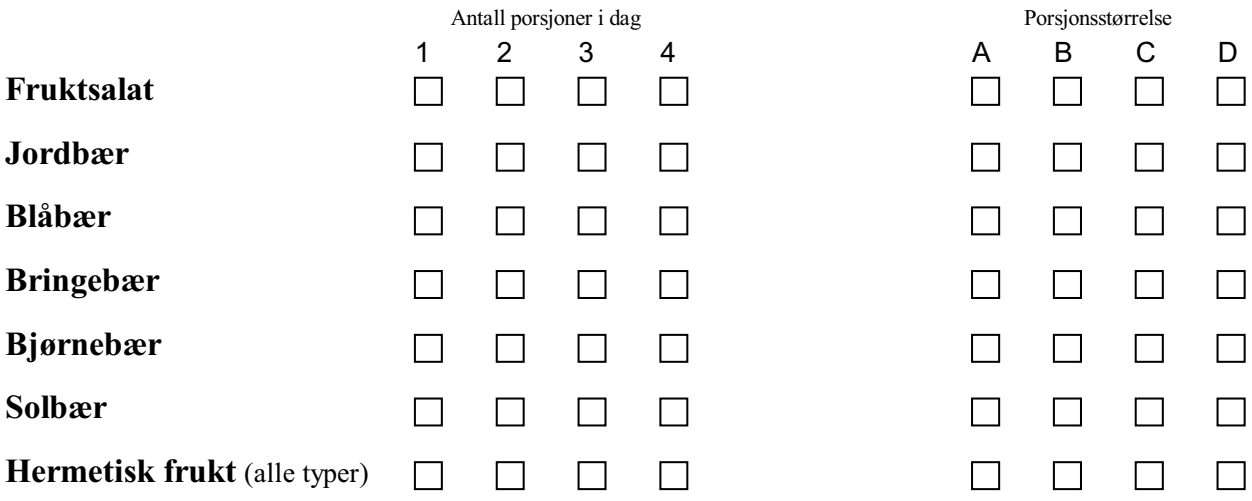

\section{Annet}

Fyll inn hva, antall porsjoner og porsjonsstørrelse

Fylles ut av den som

analyserer skjemaet

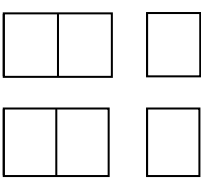


6. Ferdige lunsjretter (Her registreres det du har spist av ferdige lunsjretter med nummer. Poteter og andre "synlige grønnsaker" som ikke er en del av en rett registreres under punkt 3 og 4.)

Nummer

Lunsjrett

Lunsjrett

Lunsjrett

Lunsjrett

Lunsjrett

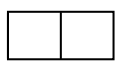

Antall porsjoner i dag
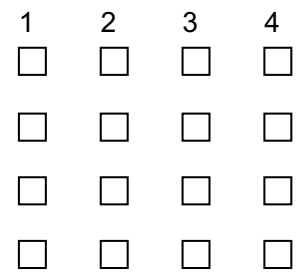

$\square \square \square \square$

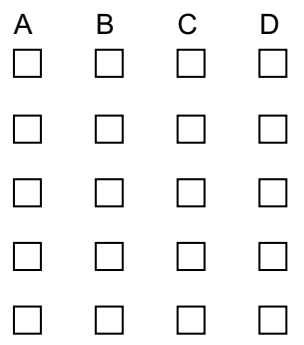

7. Ferdige middagsretter (Her registreres det du har spist av ferdige middagsretter med nummer, som gryteretter o.l som ikke er en del av en rett. Poteter og andre "synlige grønnsaker"registreres under spørsmål 3 og 4.)

Nummer Antall porsjoner i dag

Middagsrett

Middagsrett

Middagsrett

Middagsrett

Middagsrett
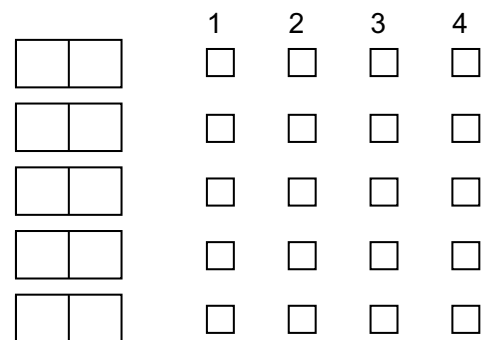

Porsjonsstørrelse

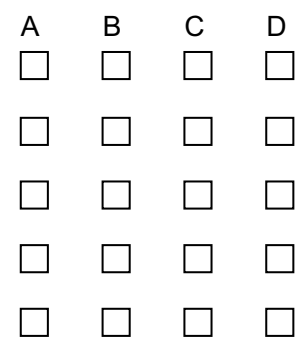

8. Smør/margarin (her registreres hvilken type smør/margarin du spiser og hvor mye du smører på brødskiven.)

Hvilken type smør/margarin bruker du?

Bruker ikke smør

Meierismør

Bremykt

Brelett

Myk margarin (soft o.l)

Lett margarin (soft light o.l)
Hvor tykt lag smør/margarin smører du på brødet?

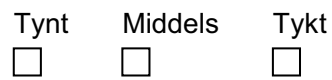

\section{Annet}

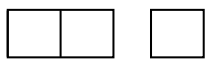


9. Drikke (Her registrerer du hva du drikker av utvalgte drikkevarer, og hvor mye du drikker i løpet av en dag. Se bort i fra alt du ikke finner i listen som vann, kaffe, te etc.)
Helmelk, kefir, drikkeyoghurt

$\begin{array}{llllllllll}1 & 2 & 3 & 4 & 5 & 6 & 7 & 8 & 9 & 10 \\ \square & \square & \square & \square & \square & \square & \square & \square & \square & \square\end{array}$
Lettmelk, cultura, biola
Ekstra lett melk
Skummet melk,
skummet kulturmelk
Smakssatt melk
(litago, sjokomelk o.1.)
Juice
(eple, appelsin o.l)

\section{Brus med sukker}
(cola, solo, mozell etc.)

\section{Brus uten sukker}
(cola light, solo light etc.)

\section{Drikker som består av} presset frukt og bær

10. Måltider og snacks som spises andre steder enn i spisemessen (Her registreres det du spiser av måltider og snacks i kantinen/kiosken og utenfor forlegningen som du ikke finner noe annet sted i skjemaet.

Mat som kommer fra spisemessen noteres ikke her, men under spørsmålene ellers i skjemaet)

Har du spist utenfor forlegningen i dag?

$$
\begin{aligned}
& \text { Hvis ja, hvor spiste du? } \\
& \square \text { I kantinen/kiosken i militærforlegningen } \\
& \square \text { Hjemme på helgeperm o.I } \\
& \square \text { Hjemme hos venner og kjente } \\
& \square \text { På kafeer, restauranter etc utenfor forlegningen } \\
& \square \text { I kasernen (mat kjøpt i dagligvarebutikk, takeaway osv.) }
\end{aligned}
$$$$
\begin{array}{ll}
\text { Ja } & \text { Nei } \\
\square & \square
\end{array}
$$

Hvilket eller hvilke måltid spiste du i kantinen/kiosken eller utenfor forlegningen?

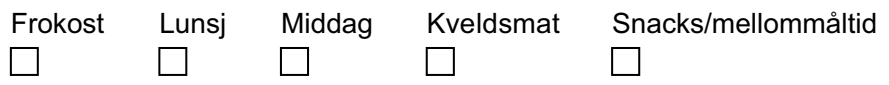

Hva spiste du i kantinen/kiosken eller utenfor forlegningen? (Angi hva og porsjonsstørrelse, for eksempel 1 hamburger, 3 stykker pizza o.l.)

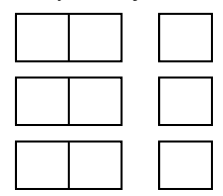


- 1

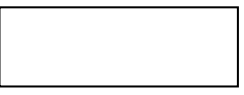


Appendix 3

Questionnaire 



\section{Del 2}

\section{Spørsmål om matvaner og hva du mener om frukt og grønnsaker}

I denne delen stiller vi en del spørsmål om dine matvaner og hva du mener om frukt/grønnsaker og helse og litt om din bakgrunn. Spørreskjemaet inneholder også noen spørsmål om bruk av spisemessen og hvor fornøyd du er med tilbudet i spisemessen.

Dato

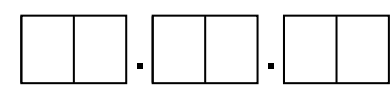

Navn

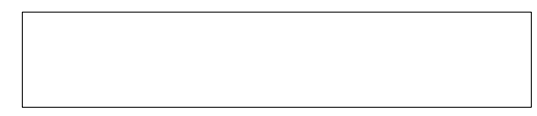

Kode etter navneliste fylles ut av den som leser skjemaet

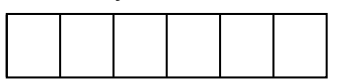

\section{Del A}

Først noen spørsmål om hvilke matvaner du er vant til hjemmefra. Når du fyller ut disse spørsmålene skal du tenke bakover i tiden på hva du spiste mens du enda bodde hjemme. Har du bodd utenfor hjemmet den siste tiden, tenk på matvanene den gangen du bodde hjemme hos dine foreldre.

1. Hvor ofte spiste du grønnsaker (stekte, kokte eller rå) mens du ennå bodde hjemme?

$\square$ Sjeldnere enn en gang i uken

$\square 1$ - 2 ganger i uken

$\square 3$ - 4 ganger i uken

$\square 5$ - 6 ganger i uken

$\square 1$ gang per dag

Flere ganger pr dag

2. Hvor ofte spiste du disse brodtypene mens du ennå bodde hjemme?

Antall skiver pr. dag

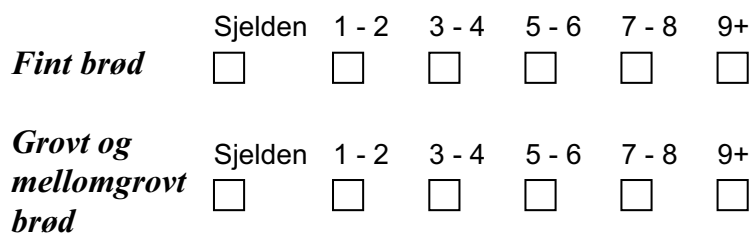

3. Hvor ofte spiste du frukt mens du ennå bodde hjemme?

\footnotetext{
$\square$ Sjeldnere enn en gang i uken

$\square 1$ - 2 ganger i uken

3 - 4 ganger i uken

5 - 6 ganger i uken

1 gang per dag

Flere ganger pr dag
}

4. Hvor ofte spiste du godterier mens du ennå bodde hjemme?

$\square$ Sjeldnere enn en gang i uken

$\square 1$ - 2 ganger i uken

$\square 3$ - 4 ganger i uken

$\square 5$ - 6 ganger i uken

$\square 1$ gang per dag

Flere ganger pr dag

5. Hvor ofte spiste du kornblandinger som 4-korn, "God dag" o.l mens du ennå bodde hjemme?

$\square$ Sjeldnere enn en gang i uken

$\square 1$ - 2 ganger i uken

$\square 3$ - 4 ganger i uken

$\square 5$ - 6 ganger i uken

$\square 1$ gang per dag

Flere ganger pr dag

6. Hvor ofte drakk du brus med sukker mens du ennå bodde hjemme?

$\square$ Sjelden/aldri

$\square 1$ - 6 glass pr uke

1 glass pr. dag

2 - 3 glass pr. dag

$4+$ glass pr. dag 


\section{Del B}

Nå følger noen utsagn om kosthold og helse. Hvor enig er du i de forskjellige utsagnene? Sett kun ett kryss for hvert spørsmål!

1. Å spise mye grønnsaker er bra for helsen

$\square$ Helt uenig
$\square$ Litt uenig
$\square$ Verken enig eller uenig
$\square$ Litt enig
$\square$ Helt enig

2. Jeg liker ikke kokte grønnsaker

$\square$ Helt uenig
$\square$ Litt uenig
$\square$ Verken enig eller uenig
$\square$ Litt enig
$\square$ Helt enig

3. Jeg har til hensikt å spise mer gronnsaker om et halvt år enn det jeg gjør nå

$\square$ Helt uenig
$\square$ Litt uenig
$\square$ Verken enig eller uenig
$\square$ Litt enig
$\square$ Helt enig

\section{Jeg spiser nok grønnsaker}

$\square$ Helt uenig
$\square$ Litt uenig
$\square$ Verken enig eller uenig
$\square$ Litt enig
$\square$ Helt enig

5. Dersom jeg bestemmer meg for det kan jeg lett spise mer grønnsaker

$\square$ Helt uenig
$\square$ Litt uenig
$\square$ Verken enig eller uenig
$\square$ Litt enig
$\square$ Helt enig

6. Dersom en ønsker å gå ned i vekt er det bra å spise mye grønnsaker

$\square$ Helt uenig
$\square$ Litt uenig
$\square$ Verken enig eller uenig
$\square$ Litt enig
$\square$ Helt enig

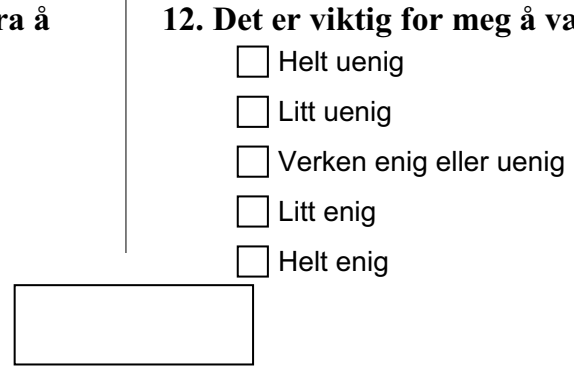

7. Vi får servert grønnsaker til alle måltider $i$ spisemessen

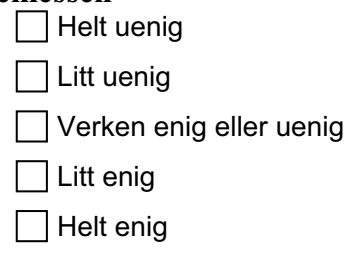

8. Det er viktig for meg å ha god helse

$\square$ Helt uenig
$\square$ Litt uenig
$\square$ Verken enig eller uenig
$\square$ Litt enig
$\square$ Helt enig

9. Jeg spiser ofte tre eller flere porsjoner gronnsaker hver dag

$\square$ Helt uenig

$\square$ Litt uenig

$\square$ Verken enig eller uenig

$\square$ Litt enig

$\square$ Helt enig

10. Det er i stor grad opp til meg selv om jeg vil spise mye grønnsaker eller ikke

$\square$ Helt uenig

$\square$ Litt uenig

$\square$ Verken enig eller uenig

$\square$ Litt enig

$\square$ Helt enig

11. Jeg synes salat og rå grønnsaker er veldig godt

$\square$ Helt uenig

$\square$ Litt uenig

$\square$ Verken enig eller uenig

$\square$ Litt enig

$\square$ Helt enig

12. Det er viktig for meg å være slank

$\square$ Helt uenig

Litt uenig

$\square$ Verken enig eller uenig

Litt enig

$\square$ Helt enig 
19. Personer som er viktige for meg mener jeg

13. Jeg føler jeg gjør noe bra for helsen min når jeg spiser mye grønnsaker

$\square$ Helt uenig
$\square$ Litt uenig
$\square$ Verken enig eller uenig
$\square$ Litt enig
$\square$ Helt enig

14. Jeg spiser for lite grønnsaker

$\square$ Helt uenig
$\square$ Litt uenig
$\square$ Verken enig eller uenig
$\square$ Litt enig
$\square$ Helt enig

15. Dersom en ønsker å holde vekten er det bra å spise mye grønnsaker

$\square$ Helt uenig
$\square$ Litt uenig
$\square$ Verken enig eller uenig
$\square$ Litt enig
$\square$ Helt enig

16. De andre soldatene mener jeg bør spise mye grønnsaker

$\square$ Helt uenig
$\square$ Litt uenig
$\square$ Verken enig eller uenig
$\square$ Litt enig
$\square$ Helt enig

17. Å spise mye grønnsaker er bra for å forhindre livsstilsykdommer som kreft og hjerte - og karsykdommer

$\square$ Helt uenig
$\square$ Litt uenig
$\square$ Verken enig eller uenig
$\square$ Litt enig
$\square$ Helt enig

18. Jeg ønsker å spise mer grønnsaker om et halvt år enn det jeg gjør nå

$\square$ Helt uenig
$\square$ Litt uenig
$\square$ Verken enig eller uenig
$\square$ Litt enig
$\square$ Helt enig


25. Det er opp til meg selv hvor mye grønnsaker jeg vil spise

$\square$ Helt uenig
$\square$ Litt uenig
$\square$ Verken enig eller uenig
$\square$ Litt enig
$\square$ Helt enig

26. Jeg føler press i militærleiren om å spise mye grønnsaker

$\square$ Helt uenig
$\square$ Litt uenig
$\square$ Verken enig eller uenig
$\square$ Litt enig
$\square$ Helt enig

27. Det er mye grønnsaker i de rettene som serveres i spisemessen

$\square$ Helt uenig
$\square$ Litt uenig
$\square$ Verken enig eller uenig
$\square$ Litt enig
$\square$ Helt enig

28. Hvor mye grønnsaker jeg spiser kan påvirke helsen min, både nå og $\mathrm{i}$ fremtiden

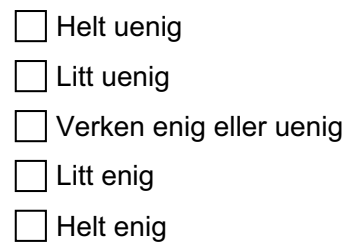

29. Jeg bør spise mer grønnsaker

$\square$ Helt uenig
$\square$ Litt uenig
$\square$ Verken enig eller uenig
$\square$ Litt enig
$\square$ Helt enig

30. Angi i hvilken grad du ønsker å øke inntaket av grønnsaker

$$
\begin{aligned}
& \square \text { I svært liten grad } \\
& \square \text { I liten grad } \\
& \square \text { I noe grad } \\
& \square \text { I stor grad } \\
& \square \text { I svært stor grad }
\end{aligned}
$$

\section{Del C}

Så følger noen kunnskapsspørsmål omkring kosthold og helse. Kryss av for det alternativet du tror er rett. Sett kun ett kryss for hvert spørsmål!

\section{Hvilket næringsmiddel tror du inneholder} mest antioksidanter?

$\square$ Kjøtt
$\square$ Fisk
$\square$ Grønnsaker
$\square$ Kornvarer
$\square$ Vet ikke

2. Hvilket næringsmiddel tror du inneholder mest fiber pr. vektenhet?

$\square$ Kjøtt
$\square$ Fisk
$\square$ Grønnsaker
$\square$ Kornvarer
$\square$ Vet ikke

3. Hva tror du de stoffene i frukt og grønnsaker som kan være med på å forebygge kreft heter?
Karsinogene stoffer
$\square$ Antioksidanter
$\square$ Enzymer
$\square$ Lipoproteiner
$\square$ Vet ikke

4. Hvor mange gram frukt og grønnsaker tror du det anbefales at en voksen person spiser daglig?
$\square 250 \mathrm{~g}$
$500 \mathrm{~g}$
$750 \mathrm{~g}$
$1000 \mathrm{~g}$
Vet ikke 


\section{Del D}

Her følger noen spørsmål om hvor du vanligvis spiser når du er i det militæret, hvor tilfreds du er med tilbudet $\mathrm{i}$ spisemessen og hva som kan gjøres for at tilbudet skal bli bedre

1. Hvor mange måltider spiser du i eller fra spisemessen pr. dag? (Anslå et gjennomsnitt over en lengre periode)

$\square$ Ingen måltid
$\square 1$ måltid
$\square 2$ måltid
$\square 3$ måltid
$\square$ Fler enn 3 måltid

2. Hvor mange måltid spiser du i kantinen pr. uke? (Anslå et gjennomsnitt over en lengre periode)
$\square$ Ingen måltid
$\square 1$ - 2 måltid
$\square 3$ - 4 måltid
5 - 6 måltid
7 - 8 måltid
Fler enn 8 måltid

3. Hvor ofte kjøper du snacks (potetgull, sjokolade

o.l.) i kiosken? (Anslå et gjennomsnitt over en lengre periode)

Sjeldnere enn 1 gang i uken

1 - 2 ganger i uken

$\square 3$ - 4 ganger i uken

$\square 5$ - 6 ganger i uken

Hver dag

\section{Hvor tilfreds er du med tilbudet i spisemessen?}

$\square$ Svært tilfreds

$\square$ Tilfreds

$\square$ Verken tilfreds eller utilfreds

$\square$ Lite tilfreds

Svært lite tilfreds

Dersom du er misfornøyd, hva kan gjøres bedre? 


\section{Del E}

Til slutt noen spørsmål omkring deg og din utdannelse og om dine foreldres utdannelse og yrkesbakgrunn

\section{Alder}

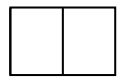

2. Hvordan vil du beskrive din fysiske aktivivet?

(Gi et gjennomsnitt for antall timer pr. uke for hver kategori)

Antall timer pr.uke

Lett aktivitet

(ikke svett/andpusten)

Hard aktivitet

(svett/andpusten)

0

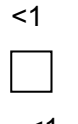

$1-2 \quad 3-4$

$5+$

3. Hva er din høyeste fullførte utdannelse? (sett bare ett kryss)

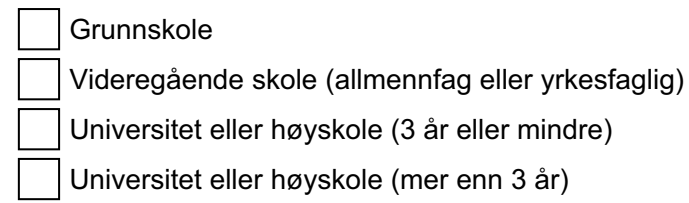

4. Hva er din mors høyeste fullførte utdannelse? (sett bare ett kryss)

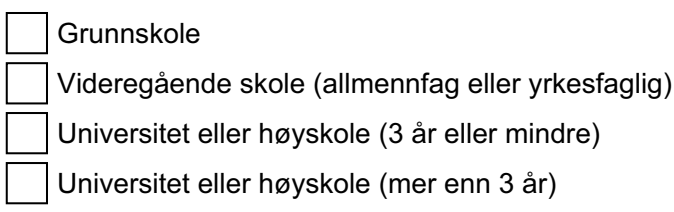

5. Mors yrke

kodes av den som leser skjemaet
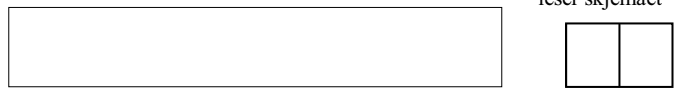

6. Hva er din fars høyeste fullførte utdannelse? (sett bare ett kryss)

\begin{tabular}{l}
$\square$ Grunnskole \\
\hline$\square$ Videregående skole (allmennfag eller yrkesfaglig) \\
$\square$ Universitet eller høyskole (3 år eller mindre) \\
$\square$ Universitet eller høyskole (mer enn 3 år)
\end{tabular}

7. Fars yrke

kodes av den som leser skjemaet

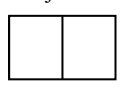


D

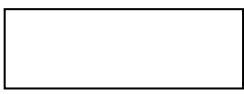


-

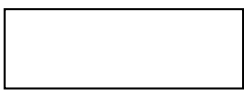


Appendix 4

Clinical questionnaire 



\section{Kliniske opplysninger}

Identifikasjon

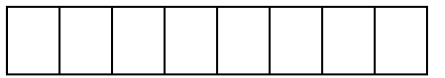

Kode fylles ut av den som behandler blodprøvene

Hvor gammel er du?

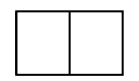

Høyde (cm)

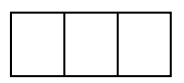

Vekt $(\mathrm{kg})$

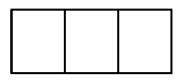

Dato

Klokkeslett

Når inntok du ditt siste måltid?
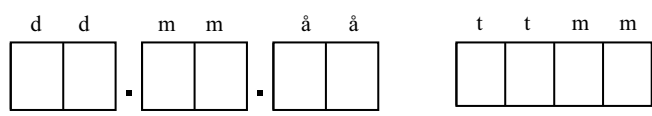

Hva spiste og drakk du?

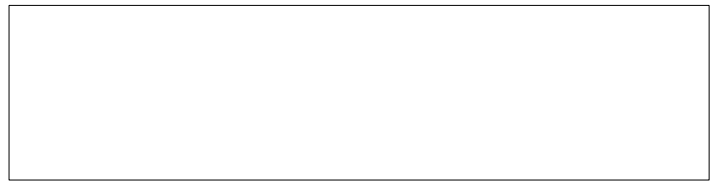

Kode fylles ut av den som behandler resultatene
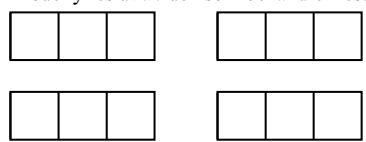

Tar du vitamintabletter?

$\mathrm{Ja} \quad \mathrm{Nei}$

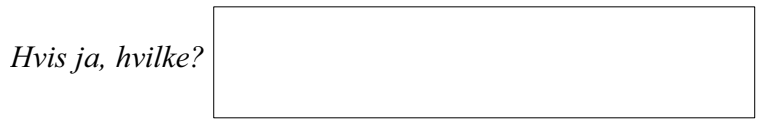

Kode fylles ut av den som behandler resultatene
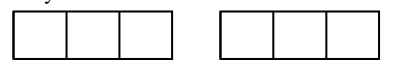

Bruker du medisiner?

$\begin{array}{ll}\mathrm{Ja} & \mathrm{Nei} \\ \square & \square\end{array}$

Hvis ja, hvilke?

Kode fylles ut av den som behandler resultatene

Hvor mange sigaretter royker du per dag? (antall)

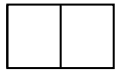

Hvor lenge har du røykt? (antall år)

Kan vi fryse ned en prøve til senere bruk i prosjektet? (i

henhold til den informasjon som er gitt om prosjektet)

$\begin{array}{ll}\text { Ja } & \text { Nei } \\ \square \quad & \square\end{array}$ 
